Universidade de Brasília - UnB

Faculdade de Tecnologia - FT

Departamento de Engenharia Elétrica - ENE

Relatório de Projeto Final 2

\title{
Interface de aquisição de dados analógicos para sistema em chip utilizando sensores externos
}

Aluno: João Vitor Bernardo Pimentel

Matrícula: 00/51799

Período: 1\%/2006

Orientador: Prof. José Camargo da Costa 


\section{SUMÁRIO}

1 - INTRODUÇÃO

$1.1-\mathrm{SCI} \quad 1$

$1.2-\mathrm{SoC} \quad 3$

1.3 - Projeto 3

2 - REVISÃO BIBLIOGÁFICA

2.1 - Sinais analógicos e digitais 4

2.2 - Princípios de condicionamento de sinal 6

2.2.1 - tipos de sinal 6

2.2.2-amplitude 6

2.2.2.1 - ruido

2.2.2.2 - linearidade $\quad 7$

2.2 .3 - resposta em freqüência 9

2.3 - Sensores e transdutores 10

2.3.1 - sensores de pressão 11

2.3.1.1 - potencial mátrico $\quad 12$

2.3.2 - sensores de temperatura 13

2.3.2.1-RTDs 13

2.3.2.2 - termistores 13

2.3.2.3 - termopares 14

2.3.2.4 - sensores de junção

2.3.3 - monitoramento da bateria 15

2.3.3.1 - estado da carga 16

2.3.3.1.1 - teste de tensão de circuito aberto 16

2.3.3.1.2 - teste de impedância e condutância 18

2.3.3.2 - avaliação do state of health 19

2.4 - Circuitos de condicionamento de sinal 19

2.4.1-Amplificadores 19

2.4.1.1 - amplificadores operacionais 19

2.4.1.2 - amplificador inversor 20

2.4.1.3 - amplificador não-inversor 21

2.4.1.4 - seguidor de tensão (buffer) 22

2.4.1.5 - amplificador de instrumentação 23

2.4.2-Filtros 24

2.4.2.1 - função de transferência 24

2.4.2.2 - implementações 26

2.4.2.2.1-filtros passivos $\quad 26$

2.4.2.2.2 - filtros ativos $\quad 27$

2.4.2.3 - modelos 28

2.4.2.3.1-filtros Butterworth 28

2.4.2.3.2 - filtros Chebyshev $\quad 29$

2.4.2.3.3-outros modelos 31

2.4.3 - circuitos chaveados $\quad 32$

2.4.3.1 - capacitores chaveados 33

2.4.3.2 - corrente chaveada 34

2.5 - Estrutura geral do sistema $\quad 35$

3-METODOLOGIA $\quad 37$

3.1 - Especificações $\quad 37$

3.1.1 - tecnologia 37

3.1 .2 - conversor $A / D \quad 38$

3.1.3 - alimentação do SoC 38

3.1.4 - sensor de pressão $\quad 39$

3.1.5 - sensor de temperatura 39 
3.1.6 - resumo das especificações $\quad 40$

3.2 - Procedimentos 41

3.2.1 - ajustes de offset 41

3.2 .2 - conversão tensão-corrente $\quad 42$

3.2.3 - filtragem $\quad 42$

3.2.3.1 - monitoramento da bateria 43

3.2.3.2 - sensor de pressão $\quad 45$

3.2.3.3 - sensor de temperatura $\quad 48$

4 - PROJETO ELÉTRICO

4.1 - Topologias $\quad 50$

4.1.1-amplificador de instrumentação $\quad 50$

4.1.1.1 - amplificadores operacionais $\quad 53$

4.1.1.2 - espelhos de corrente $\quad 57$

4.1.1.3-resistências $\quad 58$

4.1.1.4-conversores tensão-corrente 60

4.1.2 - biquads $S C \quad 62$

4.1.3 - biquads SI 64

4.1.4-monitoramento da bateria 66

4.1.4.1 - chave analógica $\quad 69$

4.2 - Cálculos dos dispositivos $\quad 70$

4.2.1 - subcircuito: sensor de temperatura $\quad 70$

4.2.1.1-amplificadores operacionais $\quad 71$

4.2.1.2 - espelhos de corrente $\quad 73$

4.2.1.3 - resistências $\quad 74$

4.2.2 - subcircuito: sensor de pressão $\quad 74$

4.2.2.1-amplificadores operacionais 74

4.2.2.2 - espelhos de corrente $\quad 77$

4.2.2.3-resistências $\quad 78$

4.2.3 - subcircuito: monitoramento da bateria 78

4.2.3.1 - teste OCV 78

4.2.3.2 - amplificador de instrumentação $\quad 80$

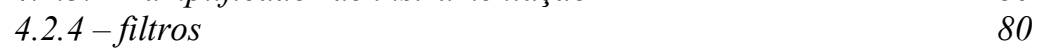

4.3 - Procedimentos de teste $\quad 82$

5 - RESULTADOS E DISCUSSÃO $\quad 84$

$\begin{array}{ll}5.1 \text { - simulações } & 84\end{array}$

5.1.1 - amplificador operacional $\quad 84$

5.1.1.1 - malha aberta $\quad 87$

5.1.1.2 - impedância de saída 90

5.1.1.3 - faixa de modo comum

5.1.1.4-PSRR 94

5.1.1.5 - resposta em freqüência 95

5.1.1.6 - slew rate e tempo de acomodação 96

5.1.2 - outros blocos 98

5.2 - Discussão 101

6 - CONCLUSÃO $\quad 102$

Bibliografia $\quad 103$

Anexo 1 - datasheet resumido LM $35 \quad 107$

Anexo 2 - datasheet resumido STCP $850 \quad 108$ 


\section{1 - INTRODUCÃ̃}

Este trabalho consiste no projeto de uma interface analógica entre sensores e um conversor analógico-digital, integrando um sistema em chip que fará parte de um sistema de controle de irrigação.

No cultivo de grandes áreas, há uma variabilidade nos parâmetros do solo que deve ser levada em consideração pelo agricultor, tanto ao longo do tempo quanto ao longo da área cultivada. Devido às grandes extensões dessas áreas e ao uso de maquinaria voltada para o cultivo, na agricultura moderna o produtor vem respondendo a essas variações. Esta situação levou ao desenvolvimento da chamada agricultura de precisão, que tem por objetivo otimizar o aproveitamento de recursos através do gerenciamento da produção a partir dos parâmetros variantes. O gerenciamento é feito medindo-se as variáveis de interesse para a caracterização da situação em locais diversos da área de cultivo, gerando mapas de manejo. Os dados obtidos são processados e interpretados, levando à aplicação de determinadas soluções (irrigação, aplicação de pesticidas, preparo do solo etc.) localizadas.

A irrigação escassa ou demasiada de determinada área de cultivo pode causar prejuízos tanto à lavoura quanto ao meio ambiente. Com este foco, dentro do objetivo da agricultura de precisão, vem sendo desenvolvido um Sistema de Controle de Irrigação (SCI), como parte do projeto "Sistema em Chip, Microssistemas e Nanoeletrônica" (SCMN), do programa "Instituto do Milênio".

\section{$1.1-\mathrm{SCI}$}

No SCI, nós espalhados em uma rede cobrindo a área de interesse são responsáveis pela caracterização da condição do solo e pelo acionamento de atuadores locais para controlar o fluxo de água da irrigação. Os nós se comunicam com uma única estação-base através de várias estações de campo, cada uma cobrindo uma área de até 100ha. 


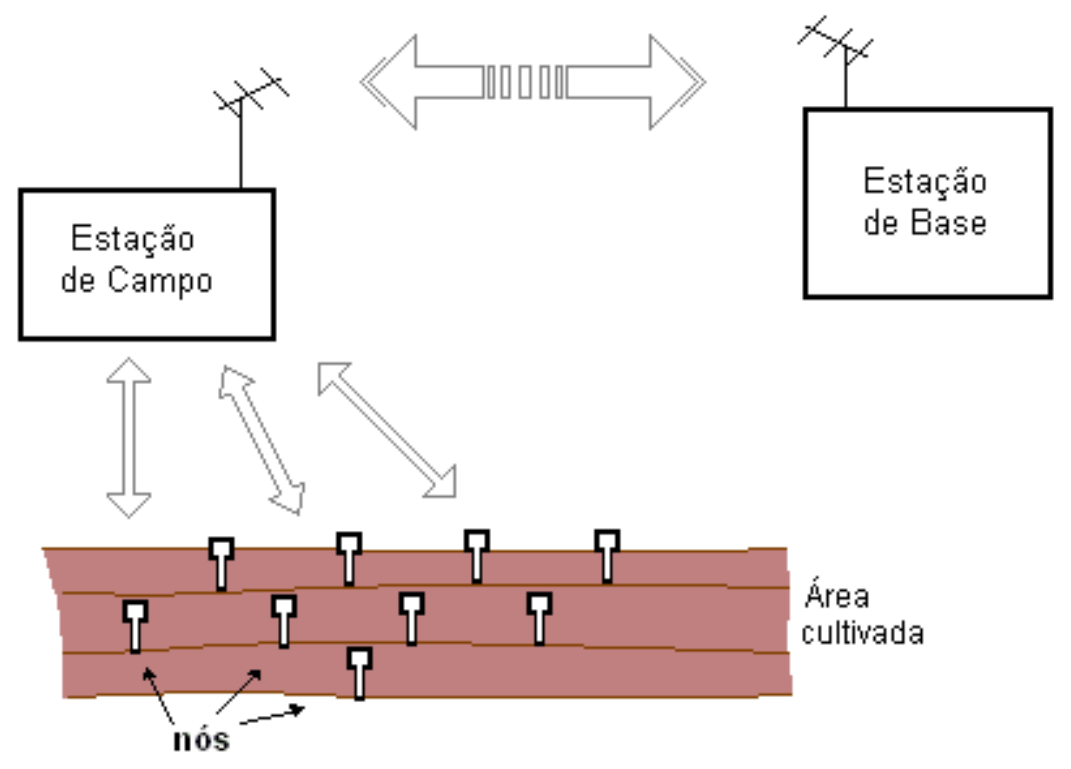

Figura 1.1 - arranjo do SCl

Os dados são analisados na estação-base e os nós são programados de acordo com a necessidade de irrigação. A caracterização local em cada nó é feita pela aferição da umidade do solo (através da medida do potencial mátrico, realizada por um sensor de pressão) e da temperatura em quatro pontos diferentes. Além dos sensores e do atuador, o nó é composto por um sistema de alimentação elétrica, uma antena para a comunicação à distância em radiofreqüência com a estação de campo e um sistema-emchip (SoC, do inglês system on chip) específico [1].

Não é possível alimentar os nós remotos através da rede elétrica devido às grandes áreas cobertas. O sistema de alimentação elétrica é, por esse motivo, composto de painéis solares responsáveis por manter carregado um conjunto de baterias que alimenta os nós. O projeto do sistema de alimentação [33] prevê uma autonomia de até 10 dias sem insolação. É desejado também que se prolongue a vida útil das baterias recarregáveis, daí a necessidade de um circuito que as monitore para se determinar a necessidade de recarga; quando necessária, é realizada com energia das células fotovoltaicas dos painéis solares. 


\section{2-SoC}

O SoC, desenvolvido em tecnologia CMOS, processa digitalmente os dados adquiridos pelos sensores para comunicação com a estação de campo. Para que isso seja possível, os dados analógicos são transformados em informações digitais - através de um conversor analógico-digital (“conversor A/D") - que são entregues ao microprocessador integrante do SoC.

\section{3 - Projeto}

Os objetivos do presente projeto são idealizar e projetar a interface analógica de aquisição de dados entre os sensores e o conversor A/D, levando em conta aspectos importantes para o SoC e para o SCI, como o baixo consumo e pequenas dimensões.

No capítulo 2 serão apresentados e revisados conceitos pertinentes para o entendimento do problema e o desenvolvimento do projeto. No capítulo 3 são estabelecidas as especificações do projeto e descritos os procedimentos e a metodologia de projeto. O capítulo 4 apresenta as topologias de circuitos utilizados e os cálculos dos circuitos e dispositivos. Os resultados são apresentados e discutidos no capítulo 5, e a conclusão do trabalho é feita no capítulo 6. Anexos e uma listagem da principal bibliografia utilizada são mostrados após a conclusão. 


\section{2 - REVISÃO BIBLIOGRÁFICA}

A seguir, são apresentados e revisados conceitos pertinentes para o entendimento do problema e o desenvolvimento do projeto. As especificações do projeto são estabelecidas no capítulo 3 - Metodologia.

\section{1 - Sinais analógicos e digitais}

Dentro do âmbito de processamento eletrônico, são considerados "sinais" valores de tensão, corrente ou carga que possam ser detectados e que forneçam alguma informação sobre o sistema ao qual eles correspondem. Geralmente, a informação está associada à variação em amplitude e no tempo destes valores.

Sinais analógicos são sinais que são definidos em uma faixa contínua de tempo e cuja amplitude pode assumir qualquer valor (possivelmente entre um máximo e um mínimo). Sinais analógicos podem ser também discretos, caso em que serão discretos no tempo ou na amplitude. Um sinal discreto no tempo pode assumir qualquer amplitude, mas apenas em determinados instantes. Fora destes instantes, sua amplitude não fornece nenhuma informação sobre o sistema. Similarmente, um sinal analógico discreto na amplitude varia continuamente ao longo do tempo, mas só pode assumir determinados valores de amplitude. Limitar o sinal a instantes no tempo é chamado de amostragem; limitá-lo a valores discretos de amplitude é chamado de quantização.

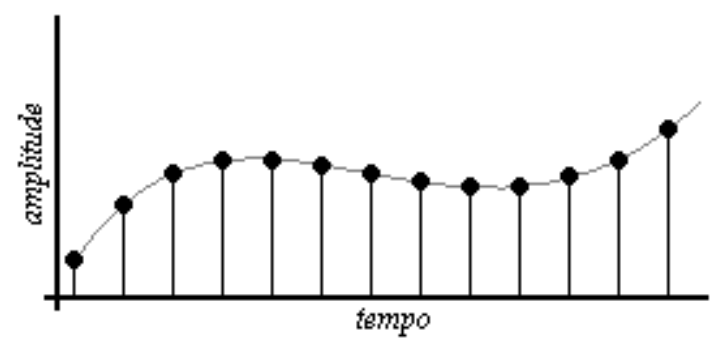

Figura 2.1 - sinal discreto no tempo 


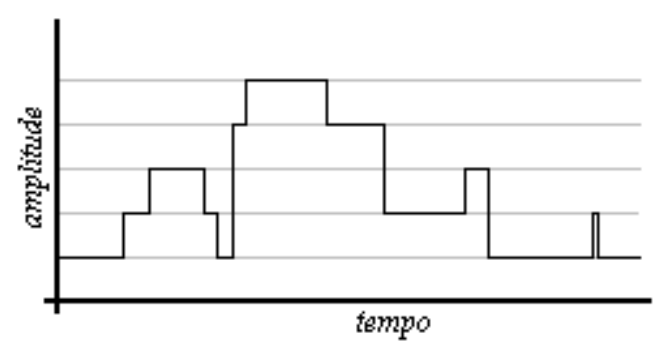

Figura 2.2 - sinal discreto na amplitude

A Figura 2.1 apresenta um exemplo de sinal analógico discreto no tempo, enquanto a Figura 2.2 apresenta um sinal analógico discreto na amplitude.

Sinais digitais, por sua vez, são sinais que assumem valores discretos tanto no tempo quanto na amplitude, como mostra a Figura 2.3.

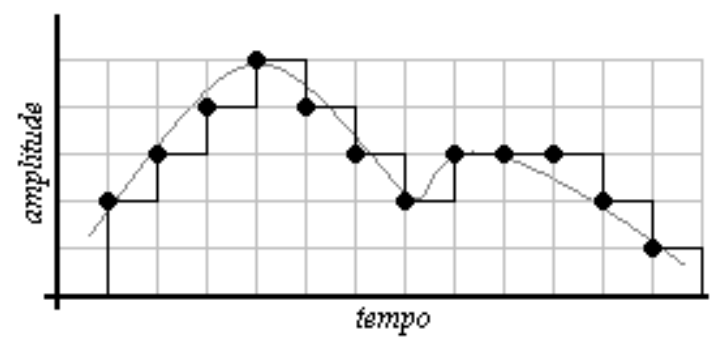

Figura 2.3 - sinal digitalizado

Na Figura 2.3, a onda mais clara mostra um sinal analógico e a onda em preto mostra um sinal quantizado em determinados instantes do tempo, assumindo o valor possível de amplitude mais próximo do sinal analógico real, até a próxima amostragem. Essa é uma possível forma teórica de conversão analógico-digital, chamada de zeroorder hold.

Valores digitais são normalmente representados por números binários. Nestes números, a menor variação é dada pelo dígito binário (bit) mais à direita, chamado por isso de bit menos significativo (ou LSB, least significant bit). Assim, a margem de variação que o sinal analógico tem para ainda ser representado pelo mesmo número binário é de $\pm 1 / 2 \mathrm{LSB}$. 


\section{2 - Princípios de condicionamento de sinal}

O condicionamento de sinal em um sistema é feito para que o sinal de saída de um bloco do sistema seja adequado às especificações da entrada do bloco seguinte. As alterações feitas ao sinal original geralmente envolvem amplificação e filtragem, além de possivelmente outros ajustes, como a linearização, casamento de impedâncias e o ajuste do tipo de sinal entregue. Em sistemas envolvendo sensores, muitas vezes fica também a cargo dos circuitos de condicionamento a excitação dos sensores para seu funcionamento correto.

\subsection{1 - tipos de sinal}

Os sinais que representam fenômenos ou eventos podem ser não apenas elétricos, mas dados em vários tipos de fenômenos físicos - térmicos, eletromagnéticos, mecânicos; a classificação varia um pouco na literatura ([7], [9]). Algumas destas formas são vantajosas em relação a outras para transmissão, armazenamento, processamento, etc. É por esse motivo que os sinais são geralmente convertidos para serem processados eletronicamente.

Os dois tipos de sinal mais usados em circuitos eletrônicos são sinais de tensão e sinais de corrente. Caso o sinal de saída de um bloco seja de um tipo diferente do que vai ser recebido em seguida, faz-se uma conversão tensão-corrente ou corrente-tensão. Os circuitos responsáveis por estas conversões são, às vezes, também chamados de transdutores, termo que será explicado mais adiante.

\subsection{2 - amplitude}

A faixa de valores que o sinal abrange deve ser compatível com a faixa de valores aceita pelo estágio que o recebe. Por isso, o ajuste de amplitude envolve ganhos e atenuações na amplitude do sinal. Idealmente, um ganho linear na amplitude do sinal não gera perda de informação. No entanto, circuitos têm faixas de entrada limitadas, então valores acima destes limites não carregam nenhuma informação (ocasionam a distorção por ceifamento, ou clipping) e sinais cuja variação não se aproxime do máximo são desperdício da capacidade do sistema. 

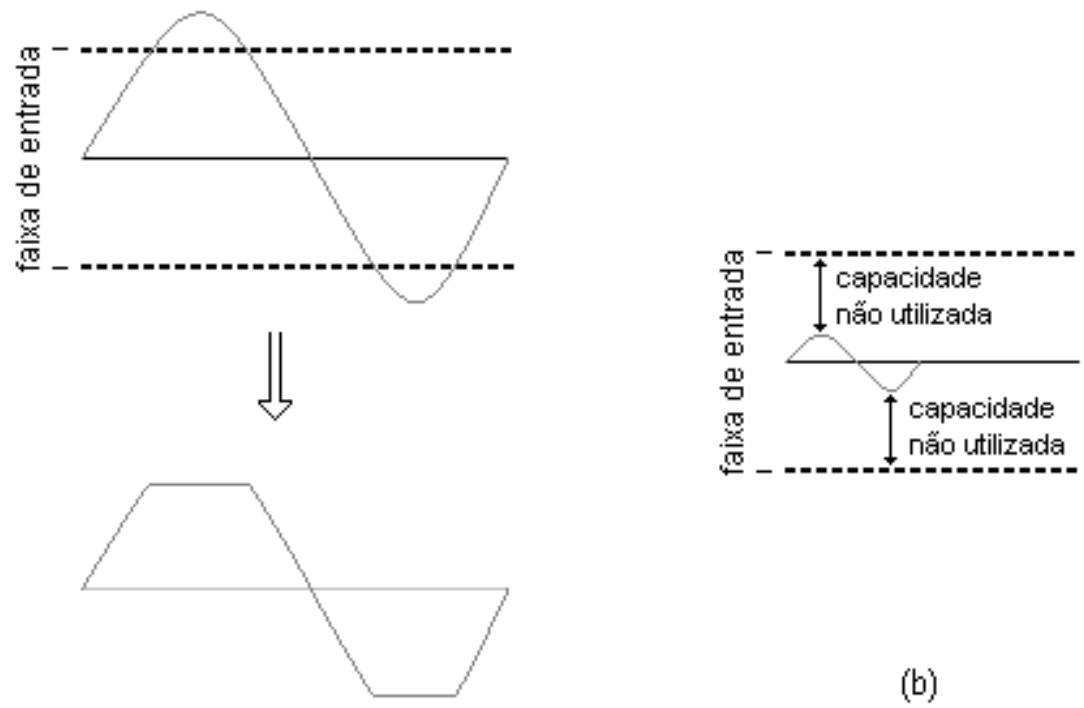

(a)

(b)

Figura 2.4 - a) ceifamento ou clipping do sinal;

b) desperdício de capacidade do sistema

\subsubsection{1 - ruído}

Além disso, em circuitos práticos sempre há o problema do ruído, aleatório ou sistemático, intrínseco ao meio. Um fator importante em um sistema de transmissão de sinais é a relação sinal/ruído ( $S / N$, ou $S N R$, do inglês signal-to-noise ratio), dada pela razão entre a amplitude do sinal e a amplitude do ruído, expressa em um valor escalar ou em decibéis $(\mathrm{dB})$.

Se o nível de ruído é independente do sinal, essa razão é maior quanto maior for a amplitude do sinal, reforçando o interesse de que a faixa de amplitudes de um sinal seja a mais próxima possível da faixa de entrada do estágio que a recebe.

\subsubsection{2 - linearidade}

Entretanto, o ajuste de amplitude pode requerer mais do que uma amplificação ou atenuação simples. Se a amplitude do sinal não variar linearmente em relação à variável que representa, pode ser necessária uma linearização. Um sistema linear é um sistema que pode ser descrito pela equação $y=a x+b, \operatorname{com} a \neq 0$.

Para o processamento de um sinal, é interessante que ele seja linear, pois facilitam-se assim sua interpretação e manipulação, e amenta-se a fidelidade ao fenômeno representado. Infelizmente, muitos sensores não apresentam saídas lineares. Nessas situações, o ajuste feito pode ser, por exemplo, multiplicando o sinal por um 
valor não-constante. A Figura 2.5(a) mostra uma relação não-linear. As figuras 2.5(b) e 2.5(c), respectivamente, ilustram a multiplicação realizada e a relação linear resultante.

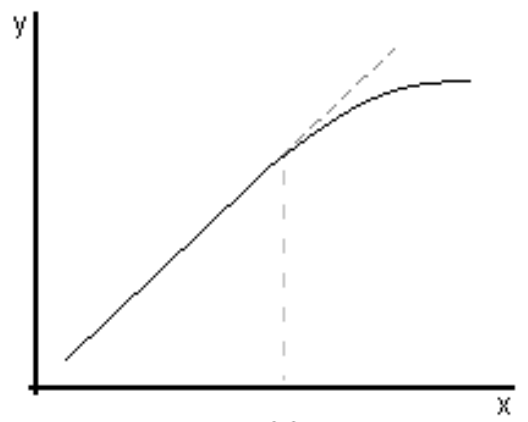

(a)

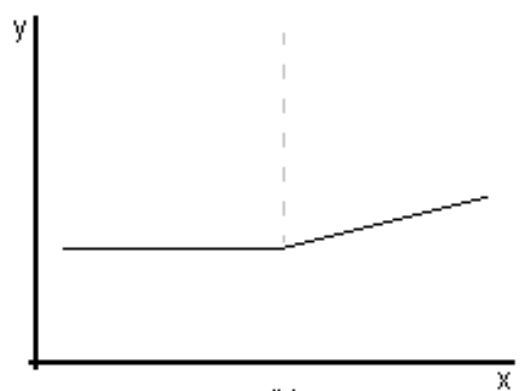

(b)

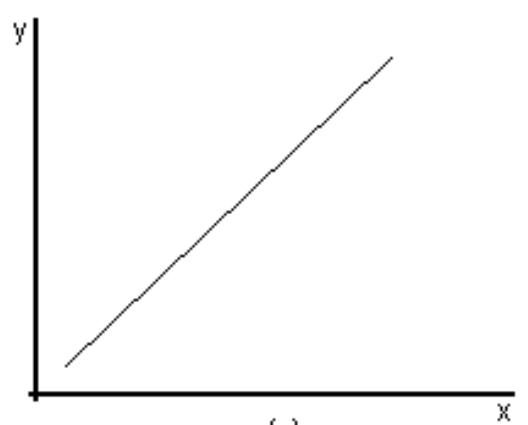

(c)

Figura 2.5 - (a) relação não-linear; (b) função multiplicada; (c) relação resultante.

Um dos fatores que podem interferir na amplitude do sinal ao longo do sistema é a impedância de cada estágio pelo qual ele passa. Estágios com impedância de entrada muito baixa podem influenciar na corrente da saída do estágio anterior, estágios com impedância de saída muito alta podem acabar atenuando o sinal para o próximo estágio, e assim por diante. Um método comum de se evitar problemas deste tipo é usar estágios 
de isolação entre dois estágios potencialmente problemáticos, eliminando o contato elétrico real entre eles.

\subsection{3 - resposta em freqüência}

Pode ser necessário também variar o ganho do sinal de acordo com sua faixa espectral. A função de transferência geral de um sistema linear invariante no tempo com entrada $X$ e saída $Y$ é dada por

$$
T(s)=\frac{Y(s)}{X(s)}
$$

Se as especificações exigirem determinada resposta em freqüência, é preciso realizar uma filtragem que limite as freqüências do sinal de acordo com a resposta exigida.

Um sinal analógico usa certa faixa de freqüências (banda). O circuito que entrega este sinal, no entanto, pode ter interferências externas, ruído ou mesmo outros sinais contidos na mesma saída, que podem abranger outras faixas de freqüência ou mesmo todas elas (como o ruído branco). A filtragem em freqüências em geral se destina a permitir que as componentes em determinadas freqüências do sinal passem inalteradas, enquanto elimina todas as outras.

A faixa de freqüências que se deseja preservar é chamada de faixa de passagem, e a faixa que se deseja eliminar é chamada de faixa de bloqueio. Os três tipos mais comuns de filtros são o passa-baixas (Figura 2.6(a)), que elimina freqüências acima de uma dada freqüência de corte; o passa-altas (Figura 2.6(b)), que elimina as freqüências abaixo da freqüência de corte; e o passa-faixa (Figura 2.6(c)), uma combinação dos dois anteriores, que permite a passagem apenas de uma determinada faixa de freqüências eliminando as demais. Há outros, como o rejeita-faixa - também uma combinação de passa-altas e passa-baixas -; o dente (notch) - um tipo de rejeita-faixa bem específico -; e o passa-todas, que não altera a amplitude do sinal, mas provoca alterações de fase. Por simplicidade, o passa-baixas será usado para generalização daqui em diante. 


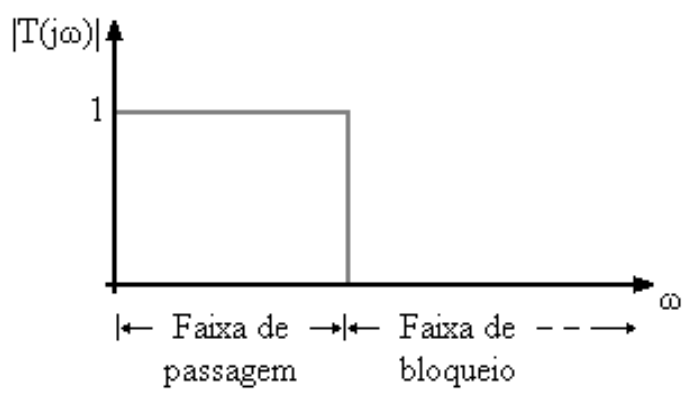

(a)

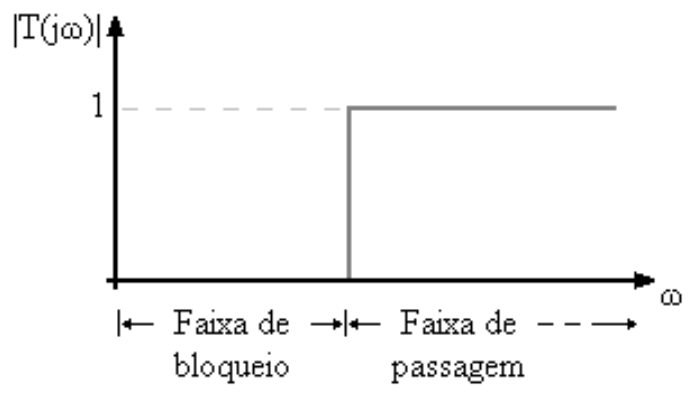

(b)

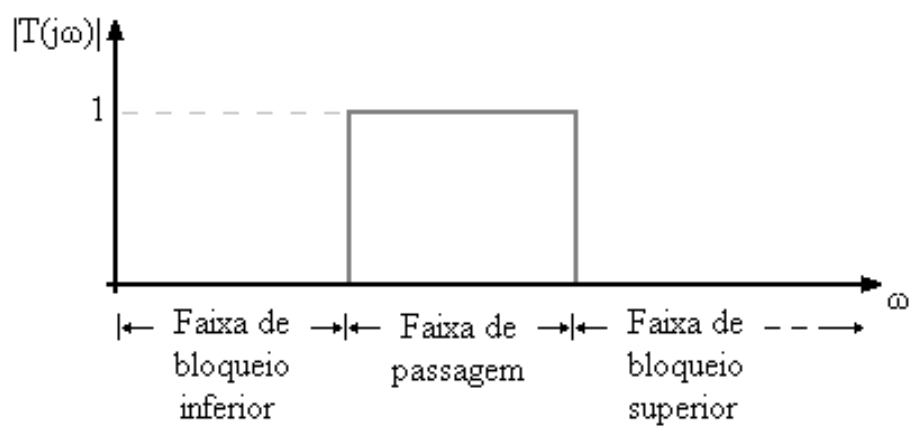

(c)

Figura 2.6 - funções ideais passa-baixas (a), passa-altas (b) e passa-faixa (c).

\section{3 - sensores e transdutores}

Transdutores são dispositivos que realizam a conversão do sinal de um tipo físico de energia para outro. Na prática, no âmbito de processamento eletrônico, são chamados de transdutores apenas os que trabalham com sinais elétricos, seja convertendo um sinal elétrico para um sinal físico de outro tipo - quando são chamados de atuadores - ou convertendo um sinal físico para elétrico - quando são chamados de sensores, usados principalmente em sistemas de aquisição de dados. 
O sensor pode envolver mais de uma conversão antes de chegar ao sinal elétrico. Por exemplo, a pressão sobre um diafragma o desloca, e este deslocamento provoca uma alteração na capacitância em seus terminais, que por fim age no circuito gerando o sinal elétrico. Mesmo assim, costuma-se considerar todo o dispositivo conversor como um único sensor.

Alguns sensores já têm como parte do dispositivo integrado algum condicionamento de sinal, anterior à saída. Este pré-condicionamento pode incluir um ajuste da faixa de saída, linearidade do sinal, amplificação, etc. Nestes casos, são chamados de sensores inteligentes (smart sensors).

\subsection{1 - sensores de pressão}

Pressão é definida como a força exercida por unidade de área. Há diversas maneiras de medi-la. Os dois meios mais comuns são medindo o deslocamento de um líquido, e a deformação em um diafragma. Em ambos os casos, há maneiras diferentes de se obter a medição, geralmente feita tendo como referência a pressão atmosférica (pressão exercida pela atmosfera acima da área) ou alguma outra pressão conhecida.

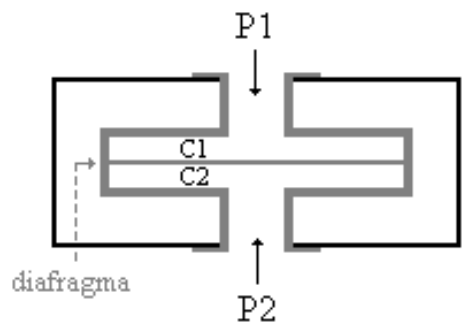

(a)

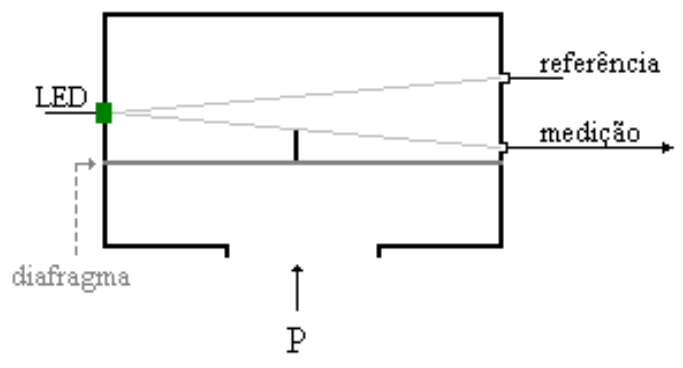

(b)

Figura 2.7 - (a) sensor de pressão diferencial capacitivo; (b) sensor de pressão óptico 
O diafragma é uma membrana, geralmente circular, que se deforma quando submetida a uma diferença de pressão entre os seus dois lados. A pressão pode então ser medida a partir do deslocamento do diafragma ou do tensionamento da membrana, entre outros modos. Para microssensores, uma abordagem bem estabelecida é a de membranas semicondutoras (em especial, de silício).

Uma forma de converter a pressão a um sinal elétrico é com um sensor como o da Figura 2.7(a); a capacitância nos terminais do sensor depende da distância entre a membrana e a placa, distância esta que varia com a pressão diferencial entre os dois lados do diafragma. Outra forma é utilizando-se do efeito piezorresistivo, isto é, a variação na resistência de um material (semicondutor, no caso) quando submetido a tensão. Desta forma, com um sensor como o da Figura 2.8, a resistência entre os terminais depende da tensão mecânica, que varia com a deformação da membrana. Em ambos os casos, é fácil fazer estas variações serem convertidas em variações em um sinal elétrico de tensão.

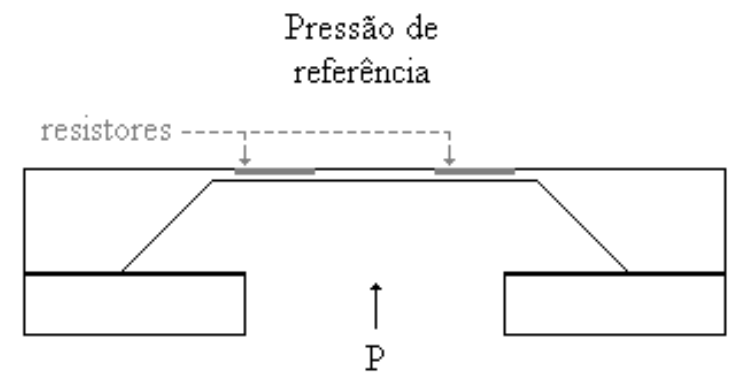

Figura 2.8 - sensor de pressão piezorresistivo (extensômetro)

\subsubsection{1 - potencial mátrico}

Entre as aplicações de sensores de pressão, que incluem barômetros e sensores acústicos, está a aferição do potencial mátrico do solo, uma medida da sua capacidade de reter água. Acontece devido à atração entre a água e partículas do solo, fazendo a água se mover de baixo para cima, contra a atração da gravidade. Em um solo saturado, o potencial mátrico é nulo, crescendo em valores negativos, já que somente diminui o potencial da água em relação a um solo saturado [14-16]. 


\subsection{2 - sensores de temperatura}

A maior parte dos sistemas eletrônicos, químicos, biológicos, etc. são afetados pela temperatura. A necessidade de medi-la tem enfoques variados e, de fato, há vários tipos de técnicas e dispositivos destinados à sua medição. Em sistemas mecânicos, o sensor de temperatura pode ser um sensor bimetal - duas peças de metais com coeficientes de expansão térmica diferentes são acopladas, de modo que, quando a temperatura é diferente da referência, o conjunto se curva - ou uma espiral metálica cuja expansão provoca o deslocamento de um ponteiro - entre outras possibilidades. Para sistemas eletrônicos, os sensores de temperatura mais comuns são os termorresistores (também abreviados por RTD, do inglês resistance temperature detector), termistores, termopares e sensores semicondutores de junção $p n$.

\subsubsection{1 - RTDs}

Nos RTDs, a variação da resistência de um elemento com a temperatura permite que este funcione como um termômetro. Em geral, uma determinada corrente é forçada através do elemento medidor e mede-se a tensão sobre ele, obtendo-se assim a informação sobre a temperatura. A relação proporcional entre resistência e temperatura é razoavelmente linear em certa faixa, e mesmo afastando-se dessa faixa a nãolinearidade é previsível, podendo ser compensada com circuitos de condicionamento de sinal.

Além desse possível ajuste de linearidade, é necessário realizar a excitação do circuito e possivelmente algum tipo de compensação para o fato de que a energização do sensor aumenta sua temperatura, afetando a medição. Há diferentes aplicações de RTDs, nem todas sofrendo das mesmas desvantagens; podem também ser feitos com diferentes materiais, funcionando em diferentes faixas de temperatura (em geral de centenas de graus Celsius).

\subsubsection{2 - termistores}

Outro tipo de sensor resistivo, os termistores são dispositivos pequenos, feitos de um material semicondutor cuja resistência varia com a temperatura mas, no caso dos termistores, de forma altamente não-linear. Sua resistência em geral cai com o aumento da temperatura (embora o contrário seja possível), ao contrário dos RTDs. Para uma temperatura determinada, respondem rapidamente à sua variação. 
Termistores simples e de baixa precisão são baratos, mas para maior precisão e funcionalidade a necessidade de circuitos externos ou processamento digital aumentam bastante, aumentando também o custo. Por esses motivos, termistores são usados mais em controle de temperatura, como termostatos.

\subsubsection{3 - termopares}

O efeito termelétrico, ou efeito Seebeck, é o surgimento de uma diferença de potencial quando as junções de dois condutores de materiais diferentes são submetidas a temperaturas diferentes. Um termômetro desta forma consiste de um par de fios unidos em uma extremidade, à temperatura que se deseja medir, e com a outra extremidade conectada aos terminais de um voltímetro, usando portanto a temperatura ambiente como referência. Para isso, a temperatura ambiente deve ser conhecida (ou a medição se sujeita a erros), freqüentemente sendo necessário o uso de um segundo sensor.

O termopar, ao contrário dos dois tipos de sensores apresentados anteriormente, não necessita de excitação - a diferença de temperatura é a causadora da diferença de potencial. Entretanto, a tensão gerada é muito baixa, da ordem de $\mu \mathrm{V} /{ }^{\circ} \mathrm{C}$. Além disso, a não-linearidade ao longo da faixa de operação pode chegar a vários graus, e geralmente há a necessidade de compensação. Ainda assim são muito utilizados, principalmente pela larga faixa de temperaturas para a qual opera (podendo chegar a mais de $1800^{\circ} \mathrm{C}$ ).

\subsubsection{4 - sensores de junção}

Uma junção $p$ - $n$ consiste de um material semicondutor tipo $p$ em contato com um material semicondutor tipo $n$. Devido à diferença nas concentrações de cargas em cada região, uma diferença de potencial pode permitir ou limitar fortemente o fluxo de cargas pelos ao longo do material. Diodos de junção são dispositivos que permitem ou não a passagem de corrente dependendo da polarização da tensão aplicada sobre eles. São também chamados de diodos semicondutores, por serem fabricados em material semicondutor (por exemplo, silício) que permite realizar a junção $p$ - $n$ (Figura 2.9) em um mesmo cristal. 


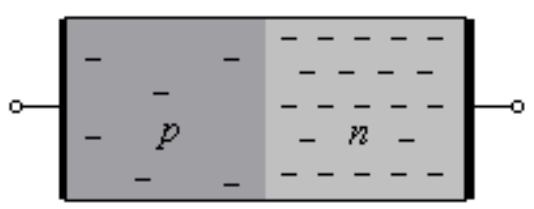

Figura 2.9 - junção p-n

A condução de um diodo semicondutor é influenciada pela temperatura. Embora seja considerada uma característica desvantajosa, essa dependência da temperatura permitiu o uso de junções $p$ - $n$ como sensores de temperatura. Este uso permanece válido para uma faixa de temperaturas não muito grande, uma vez que a corrente na junção no sentido reverso (boa parte sendo correntes de fuga) pode aumentar bastante e corromper os resultados.

Mesmo com essa limitação, os diodos semicondutores são muito utilizados como sensores de temperatura - principalmente em equipamentos eletrônicos, devido à possibilidade de fabricá-los como parte de circuitos integrados, motivo pelo qual o termo sensor de circuito integrado é às vezes utilizado como sinônimo de sensor semicondutor ou sensor de junção $p$ - $n$. Outras vantagens dos sensores semicondutores incluem a linearidade, a boa acurácia (em torno de $\pm 0,5{ }^{\circ} \mathrm{C}$ ) e sensibilidade (aproximadamente $2,1 \mathrm{mV} /{ }^{\circ} \mathrm{C}$, para o silício). Outros materiais que não o silício também podem ser usados para se alterar a faixa de temperaturas do sensor.

\subsection{3 - monitoramento da bateria}

O monitoramento da bateria é feito por um circuito que permita estimar o estado da bateria e sua capacidade de entregar carga ao sistema. É feito para se poder prever ou detectar quando uma pilha deve ser substituída ou recarregada, seja por não estar tendo desempenho suficiente ou por apresentar alguma anormalidade.

Não basta simplesmente medir a tensão sobre cada célula da bateria ou sobre todas, pois em pilhas deste tipo a tensão varia muito pouco e não reflete necessariamente a carga disponível restante. Há dois parâmetros principais usados comumente para se definir o estado e condições de uso de uma pilha: o estado da carga (state of charge em inglês, geralmente abreviado por $S o C$; como esta sigla já denomina system on chip, aqui se representará o estado da carga por SofCh) e o state of health (em tradução literal, "estado da saúde"), abreviado por $\mathrm{SoH}$. 


\subsubsection{1 - estado da carga}

O estado da carga é uma medida percentual da capacidade de carga disponível em relação à capacidade de carga nominal da bateria. (Uma bateria carregada, antes do primeiro uso, deve ter o SofCh de 100\%.) Como o SofCh tem como referência um valor nominal, não leva em conta a queda na capacidade da bateria que ocorre inevitavelmente com o tempo ou uso. Assim, se a capacidade real da célula em dado momento for de $90 \%$ da nominal, e estiver totalmente carregada, o SofCh indicará $90 \%$.

Este desvio, no entanto, pode ser útil para indicar a condição da vida da bateria; o SofCh não indica se a bateria está plenamente carregada, mas ao fim de um ciclo de carga pode dizer qual a capacidade de recarga que tal bateria ainda mantém. Além disso, a carga mínima que a bateria deve ter antes de precisar ser recarregada não é percentual, continua sendo relativa à nominal, logo é bom manter uma medição desta maneira. É possível também medir a carga máxima atual e usá-la computacionalmente no lugar da nominal como uma nova a referência. Deste modo, a bateria carregada indicaria $100 \%$ sempre, mesmo este valor correspondente a uma carga cada vez menor que o $100 \%$ indicado no início do uso.

Um método simples de medição do SofCh é chamado de OCV (de open circuit voltage), baseado na tensão de circuito aberto. Em casos onde a precisão não é necessária, esta medida basta pois, apesar de quase sempre constante, ao fim de um ciclo de carga-e-descarga a tensão da célula cai. Se a precisão for importante, então somente a tensão de circuito aberto não vale.

Outro método, válido, é medindo a corrente, basicamente do mesmo modo OCV anteriormente visto, mas com outro enfoque. A carga transferida pela célula é obtida acumulando-se a drenagem de corrente com o tempo.

\subsubsection{1 - teste de tensão de circuito aberto}

O circuito utilizado para o teste é o seguinte: 


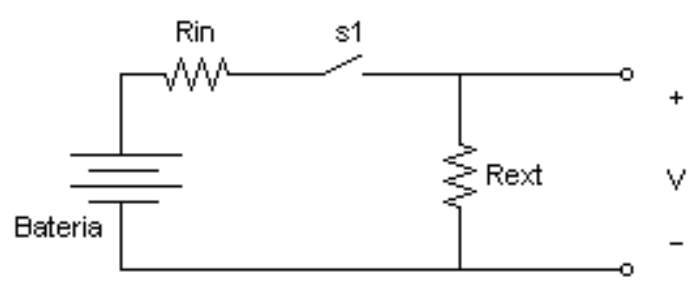

Figura 2.10- OCV

Quando a chave $s 1$ estiver aberta, a tensão $V=V_{o c}$, que é a tensão em circuito aberto da bateria; quando $s 1$ estiver fechada (conduzindo), $V=V_{\text {out }}$, que é a tensão medida sobre o resistor $R_{e x t}$. $R_{\text {in }}$ é a resistência interna da bateria, a ser medida.

O procedimento é:

1. Com a chave aberta, mede-se o valor de $V_{o c}$;

2. Com a chave fechada, sabendo o valor de $R_{\text {ext }}$ e medindo o valor de $V_{\text {out }}$, podese calcular o valor da corrente $I$ circulando no circuito.

A diferença entre a tensão de circuito aberto e a tensão com carga, $V_{i n}$, é dada por:

$$
V_{\text {in }}=V_{o c}-V_{o u t}
$$

esta queda de tensão corresponde à tensão dissipada na impedância interna $R_{\text {in }}$ da bateria. Como já se achou o valor de $I$, tem-se:

$$
R_{i n}=\frac{V_{i n}}{I}
$$

Este método fornece dois valores importantes: $R_{i n} \mathrm{e} I$. A corrente $I$ deve ser medida várias vezes consecutivas, com um intervalo de tempo controlado entre as medições (processo chamado de coulomb counting), e a partir daí se dá a estimativa do estado da carga. A equação de Peukert é usada para este cálculo: 
Na equação, as unidades são:

$[\mathrm{C}]: \mathrm{Ah}$;

[I]: A;

[T]: h;

$\mathrm{n}=$ número de Peukert, uma constante para dada bateria.

Como a equação de Peukert considera o tempo como contínuo, é preciso que se haja um desenvolvimento computacional para o uso de sucessivas medidas.

A resistência interna $R_{\text {in }}$ não informa diretamente a capacidade de carga da bateria, mas é um dos fatores que determinam as condições em que a célula se encontra, conforme será melhor explicado adiante.

\subsubsection{2 - teste de impedância e condutância}

O processo anterior $(\mathrm{OCV})$ mede uma resistência $R_{i n}$; no entanto, a impedância interna da pilha pode ter componentes imaginárias. Para se estimar a impedância interna, um método que se propõe é ligar a pilha a uma fonte de tensão $\mathrm{AC}$ de pequena amplitude e freqüência conhecida, e medir a corrente em fase que circula através da pilha. Assim, se determina a fase da impedância interna e também se tem um valor da condutância $Y$. Medidas DC não levam em conta capacitâncias; já este procedimento dá uma aproximação indireta do state of health da bateria, apresentado a seguir.

Ambos os métodos necessitam de alguma compensação matemática e computacional para levar em conta temperatura, idade da célula, etc. Estes são fatores que influenciam a estimativa tanto do $S o f C h$ quanto do $S o H$. A idéia é que se tenha um conjunto de parâmetros e/ou tabelas de características da bateria, para que sejam processados junto à medida de corrente, tensão e impedância interna. A temperatura, por exemplo, pode ser medida a cada vez que a corrente for medida, diretamente pelo sensor; a idade pode ser calculada ou mantida como um registro computacional; enfim, com estes parâmetros, que podem se relacionar, e as medidas de corrente e tensão, o cálculo do SofCh se torna mais acurado. 


\subsubsection{2 - avaliação do state of health}

O state of health é uma "medida" que reflete a condição geral de uma bateria e sua capacidade de desenvolver dada performance comparada a uma bateria nova. Leva em conta principalmente impedância interna, capacidade de carga, tensão e autodescarga. Na realidade, o $S o H$ não é uma medida clara, e seus objetivos e parâmetros são definidos em geral pelos fabricantes das pilhas ou dos equipamentos de recarga. A impedância interna, por exemplo, aumenta com a idade da célula, mas um aumento desproporcional em relação às outras células com mesmas condições de uso pode indicar a necessidade de troca. Seja qual for o parâmetro (ou mais de um) usado para estimar o $\mathrm{SoH}$, deve haver um registro ou referência da condição inicial (pilha nova) de tal parâmetro.

\section{4 - circuitos de condicionamento de sinal}

Nesta seção serão apresentados alguns circuitos utilizados em condicionamento de sinais, e revisados alguns conceitos.

\subsection{1 - amplificadores}

De forma geral, amplificadores são quaisquer dispositivos que aumentem a amplitude de um sinal. Na realidade, o ganho de um amplificador pode ser maior que unitário (amplificação), unitário ou menor que o unitário (atenuação), e pode haver ou não inversão. Entretanto, pela natureza da amplificação, fica claro que o amplificador deve ser um elemento ativo, utilizando alguma fonte de energia externa ao sinal para que possa amplificá-lo. Serão apresentados a seguir alguns tipos comuns de amplificadores.

\subsubsection{1 - amplificadores operacionais}

Grande parte dos circuitos fundamentais para as funções básicas de condicionamento de sinal envolve amplificadores operacionais (amp-ops). O amp-op é um dispositivo diferencial de ganho idealmente infinito, alta impedância de entrada e baixa impedância de saída. As entradas do amp-op são chamadas de inversora e nãoinversora, e indicadas por - e +, respectivamente, na representação do dispositivo. Quando realimentado negativamente (isto é, o terminal de saída ligado ao terminal da 
entrada inversora), o amp-op tem entre estas entradas um "curto-circuito virtual", pois a diferença das tensões será idealmente zero. Quando a entrada não-inversora está ligada ao terra, diz-se que há o "terra virtual".

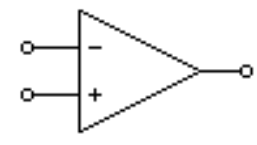

Figura 2.11 - amplificador operacional

\subsubsection{2 - amplificador inversor}

Diversos tipos de amplificadores podem ser implementados com amp-ops alterando-se a configuração da entrada e realimentação, e dimensionando-se os dispositivos conectados ao amp-op. No amplificador inversor (Figura 2.12), a corrente $i_{1}$ que circula por R1 é dada por $V_{i n} / R 1$; como não há corrente entrando no amp-op (considerado-o ideal), esta mesma corrente circula por R2, dando portanto na saída $V_{\text {out }}$ $=-i_{1} \cdot R 2=-V_{\text {in }}(R 2 / R 1)$.

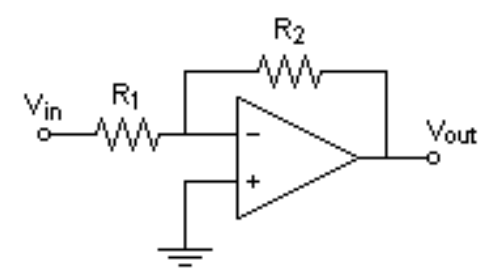

Figura 2.12 - amplificador inversor

Ou seja, o amplificador inversor tem um ganho de tensão $-R 2 / R 1$, onde $R 2$ e $R 1$ são os valores das resistências do circuito. Nota-se que, apesar do ganho diferencial em malha aberta $\left(A_{v}\right)$ do amp-op ideal ser infinito, o ganho da configuração inversora é dado pelos valores dos elementos externos, assim como a impedância de entrada, dada por R1. 


\subsubsection{3 - amplificador não-inversor}

A configuração não-inversora (Figura 2.13) não tem o terra virtual. Seu ganho de tensão é de $1+\mathrm{R} 1 / \mathrm{R} 2$. Neste caso, a impedância de entrada é de fato amplificada pelo ganho do amp-op, e é muito alta (idealmente infinita).

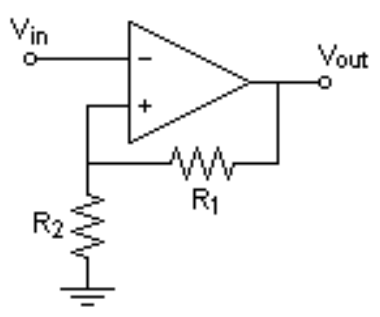

Figura 2.13 - amplificador não-inversor

Esta configuração pode ser aplicada para sensores que tenham uma alta impedância de saída e seriam afetados pela drenagem de corrente de um sistema de aquisição de dados com baixa impedância de entrada.

É possível também realizar configurações que combinem mais de uma entrada, como mostrado nas figuras 2.14 e 2.15 .

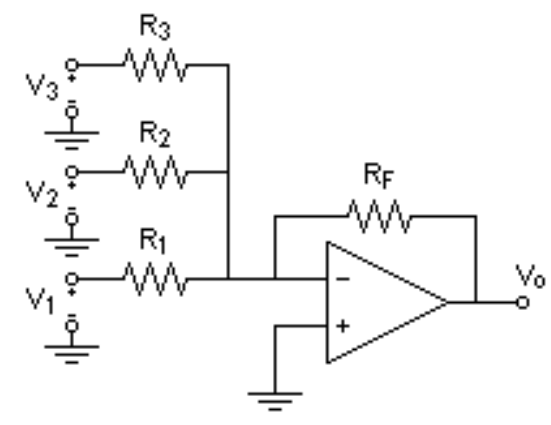

Figura 2.14 - amplificador somador inversor

O circuito da Figura 2.14 é muito similar ao amplificador inversor, mas envolve diferentes entradas de tensão. Sua tensão de saída depende da soma das entradas e é dada pela expressão 


$$
V_{o}=-\left(V_{1} \frac{R_{F}}{R_{1}}+V_{2} \frac{R_{F}}{R_{2}}+V_{3} \frac{R_{F}}{R_{3}}\right)
$$

Daí se chamar esta configuração de amplificador somador. Uma configuração que realiza a subtração de dois sinais de entrada é mostrada na Figura 2.15.

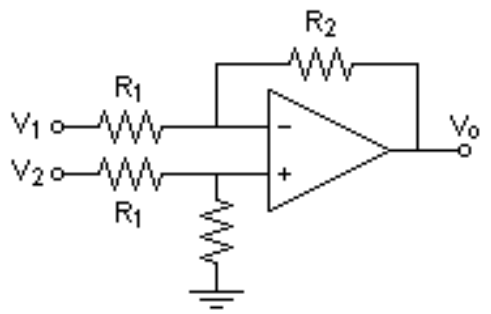

Figura 2.15 - amplificador de diferenças

Esta configuração é chamada de amplificador de diferenças e sua saída é dada por

$$
V_{o}=\left(V_{2}-V_{1}\right) \frac{R_{2}}{R_{1}}
$$

É útil, por exemplo, para remover tensão de offset de sinais, ou para eliminar a diferença entre terras de dois subcircuitos.

\subsubsection{4 - seguidor de tensão (buffer)}

Uma variação da configuração não-inversora é o seguidor de tensão (buffer, Figura 2.16), utilizado para isolação em acoplamentos deste tipo. Se fizermos $R_{l}=0 \mathrm{e}$ $R_{2}=\infty$ na configuração não-inversora da Figura 2.13, o amplificador passa a ter ganho unitário. A tensão na saída portanto segue a tensão da entrada (daí o nome), mas não há corrente realmente fluindo da entrada para a saída. Este circuito tem, no caso ideal, impedância de entrada infinita e impedância de saída nula, $R_{\text {in }}=\infty$ e $R_{\text {out }}=0$. 


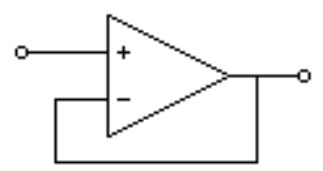

Figura 2.16 - seguidor de tensão (buffer)

\subsubsection{5 - amplificador de instrumentação}

As configurações simples apresentadas acima são frequentemente combinadas e alteradas com o fim de se obter aplicações mais específicas e complexas. Um circuito popular para amplificação em circuitos de condicionamento de sinais, especialmente para sensores, é o amplificador de instrumentação (IA, do inglês instrumentation amplifier), mostrado abaixo (Figura 2.17).

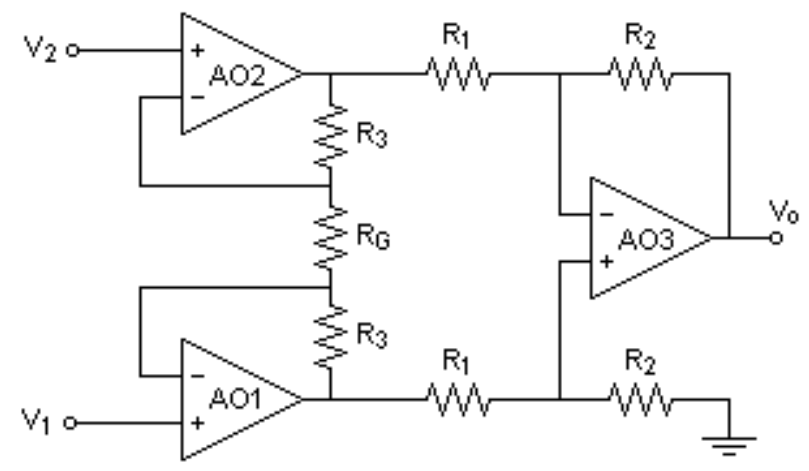

Figura 2.17 - amplificador de instrumentação (IA)

O IA tem ganho finito e preciso, tipicamente entre 1 e 1000, dado pela expressão

$$
A_{v}=\left(1+2 \frac{R_{3}}{R_{G}}\right)\left(\frac{R_{2}}{R_{1}}\right)
$$

de onde se obtém

$$
V_{o}=A_{v}\left(V_{2}-V_{1}\right)
$$


Tem impedância de entrada muito alta e impedância de saída muito baixa. Além disso, apresenta alta razão de rejeição de modo comum (CMRR, de common mode rejection ratio). A CMRR é uma razão entre o ganho do amplificador quando aplicados sinais diferentes entre as duas entradas (modo diferencial) e o ganho quando aplicado o mesmo sinal às duas entradas (modo comum).

\subsection{2 - filtros}

Os circuitos destinados à obtenção da resposta em freqüência desejada em certo sistema são os filtros. Há vários métodos ou tecnologias que podem ser aplicados no projeto de filtros (aqui, serão considerados os filtros analógicos). Dependendo do objetivo, alteram-se os dispositivos utilizados, sua disposição ou dimensionamento.

$\mathrm{Na}$ prática, as freqüências fora da faixa de passagem de um filtro nunca são totalmente eliminadas. Além disto, a queda da amplitude após a freqüência de corte nunca é absolutamente brusca, como na Figura 2.6, mas sofre uma queda que, dependendo da função de transferência do filtro, pode ser menos ou mais suave (daí a freqüência de corte ser definida geralmente como a freqüência para a qual a amplitude cai $3 \mathrm{~dB}$ ). Estas duas questões são fundamentais no projeto de filtros.

\subsubsection{1 - função de transferência}

A função de transferência $T(s)$ de um filtro pode ser dada pela equação

$$
T(s)=\frac{a_{M} s^{M}+a_{M-1} s^{M-1}+\cdots+a_{0}}{s^{N}+b_{N-1} s^{N-1}+\cdots+b_{0}}
$$

que pode ser reescrita como

$$
T(s)=\frac{a_{M}\left(s-z_{1}\right)\left(s-z_{2}\right) \cdots\left(s-z_{M}\right)}{\left(s-p_{1}\right)\left(s-p_{2}\right) \cdots\left(s-p_{N}\right)}
$$

As raízes do denominador são chamadas de pólos, e as raízes do numerador, de zeros. A influência de um pólo é uma queda de $20 \mathrm{~dB}$ por década, a partir da freqüência do pólo (Figura 2.18(a)). Analogamente, para um zero há um crescimento de $20 \mathrm{~dB}$ por 
década (Figura2.18(b)). A combinação dos coeficientes $a$ e $b$, portanto, definem a função que o filtro irá realizar, ou seja, sua resposta em freqüência.

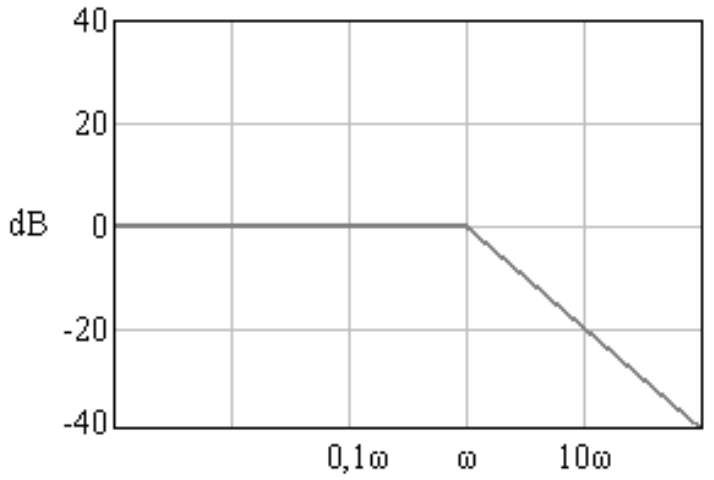

(a)

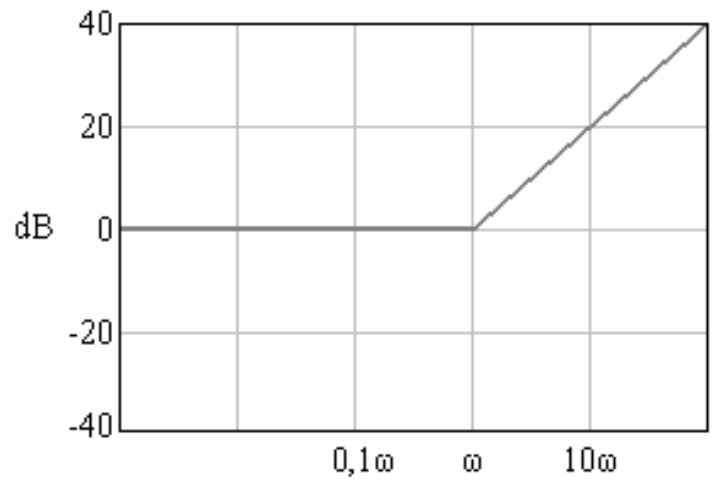

(b)

Figura 2.18 - diagramas de Bode de (a) um pólo; e (b) um zero

Vê-se, portanto, a dificuldade em se obter uma resposta em freqüência próxima das ideais, mostradas na Figura 2.6. Para que a resposta seja estável, é preciso que $M \leq N$. O grau $N$ do denominador define a ordem do filtro. Em geral, quanto maior a ordem $N$, maior a complexidade do circuito que realiza o filtro, e mais próxima da ideal é sua resposta. Como o corte não ocorre bruscamente, há a introdução de um novo conceito, de faixa de transição, faixa de freqüências na qual o ganho do filtro está entre o ganho determinado para a faixa de passagem e o ganho determinado para a faixa de bloqueio. A Figura 2.19 ilustra a faixa de passagem e outros conceitos necessários, já apresentados ou que serão mostrados em seguida. 


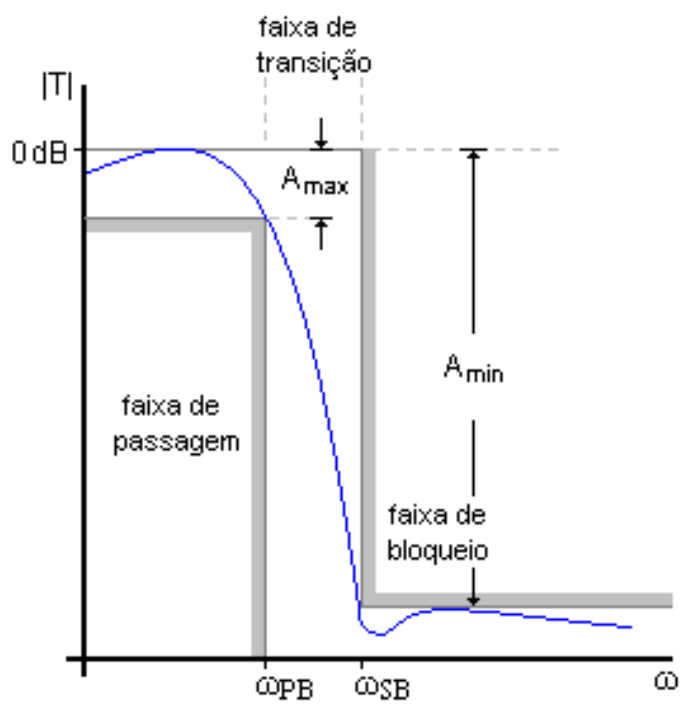

Figura 2.19 - especificações de transmissão de um filtro passa-baixas

\subsubsection{2 - implementações}

Há diversas possíveis construções de circuitos eletrônicos que apresentem determinada resposta em freqüência. Cada tipo de implementação tem vantagens e desvantagens, sendo usadas diferentes implementações para diferentes aplicações.

\subsubsection{1 - filtros passivos}

Pode ser extremamente simples implementar filtros em um circuito, dependendo de sua ordem e complexidade. A tecnologia mais primitiva nesse aspecto consiste basicamente em circuitos que usam indutores e capacitores para obter uma determinada função de transferência. Filtros implementados desta maneira são os chamados filtros passivos, por não incluirem amplificadores ou outros elementos ativos, e portanto não necessitarem de alimentação. Outra vantagem dos filtros passivos é que o ruído gerado é basicamente o ruído térmico das resistências envolvidas, que é pode ser menor do que o ruído de elementos de ganho ativo. Mas isto ocorre justamente porque filtros passivos não podem adicionar ganho ao sinal, então muitas vezes alguma outra forma de amplificação é necessária.

Outro problema é que a impedância de entrada dos filtros passivos geralmente não é tão alta, nem a impedância de saída tão baixa, quanto desejável. Por fim, filtros passivos geralmente incluem indutores, para limitar baixas freqüências, o que já 
praticamente os elimina de aplicações que exijam precisão ou miniaturização devido ao tamanho de tais elementos.

\subsubsection{2 - filtros ativos}

Os chamados filtros ativos surgiram justamente para simular indutâncias com elementos ativos - amplificadores conectados a elementos resistivos e capacitivos, sendo por isso esta composição chamada às vezes de filtros ativos-RC. Solucionam os problemas de impedância, e podem ter praticamente qualquer ganho que se queira, além de serem em geral simples de serem projetados. A ausência de indutores nos filtros ativos reduz bastante os problemas relacionados a miniaturização e falta de acurácia, e a precisão do filtro depende muito da tolerância dos resistores e capacitores. A figura abaixo (Figura 2.20) mostra exemplos de filtros ativos.

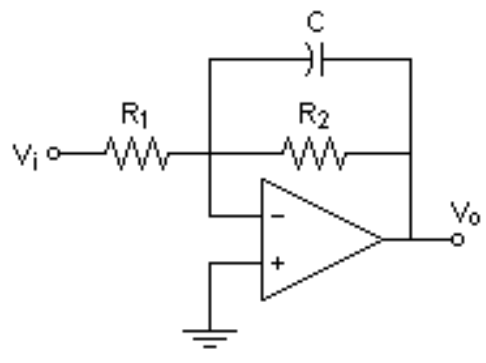

(a)

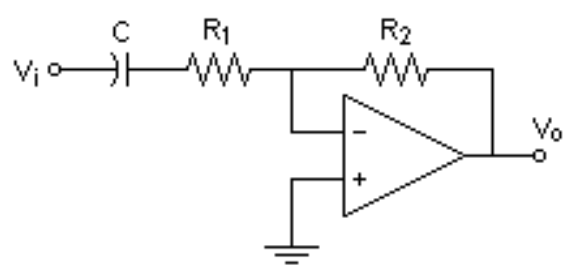

(b)

Figura 2.20 - circuitos de primeira ordem de (a) filtro ativo passa-baixas; e (b) filtro ativo passa-altas

Apesar do avanço em relação aos filtros passivos no que concerne a redução das dimensões dos dispositivos, os filtros ativos RC ainda são empecilhos na fabricação em uma placa de circuito integrado com sensores, por exemplo, devido principalmente a dois aspectos: a precisão das constantes de tempo RC é limitada (por variações de temperatura, dificuldade de fabricação etc.) e há a necessidade de elementos externos para compensar estes aspectos, e os capacitores de grandes valores necessários podem ser grandes demais. Soluções propostas nestes sentidos serão apresentadas mais adiante. São na realidade propostas de circuitos que têm o funcionamento análogo aos filtros $\mathrm{RC}$, considerados assim os blocos fundamentais em projeto de filtros. 


\subsubsection{3 - modelos}

Existem alguns modelos de filtros que podem ser escolhidos de acordo com a aplicação a ser projetada. Cada modelo é representado por uma função de transferência geral e tem características distintas de resposta em freqüência.

\subsubsection{1 - filtros Butterworth}

O modelo Butterworth apresenta decaimento suave na faixa de transição e resposta idealmente plana na faixa de passagem. Seus pólos estão distribuídos no plano $s$ ao longo de um círculo de raio unitário. Sua resposta $T(j \omega)$ é dada por

$$
T(j \omega)=\frac{1}{\sqrt{1+\varepsilon^{2} \omega_{n}^{2 N}}}
$$

Onde $\omega_{\mathrm{n}}$ é a freqüência normalizada $\omega / \omega_{\mathrm{p}}$. Para um passa-baixas, $T(s)$ fica:

$$
T(s)=\frac{K \omega_{0}^{N}}{\left(s-p_{1}\right)\left(s-p_{2}\right) \cdots\left(s-p_{N}\right)}
$$

A atenuação máxima na faixa de passagem, $A_{\max }$, de um filtro Butterworth é dada por

$$
A_{\max }=20 \log \sqrt{1+\varepsilon^{2}}
$$

onde $\varepsilon$ é dado por

$$
\varepsilon=\sqrt{10^{A_{\max } / 10}-1}
$$

Para se encontrar a ordem do filtro que dá a resposta de acordo com as especificações acima e de freqüência de passagem $\left(\omega_{P B}\right)$, bloqueio $\left(\omega_{P B}\right)$ e transição, testa-se para diferentes valores de $N$ a equação abaixo, onde $\Omega_{n}=\omega_{S B} / \omega_{P B}$.

$$
T\left(\omega_{S B}\right)=-10 \log \left(1+\varepsilon^{2} \Omega_{n}^{2 N}\right)
$$


Uma vez conhecida a ordem $N$, o próximo passo é obter a função de transferência, que pode ser separada em estágios de segunda ordem (incluindo um estágio de primeira ordem se $N$ for ímpar). O resultado pode ser comparado, para cada estágio, com a equação geral para um estágio de segunda ordem (filtro biquadrático, ou biquad):

$$
T\left(s_{n}\right)=\frac{a_{2} s^{2}+a_{1} s+a_{0}}{s_{n}^{2}+\frac{\omega_{n}}{Q} s_{n}+\omega_{n}^{2}}
$$

Assim, acha-se o fator de qualidade $Q$ de cada pólo. Cada estágio é classificado então de acordo com o fator Q ( basicamente, $Q<5 \rightarrow Q$ baixo; $Q>5 \rightarrow Q$ alto). Com esta classificação, é possível utilizar modelos existentes para o projeto de estágios que correspondam à função de transferência desejada.

\subsubsection{2 - filtros Chebyshev}

Outro modelo comum é o modelo Chebyshev. Filtros Chebyshev apresentam decaimento mais acentuado do que filtros Butterworth na faixa de transição, mas o módulo da resposta na faixa de passagem apresenta ondulação (ver figuras 2.21 e 2.22 , abaixo). Sua resposta $T(j \omega)$ é dada por:

$$
T(j \omega)=\frac{1}{\sqrt{1+\varepsilon^{2} \cos ^{2}\left[N \cos ^{-1}\left(\omega / \omega_{P B}\right)\right]}}
$$

para a faixa de passagem, e

$$
T(j \omega)=\frac{1}{\sqrt{1+\varepsilon^{2} \cosh ^{2}\left[N \cosh ^{-1}\left(\omega / \omega_{P B}\right)\right]}}
$$

para a faixa de bloqueio. Com estas equações - especialmente (2.4-14) calcula-se a ordem $N$ necessária para o filtro. Reescrevendo, a resposta na faixa de bloqueio fica: 
$T\left(\omega_{S B}\right)=-10 \log \left\{1+\varepsilon^{2} \cosh ^{2}\left[N \cosh ^{-1}\left(\Omega_{n}\right)\right]\right\}$

Os pólos do filtro Chebyshev são calculados pela equação (2.4-16) abaixo:

$p_{k}=-\omega_{P B} \sin \left(\frac{2 k-1}{N} \frac{\pi}{2}\right) \sinh \left(\frac{1}{N} \sinh ^{-1} \frac{1}{\varepsilon}\right)+j \omega_{P B} \cos \left(\frac{2 k-1}{N} \frac{\pi}{2}\right) \cosh \left(\frac{1}{N} \sinh ^{-1} \frac{1}{\varepsilon}\right)$

Para um passa-baixas, $T(s)$ fica:

$$
T(s)=\frac{K \omega_{0}^{N}}{\varepsilon 2^{N-1}\left(s-p_{1}\right)\left(s-p_{2}\right) \cdots\left(s-p_{N}\right)}
$$

As respostas de filtros passa-baixas Butterworth e Chebyshev estão ilustradas a seguir (figuras 2.21 e 2.22) [43].

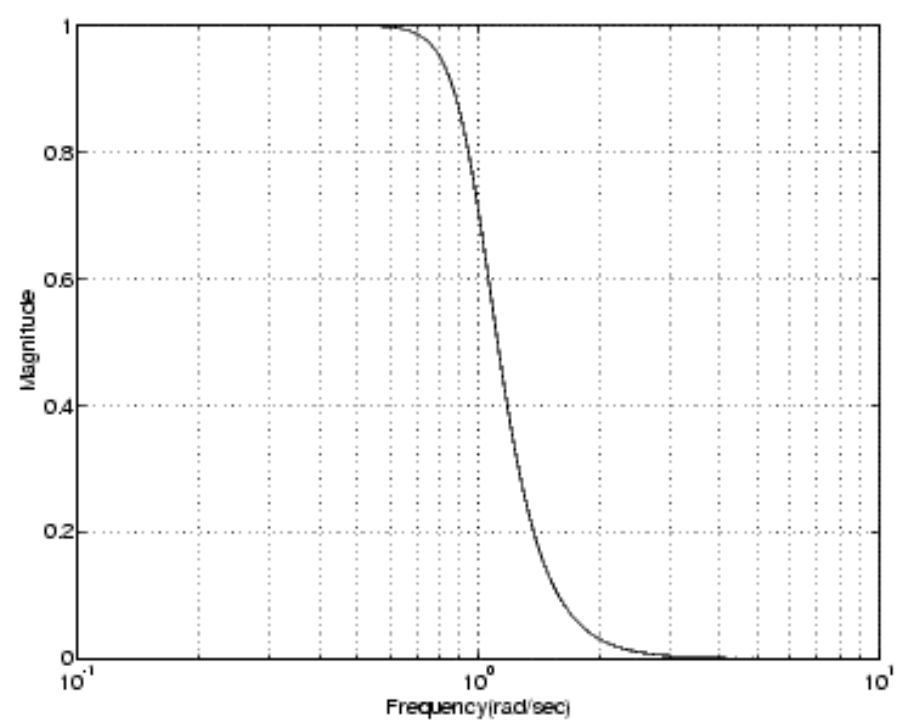

Figura 2.21 - resposta de um filtro passa-baixas Butterworth 


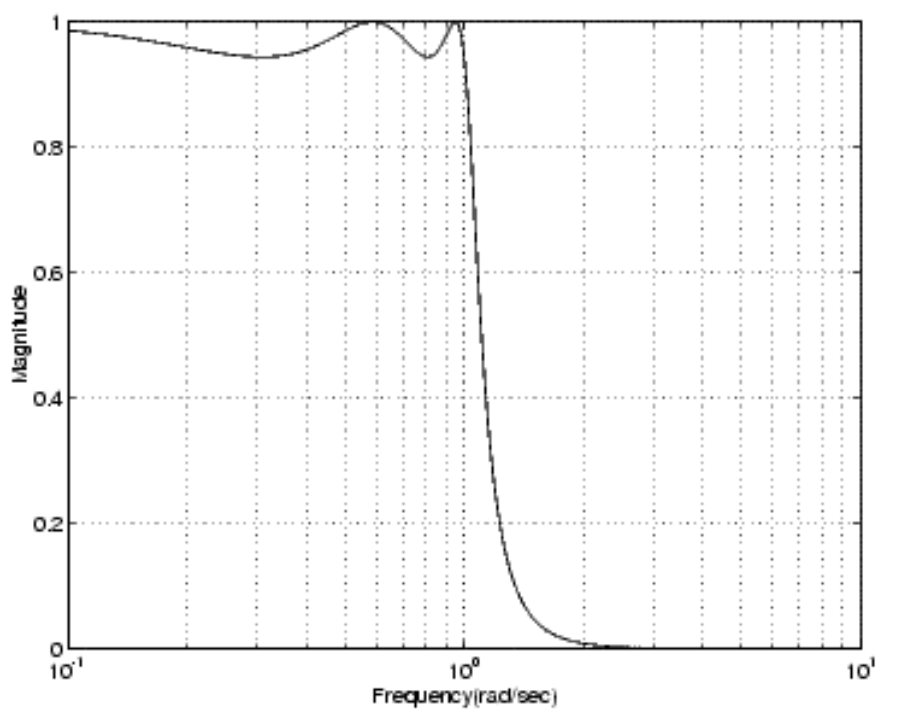

Figura 2.22 - resposta de um filtro passa-baixas Chebyshev

\subsubsection{3 - outros modelos}

Há outros tipos de filtros, com comportamentos em freqüência diferentes. Os filtros Bessel, por exemplo, têm resposta em amplitude pior do que as de filtros Butterworth ou Chebyshev, mas resposta de fase mais plana que os outros modelos, e sem ultrapassagem (overshoot) na resposta a uma entrada degrau.

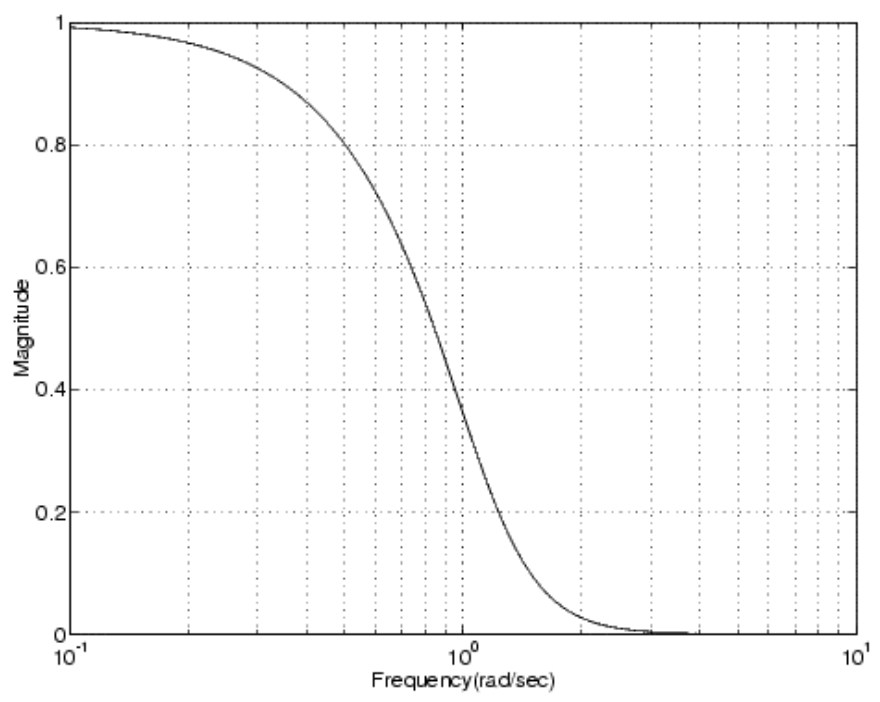

Figura 2.23 - resposta de um filtro passa-baixas Bessel [43] 
Por isso, filtros Bessel são usados em sistemas onde se tenha essa preocupação, como sistemas pulsados onde a distância entre os pulsos é de maior importância que sua atenuação [8], ou onde se queria manter o atraso de grupo constante.

Outra família de filtros são os filtros elípticos. O nome vem do fato de seus pólos estarem distribuídos no plano $s$ ao longo de uma elipse, assim como acontece com os filtros Chebyshev. Ao contrário dos filtros Chebyshev e Butterworth, entretanto, os filtros elípticos não têm somente pólos, mas também têm zeros na sua função de transferência. Por isso, ao contrário dos filtros só de pólos, que só têm atenuação infinita em freqüência infinita ou nula, os filtros elípticos podem rejeitar mais eficientemente freqüências específicas, e ter uma queda mais acentuada. Esses filtros têm ondulações na resposta em freqüência tanto na faixa de passagem quanto na faixa de bloqueio, e um decaimento acentuado no corte. Sua implementação também exige circuitos mais complexos.

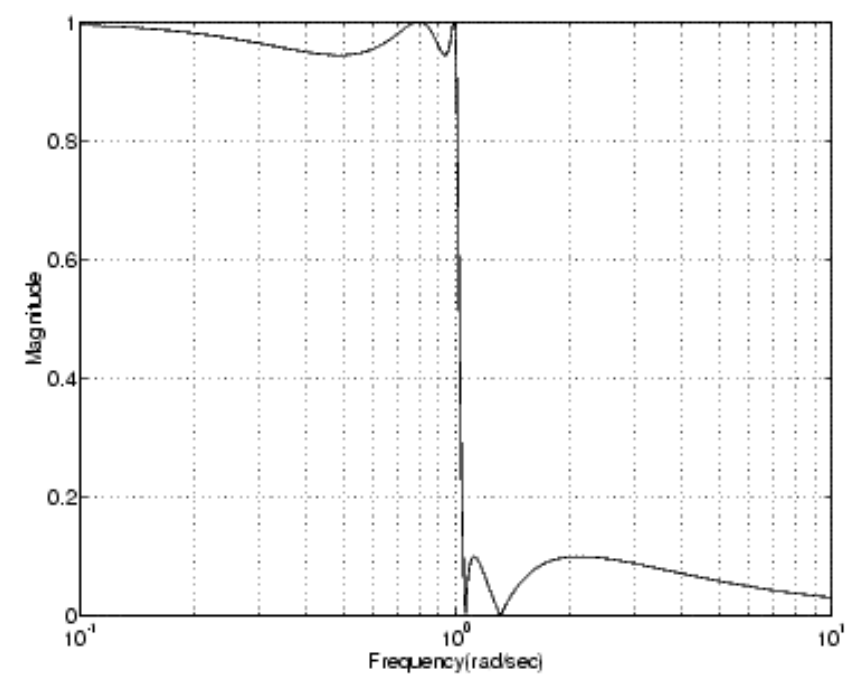

Figura 2.24 - resposta de um filtro passa-baixas elíptico [43]

\subsection{3 - circuitos chaveados}

Uma outra família de filtros, diferente dos filtros passivos e dos filtros RC, é a dos filtros implementados com circuitos chaveados. Nestes circuitos, o sinal é propagado de acordo com um chaveamento, associado à freqüência de um relógio que se supõe disponível, e diversos processamentos se tornam possíveis. 


\subsubsection{1 - capacitores chaveados}

Assim como os filtros ativos vieram substituir os filtros RLC, os filtros com capacitores chaveados (chamados também de filtros SC, do inglês switched-capacitor, por simplificação) surgiram a partir de um princípio muito simples apresentado por Fried que simula uma resistência a partir de um capacitor e chaves, ilustrado abaixo (Figura 2.25(a)).

O método de capacitores chaveados estabelece como condições: a) uma freqüência de chaveamento suficientemente alta, e b) um relógio que forneça duas fases não-superpostas (Figura 2.25(b)).

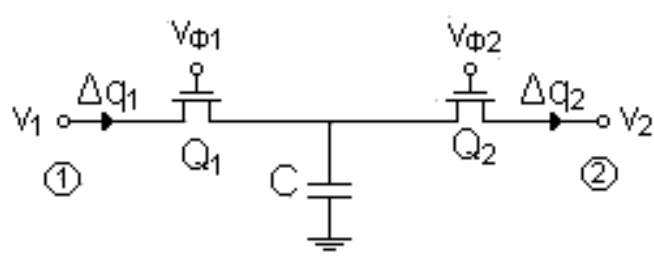

(a)

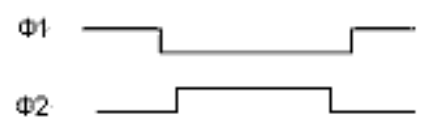

(b)

Figura 2.25 - (a) capacitor chaveado; (b) fases não-superpostas

Durante a fase $\Phi 1$ o transistor $\mathrm{Q}_{1}$ conduz e o transistor $\mathrm{Q}_{2}$ não. Na fase $\Phi 2$, acontece o oposto. Logo, o capacitor é carregado pela tensão $v_{l}$ com uma carga que, na fase seguinte, é descarregada para o nó 2 . Assim, a corrente média $i$ que flui entre os nós é $C / T\left(v_{1}-v_{2}\right)$, onde $T$ é o período do relógio, que compreende as fases $\Phi 1$ e $\Phi 2$. Este comportamento é equivalente o de uma resistência $R=T / C$.

O método minimiza problemas relacionados ao comportamento de resistores com a temperatura, faz a constante $\mathrm{RC}$ ser dependente do relógio, supostamente bem preciso, e, para a implementação de filtros ativos SC, os parâmetros do circuito não dependem dos módulos das capacitâncias, só da razão entre elas, aspecto bem preciso da tecnologia CMOS. Por estes motivos, o método de capacitores chaveados é muito recomendado em lugar de filtros ativos RC em sistemas VLSI (Very Large Scale Integration). As suas principais desvantagens são o ruído de clock feedthrough, devido a cargas injetadas pelo chaveamento, a exigência de relógio com fases não superpostas e de freqüência maior do que a banda do sinal. Quão maior esta freqüência deve ser é uma 
questão de compromisso entre a acurácia da amostragem e o consumo (além do ruído já citado), que crescem com a velocidade de chaveamento. Costuma-se usar freqüências de chaveamento de entre 20 e 100 vezes a freqüência do sinal, ou limites ainda mais amplos dependendo das necessidades do sistema.

Um bloco funcional SC amplamente usado em circuitos de amplificação e filtragem é o integrador (Figura 2.26)

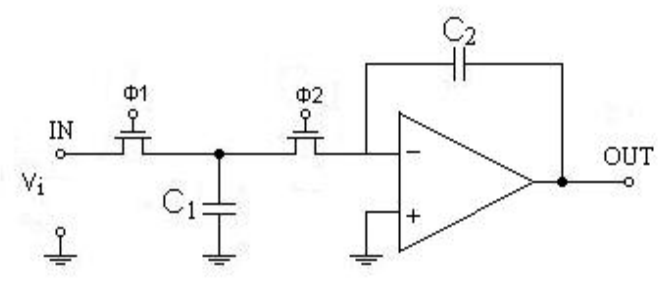

Figura 2.26 - amplificador integrador SC

\subsubsection{2 - corrente chaveada}

A técnica de correntes chaveadas (switched-current, indicada por SI) é relativamente nova - proposta em sua forma inicial em 1989 por J.B. Hughes - e veio concorrer com o método SC para a integração de circuitos integrados CMOS em processos VLSI. Seu funcionamento tem como elemento básico a célula de memória ilustrada abaixo (Figura 2.27) e explora a capacidade do transistor MOS de "armazenar" sua corrente de dreno na capacitância parasitária porta-fonte $C_{g s}$.

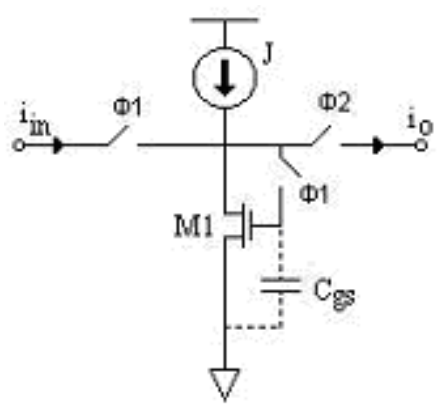

Figura 2.27 - célula de memória de corrente chaveada 
Durante a fase $\Phi 1$ uma corrente $J+i_{\text {in }}$ é carregada em $C_{g s}$, e à medida que isso ocorre a tensão porta-fonte sobre; quando a tensão excede a tensão de limiar M1 passa a conduzir, e a corrente $J+i_{\text {in }}$ flui pelo dreno de M1;

Durante a fase $\Phi 2$ a porta é desconectada do dreno e assim a tensão de porta é armazenada em $C_{g s}$. Com a chave da entrada aberta e da saída agora fechada, se força na saída $i_{o}=-i_{i n}$.

Este princípio permite uma vasta gama de aplicações, incluindo possivelmente as aplicações onde seria utilizado o método SC. No entanto, este método não substituiu os circuitos $\mathrm{SC}$, pelo menos por enquanto, até porque compartilha de alguns de seus defeitos, embora supere o método SC no quesito de consumo de potência e de tensão de operação baixa, dispensando o uso de amplificadores de alta performance. Ambos os métodos sofrem do problema de clock feedthrough, e a questão da compatibilidade de capacitores no SC se reflete aqui no casamento de transistores.

\section{5 - estrutura geral do sistema}

O esquema geral da interface entre sensores e conversor A/D é como ilustrado abaixo (Figura 2.28).

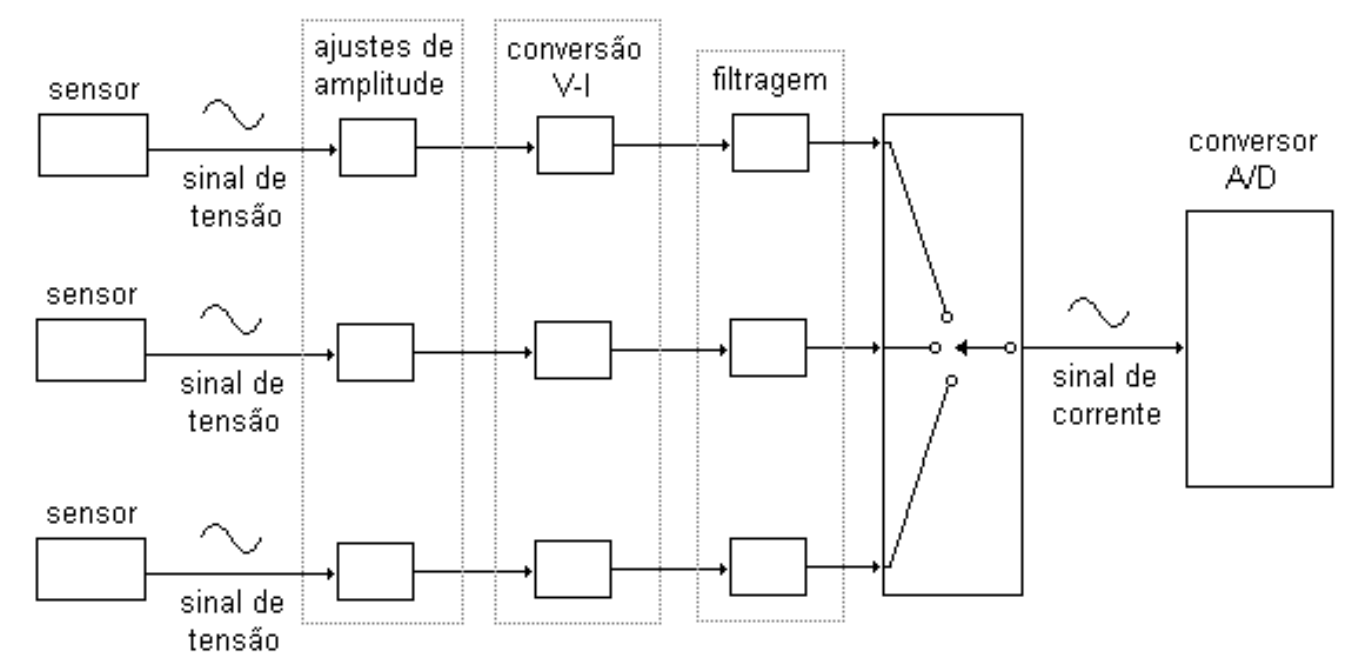

Figura 2.28 - interface analógica entre sensores e conversor A/D 
As especificações detalhadas serão dadas na seção 3.1, a seguir, com um resumo apresentado ao final, no item 3.1.6 - resumo das especificações. 


\section{3- METODOLOGIA}

O desenvolvimento do projeto dos circuitos de condicionamento de sinais é descrito a seguir.

\section{1 - Especificações}

A interface de condicionamento de sinais projetada visa funcionar com baixo consumo e pequena área ocupada no chip. Foi projetada com as especificações a seguir.

\subsection{1 - tecnologia}

A tecnologia usada no projeto do SoC é a tecnologia CMOS $C 35 B 4 C 3$, da Austria Microsystems.

\begin{tabular}{|l|l|l|l|c|}
\hline Parâmetro & \multicolumn{1}{|c|}{ representa } & \multicolumn{2}{|c|}{ Valores típicos } & \multirow{2}{*}{ Unidade } \\
\cline { 3 - 5 }$V_{T O}$ & $\begin{array}{l}\text { Nensão de limiar } \\
\text { (com VSB }=0)\end{array}$ & $0,50 \pm 0,10$ & $-0,65 \pm 0,10$ & $\mathrm{~V}$ \\
\hline$K^{\prime}$ & $\begin{array}{l}\text { Parâmetro de } \\
\text { transcondutância }\end{array}$ & $170 \pm 20$ & $58 \pm 10$ & $\mu \mathrm{A} / \mathrm{V}^{2}$ \\
\hline $\mathrm{Y}$ & $\begin{array}{l}\text { Parâmetro de efeito } \\
\text { de corpo }\end{array}$ & $0,58 \pm 0,10$ & $-0,40 \pm 0,08$ & $\mathrm{~V}^{1 / 2}$ \\
\hline$\lambda$ & $\begin{array}{l}\text { Modulação do } \\
\text { comprimento do } \\
\text { canal }\end{array}$ & $\begin{array}{l}0,01(\mathrm{~L}=0,35 \mu \mathrm{m}) \\
0,007(\mathrm{~L}=10 \mu \mathrm{m})\end{array}$ & $\begin{array}{l}0,08(\mathrm{~L}=0,35 \mu \mathrm{m}) \\
0,006(\mathrm{~L}=10 \mu \mathrm{m})\end{array}$ & $\mathrm{V}^{-1}$ \\
\hline $2\left|\Phi_{F}\right|$ & $\begin{array}{l}\text { Potencial de } \\
\text { superfície em } \\
\text { inversão forte }\end{array}$ & 0,43 & 0,41 & $\mathrm{~V}$ \\
\hline
\end{tabular}

Tabela 3.1 - parâmetros do processo de fabricação 
Este processo de fabricação utiliza poços $n$ em substratos $p$, com quatro camadas de metal disponíveis [2]. Permite alimentação de $5 \mathrm{~V}$ ou $3,3 \mathrm{~V}$, sendo a última a utilizada no SoC. O menor comprimento de canal realizável é de $0,35 \mu \mathrm{m}$ e a menor largura de $0,4 \mu \mathrm{m}$, com uma precisão máxima de $0,05 \mu \mathrm{m}$. A tabela 3.1 mostra parâmetros da tecnologia utilizados nos cálculos.

\subsection{2 - conversor $A / D$}

O conversor A/D projetado para o SoC faz uma conversão do sinal de entrada usando 8 bits, ou seja, o sinal será quantizado em 256 níveis. A entrada do conversor tem alta impedância e aceita sinais de corrente na faixa de $\pm 5 \mu \mathrm{A}$, e freqüências de até $50 \mathrm{kHz}$ - valor de projeto, mas previu-se a possibilidade de conversão de sinais de até $100 \mathrm{kHz}$, embora com desempenho reduzido [30]. Um de seus estágios iniciais é um estágio de amostragem e retenção (sample-and-hold, ou $S / H$ ).

O conversor é baseado no método de correntes chaveadas, usando uma freqüência de chaveamento de $250 \mathrm{kHz}$, submúltiplo da freqüência do relógio externo, de $16 \mathrm{MHz}$.

\subsection{3 - alimentação do SoC}

A alimentação do SoC é feita por 4 pilhas recarregáveis de niquel-cádmio de tensão nominal de $1,2 \mathrm{~V}$ (totalizando $4,8 \mathrm{~V}$ quando em série), recarregadas por células fotovoltaicas. A tensão das pilhas deve variar apenas quando estiverem mais próximas do fim do ciclo de carga-recarga, lentamente, e mesmo assim a variação não deve ser grande, nem há necessidade de grande precisão em sua medida [33, 34]. Por isso, sua conversão para digital não precisaria ser efetuada com 256 níveis.

Foi estabelecido então que 16 níveis ( 4 bits) bastariam para definir o sinal de tensão de uma pilha. A tensão na bateria varia até quatro vezes o valor individual de cada pilha, portanto foi determinado que a conversão do sinal da bateria pode ser feito com apenas 6 bits. (Na realidade, o conversor A/D o representará com 8 bits de qualquer forma, mas não há aqui necessidade de entregar-lhe o sinal com tanta precisão.)

Outra característica deste subcircuito é que a freqüência de interesse é baixíssima - quase nula - uma vez que a pilha fornece tensão constante. Foi definido como especificação que a interface deveria eliminar a freqüência de $60 \mathrm{~Hz}$, e que a faixa de $0-10 \mathrm{~Hz}$ é suficiente para o sinal de tensão da bateria. 


\subsection{4 - sensor de pressão}

O sensor de pressão utilizado no SCI funciona com uma membrana semicondutora, e fornece uma saída de tensão linearmente proporcional à pressão medida. O valor da pressão é multiplicado pela tensão DC de entrada do sensor, de 4,8V. A variação de tensão de saída é de 2,0mV/(V $\mathrm{V}_{\mathrm{DC}}$.PSI) (ou, equivalentemente, $290 \mu \mathrm{V} / \mathrm{V}_{\mathrm{DC}}$.cbar). O sensor só é capaz de medir adequadamente pressões até 11,6 PSI; a tensão de saída $\mathrm{V}_{\text {out }}$ tem assim seus valores mínimo e máximo respectivamente $0 \mathrm{~V}$ e $111,4 \mathrm{mV}$, totalizando uma faixa de $111,4 \mathrm{mV}$. Esta faixa de valores é que deverá ser fornecida ao conversor analógico/digital, sob a forma de um sinal de corrente. A impedância de saída do sensor de pressão foi especificada em $4,5 \mathrm{k} \Omega$.

Como o protótipo descrito no Livro Branco do SCI não especifica freqüências operacionais, foi considerada a resposta de um sensor comercial, de mesma aplicação e especificações semelhantes [13]. Este sensor tem uma velocidade de resposta de 1ms; portanto, foi considerada para o projeto a máxima freqüência do sensor de pressão como sendo $1 \mathrm{kHz}$, ou seja, a freqüência de passagem, na filtragem do sinal, será de $1 \mathrm{kHz}$. A freqüência de bloqueio foi escolhida como $2 \mathrm{kHz}$, principalmente para evitar distorções harmônicas.

\subsection{5 - sensor de temperatura}

O sensor de temperatura escolhido para o SCI é o sensor de precisão inteligente LM35, da National Semiconductor [12]. Este sensor fornece uma saída de tensão que varia linearmente com a temperatura, a uma taxa de $10,0 \mathrm{mV} /{ }^{\circ} \mathrm{C}$. O LM35 opera entre as temperaturas de $-55{ }^{\circ} \mathrm{C}$ a $+150{ }^{\circ} \mathrm{C}$; a faixa de valores de tensão de saída é, portanto, de $550 \mathrm{mV}$ a $1500 \mathrm{mV}$. Esta faixa dinâmica deve ser ajustada para se adequar à entrada do conversor $\mathrm{A} / \mathrm{D}$, e a qualquer processamento que seja feito entre o sensor e o conversor. A impedância de saída varia, mas sempre em valores muito baixos, de até $1 \Omega$.

A velocidade de resposta do sensor é relativamente lenta. Em espaço aberto, com ar parado, chega a $100 \%$ do valor final em aproximadamente 4 minutos. Com condições otimizadas, esta resposta é atingida em aproximadamente 4 segundos. Por ter uma freqüência de resposta tão baixa, foram escolhidos os seguintes valores de freqüência para a faixa de passagem e a faixa de bloqueio da filtragem do sinal:

$$
\omega_{P B}=10 \mathrm{~Hz}=20 . \pi \mathrm{rad} / \mathrm{s}
$$




$$
\omega_{S B}=60 \mathrm{~Hz}=120 . \pi \mathrm{rad} / \mathrm{s}
$$

A resposta do LM35 a um degrau na entrada (a start-up response) apresenta, durante aproximadamente $30 \mu$ s, uma pequena oscilação, dentro da faixa de saída, de freqüência não menor que $100 \mathrm{kHz}$. Esta oscilação é esperada no funcionamento do sensor, e não é considerada um erro de leitura. Além disso, por ser de freqüência tão distante da freqüência de interesse, sua filtragem já está prevista considerando as freqüências escolhidas acima.

\subsection{6 - resumo das especificações}

As tabelas a seguir (tabelas 3.2 a 3.5) resumem as especificações do sistema.

\section{Conversor A/D}

\begin{tabular}{|l|l|}
\hline Chaveamento & $250 \mathrm{kHz}$ \\
\hline Freqüência do sinal de entrada & Até $50 \mathrm{kHz}$ \\
\hline Sinal de entrada & Corrente \\
\hline Faixa de entrada & $\pm 5 \mu \mathrm{A}$ \\
\hline Resolução da conversão & 8 bits \\
\hline
\end{tabular}

Tabela 3.2 - principais especificações do conversor A/D

\section{Alimentação elétrica}

\begin{tabular}{|l|l|}
\hline Tensão da bateria (4 pilhas em série) & $4,8 \mathrm{~V}$ \\
\hline Tensão de pilha individual & $1,2 \mathrm{~V}$ \\
\hline Resolução desejada & $6 \mathrm{bits}$ \\
\hline Freqüência máxima & $10 \mathrm{~Hz}$ \\
\hline Faixa de transição & $10 \mathrm{~Hz}-60 \mathrm{~Hz}$ \\
\hline
\end{tabular}

Tabela 3.3 - principais especificações da alimentação elétrica do SoC 
Sensor de pressão

\begin{tabular}{|l|l|}
\hline Amplitude do sinal & Entre 0V e 111,4mV \\
\hline Resolução desejada & $8 \mathrm{bits}$ \\
\hline Freqüência máxima & $1 \mathrm{kHz}$ \\
\hline Faixa de transição & $1 \mathrm{kHz}-2 \mathrm{kHz}$ \\
\hline
\end{tabular}

Tabela 3.4 - principais especificações do sensor de pressão

\section{Sensor de temperatura}

\begin{tabular}{|l|l|}
\hline Amplitude do sinal & Entre $-0,55 \mathrm{~V}$ e $1,5 \mathrm{~V}$ \\
\hline Resolução desejada & $8 \mathrm{bits}$ \\
\hline Freqüência máxima & $10 \mathrm{~Hz}$ \\
\hline Faixa de transição & $10 \mathrm{~Hz}-60 \mathrm{~Hz}$ \\
\hline
\end{tabular}

Tabela 3.5 - principais especificações do sensor de temperatura

\section{2 - Procedimentos}

Cada bloco esquemático da Figura 2.28 foi projetado separadamente, seguindo uma metodologia de projeto bottom-up, uma vez que as especificações mais detalhadas são relativas à tecnologia usada, que define todo o projeto.

Das especificações, vê-se que os procedimentos necessários são os de eliminação de offset, amplificação (ambos mostrados como “ajustes de amplitude"), conversão tensão-corrente e filtragem. Internamente aos subcircuitos, se mostraram recomendáveis a isolação e procedimentos de redução de ruído.

As especificações dos sensores não detalham o comportamento em freqüência dos sinais. Caso seja obtido experimentalmente ou por outros meios um conhecimento desse comportamento, uma equalização, se necessária, pode ser feita computacionalmente, através de métodos de processamento digital de sinais [48].

\subsection{1 - ajustes de offset}

A minimização de offset será feita com amplificadores de instrumentação derivados do apresentado anteriormente. Nenhum dos sinais apresenta offset muito 
grande, portanto este será tratado simplesmente com amplificadores de entrada diferencial com CMRR alta. O IA também oferece outras vantagens que serão discutidas.

\subsection{2 - conversão tensão-corrente}

A conversão dos sinais de tensão para sinais de corrente será realizada com o uso de current conveyors (transportadores de corrente), conforme explicado adiante. Alternativamente, outra topologia de conversão será proposta e poderá ser usada caso se mostre vantajosa.

\subsection{3 - filtragem}

A filtragem é feita com circuitos que implementam os filtros explicados anteriormente.

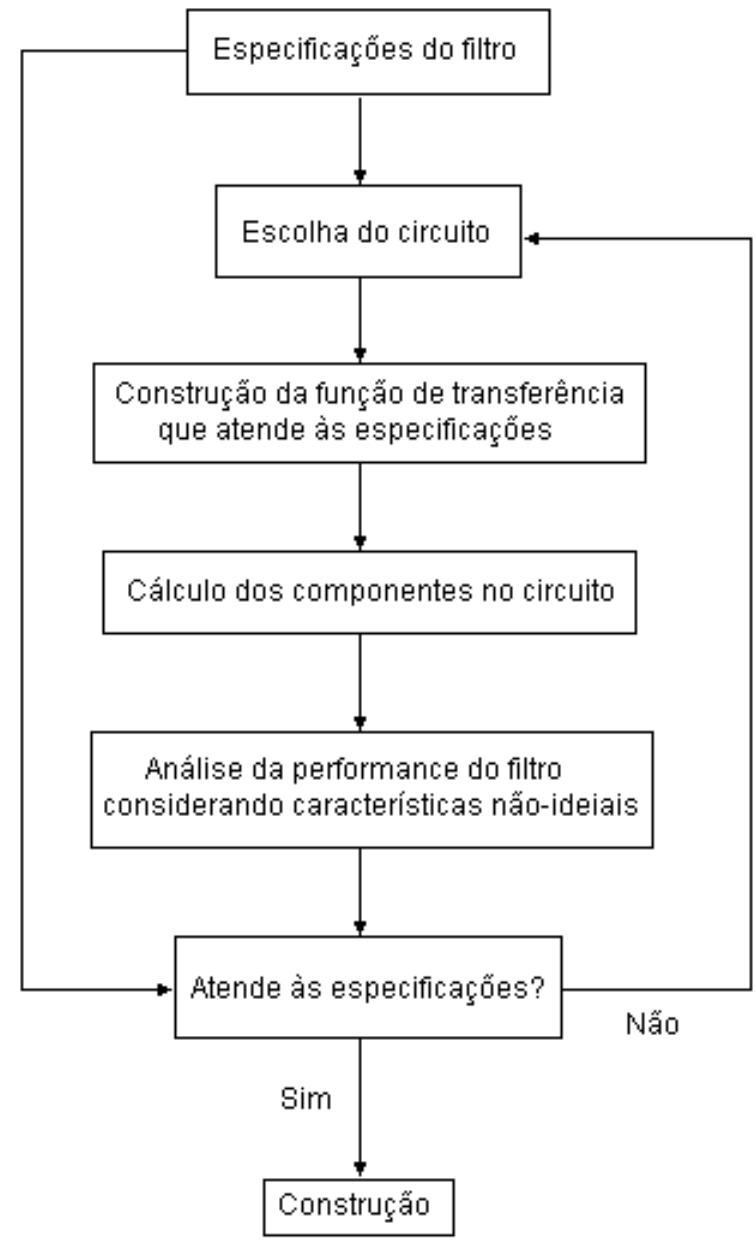

Figura 3.1 - esquema de projeto de filtros 
Para o projeto dos filtros, o esquema básico de projeto seguido foi o mostrado na Figura 3.1 acima. Os cálculos das especificações dos filtros e a escolha de seus modelos estão apresentados em seguida. Os circuitos de implementação e seu projeto será apresentado no capítulo 4 - Projeto elétrico.

\subsubsection{1 - monitoramento da bateria}

Com as especificações dadas e os procedimentos descritos, chegou-se, para este circuito, ao seguintes valores (relacionados à Figura 2.19):

$$
\begin{aligned}
& A_{\max }=0,068 \mathrm{~dB} ; \\
& A_{\text {min }}=42,14 \mathrm{~dB} ; \\
& \Omega_{n}=\omega_{S B} / \omega_{P B}=60 / 10=6 ; \\
& \varepsilon=0,126 ;
\end{aligned}
$$

Com um filtro Butterworth de ordem N:

$$
\begin{aligned}
& \mathrm{N}=3 \rightarrow \mathrm{A}=28,67 \mathrm{~dB} \\
& \mathrm{~N}=4 \rightarrow \mathrm{A}=44,23 \mathrm{~dB}
\end{aligned}
$$

Com um filtro Chebyshev de ordem N:

$$
\begin{aligned}
& \mathrm{N}=3 \rightarrow \mathrm{A}=40,53 \mathrm{~dB} \\
& \mathrm{~N}=4 \rightarrow \mathrm{A}=62,05 \mathrm{~dB}
\end{aligned}
$$

Para este circuito, portanto, é vantajoso usar um filtro Butterworth, por ser mais mais simples. Os pólos da função de transferência para o filtro do sinal de saída do leitor de bateria são:

$$
\begin{aligned}
& p_{1}, p_{4}=(-0,38268 \pm \mathrm{j} 0,92388) \\
& p_{2}, p_{3}=(-0,92388 \pm \mathrm{j} 0,38268)
\end{aligned}
$$

Nota-se a equivalência entre a parte real de um par e a parte imaginária do outro. Isso ocorre devido à distribuição dos pólos no plano-s, esboçada a seguir: 


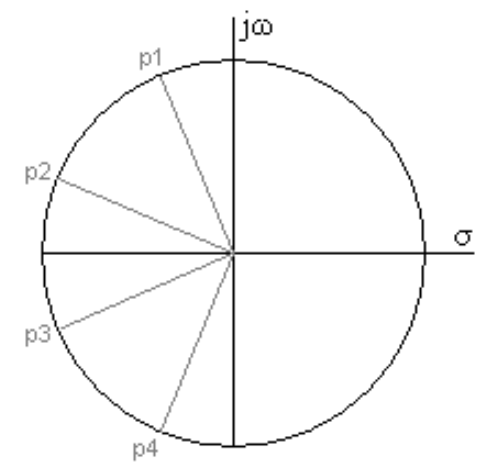

Figura 3.2 - distribuição dos pólos no plano-s

Para este filtro, a função de transferência normalizada é

$$
H(s)=\frac{1}{s^{2}+0,7654 s+1} \cdot \frac{1}{s^{2}+1,8478 s+1}
$$

ou

$$
H(s)=124,07 \cdot 10^{6} \cdot \frac{1}{s^{2}+80,776 s+11138,61} \cdot \frac{1}{s^{2}+195,012 s+11138,61}
$$

A resposta em freqüência desta função de transferência é representada a seguir (Figura 3.3). A figura foi obtida pela simulação da função de transferência do filtro no software matemático MatLab. 


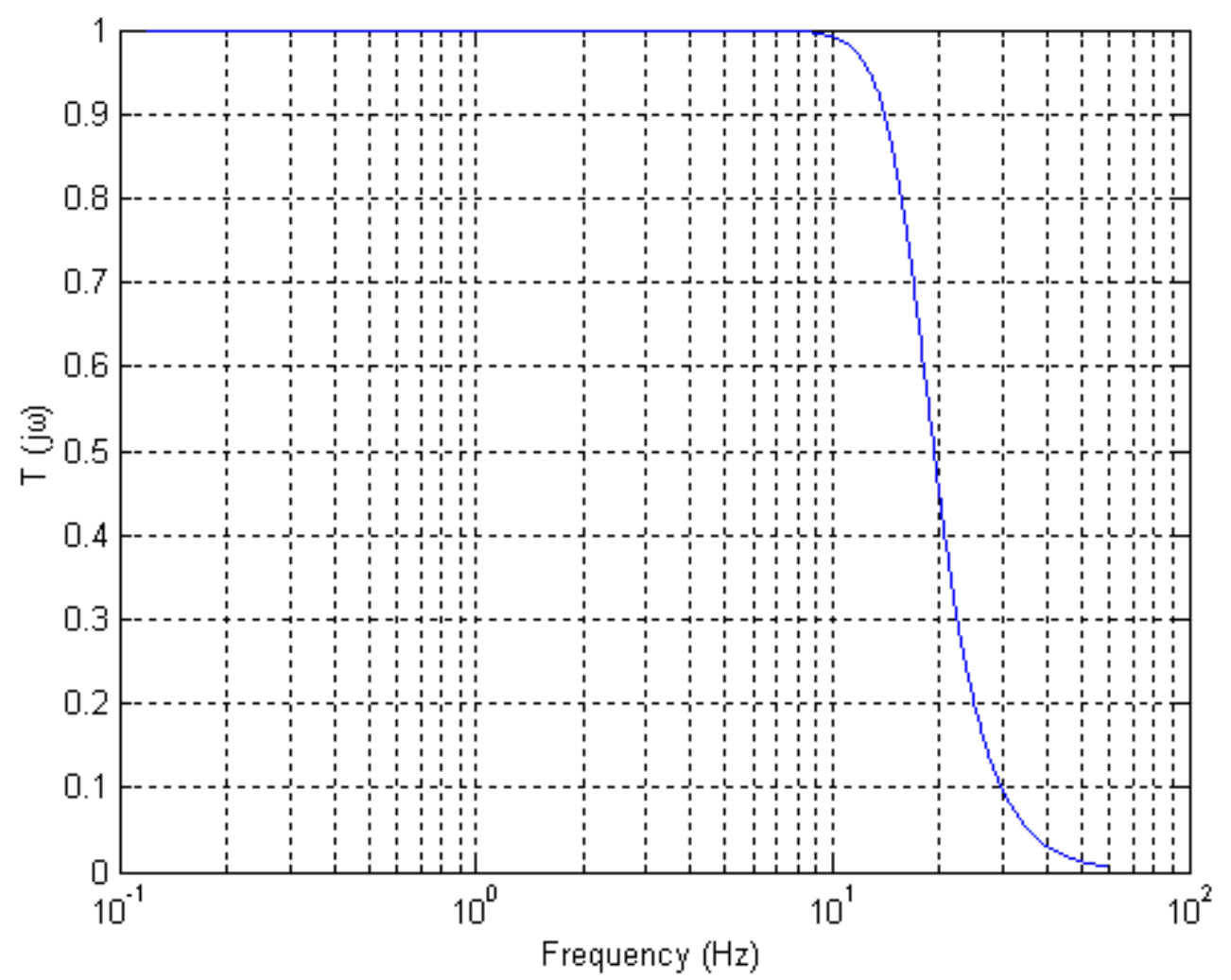

Figura 3.3 - resposta em freqüência do filtro do monitor da bateria

\subsubsection{2 - sensor de pressão}

A informação dos sinais de entrada será filtrada com um filtro passa-baixas, mantendo apenas as freqüências abaixo de $1 \mathrm{kHz}$ inalteradas e atenuando as freqüências da faixa de bloqueio, com limite inferior de $2 \mathrm{kHz}$. Na faixa de passagem, o filtro pode causar alguma distorção ao sinal, atenuando-o. Daí, conforme as especificações:

$$
\begin{aligned}
& A_{\text {max }}=\frac{1}{2} \cdot \frac{1}{256} \approx 0,01 \mathrm{~dB} \\
& \varepsilon=0,048 \\
& \Omega_{n}=2 \\
& A_{\text {min }}=54,19 \mathrm{~dB} .
\end{aligned}
$$

Para estes valores, um filtro Chebyshev de ordem $\mathrm{N}$ daria as seguintes atenuações $A$ na faixa de bloqueio: 


$$
\begin{aligned}
& \mathrm{N}=7 \rightarrow \mathrm{A}=47,68 \mathrm{~dB} \\
& \mathrm{~N}=8 \rightarrow \mathrm{A}=59,12 \mathrm{~dB}
\end{aligned}
$$

Logo, um filtro Chebyshev de oitava ordem é suficiente para realizar a filtragem do sinal. (Aqui, faz-se uma observação: um valor mais preciso de $A_{\max }$ é $0,01698 \mathrm{~dB}$; aproximá-lo para o valor mais próximo com um algarismo significativo significaria ter $A_{\max }=0,02 \mathrm{~dB}$. Apesar de ser na prática uma aproximação quase insignificante, a rigor causaria erro. Além disso, os cálculos com esta aproximação resultariam na necessidade de um filtro Chebyshev de ordem 8, por isso usou-se o valor de 0,01dB.)

Fazendo os cálculos para um filtro Butterworth:

$$
\begin{aligned}
& \mathrm{N}=8 \rightarrow \mathrm{A}=21,81 \mathrm{~dB} \\
& \mathrm{~N}=14 \rightarrow \mathrm{A}=57,91 \mathrm{~dB}
\end{aligned}
$$

jusitificando a escolha pelo modelo Chebyshev.

Um filtro do tipo escolhido pode ser construído associando-se quatro estágios de segunda ordem, que podem ser construídos com integradores (filtros biquadráticos), por exemplo.

As informações obtidas permitem calcular os pólos $p_{i}$ da função de transferência do filtro. Os pólos são pares conjugados, apresentados a seguir normalizados quanto à freqüência:

$$
\begin{aligned}
& p_{1}, p_{8}=(-0,09430 \pm \mathrm{j} 1,08935) \\
& p_{2}, p_{7}=(-0,26854 \pm \mathrm{j} 0,92351) \\
& p_{3}, p_{6}=(-0,40190 \pm \mathrm{j} 0,61707) \\
& p_{4}, p_{5}=(-0,47408 \pm \mathrm{j} 0,21669)
\end{aligned}
$$

O resultado é a função de transferência:

$$
H(s)=\frac{1,1956 \omega_{P B}^{2}}{s^{2}+0,18860 \omega_{P B} s+1,1956 \omega_{P B}^{2}} \cdot \frac{0,92498 \omega_{P B}^{2}}{s^{2}+0,53709 \omega_{P B} s+0,92498 \omega_{P B}^{2}} \cdot \frac{0,54230 \omega_{P B}^{2}}{s^{2}+0,80381 \omega_{P B} s+0,54230 \omega_{P B}^{2}} \cdot \frac{0,27170 \omega_{P B}^{2}}{s^{2}+0,94816 \omega_{P B} s+0,27170 \omega_{P B}^{2}}
$$

A resposta em freqüência desta função de transferência é apresentada na Figura 3.4, a seguir. 


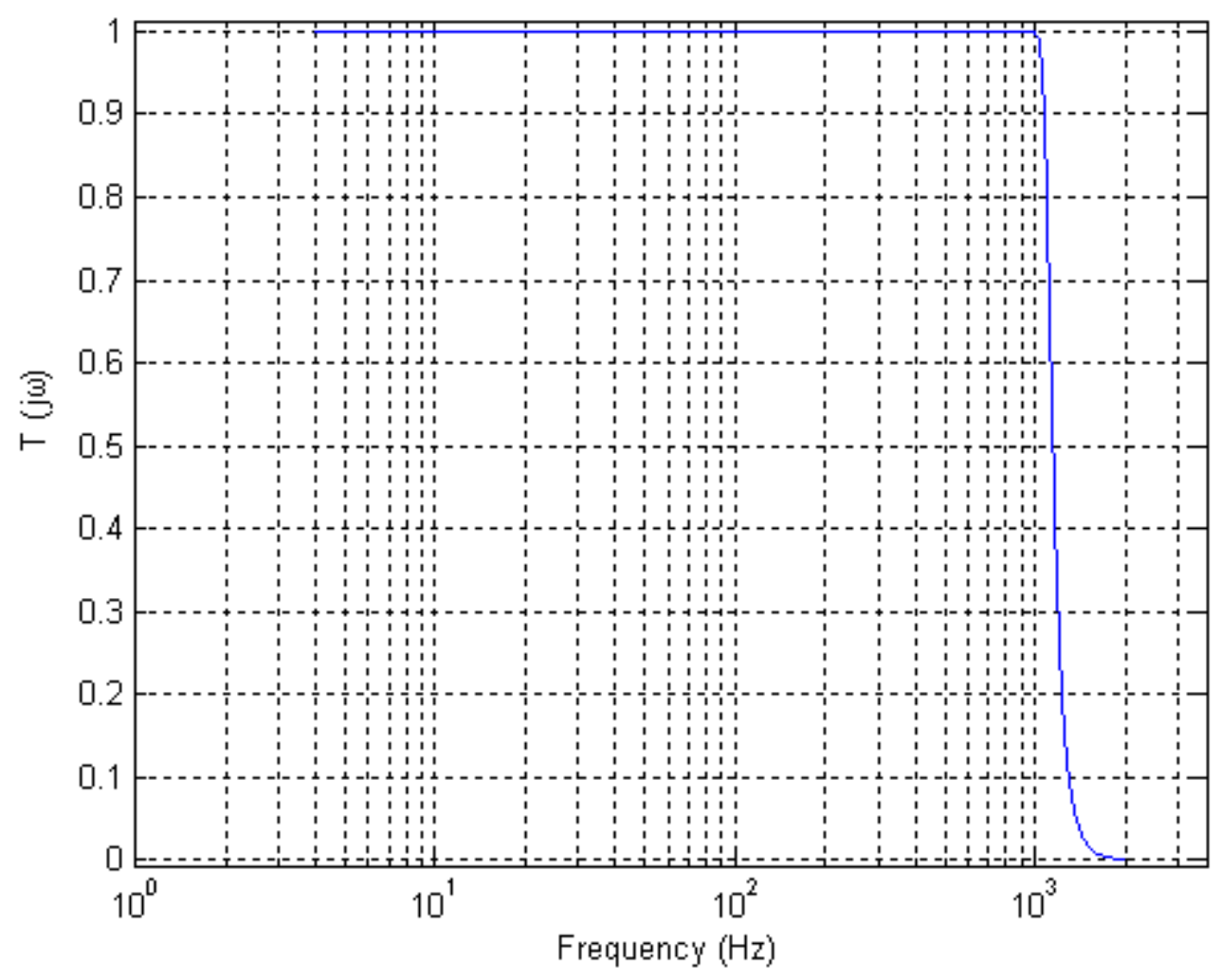

Figura 3.4 - resposta em freqüência da filtragem do sinal do sensor de pressão

Não é possível perceber a ondulação na faixa de passagem na figura devido à escala do gráfico, pois é extremamente pequena; uma ampliação dessa faixa está mostrada na Figura 3.5.

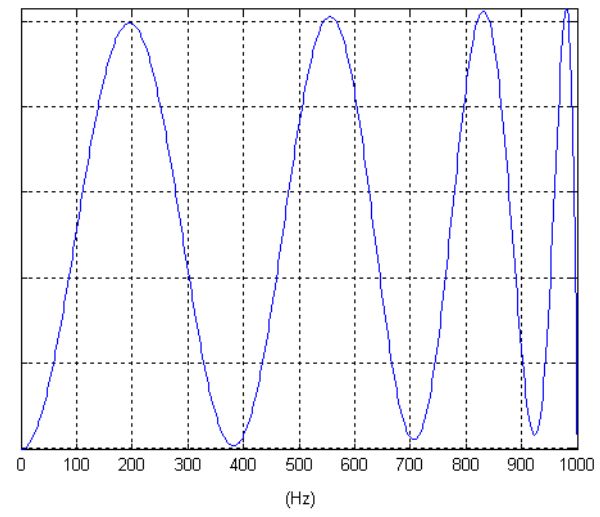

Figura 3.5 - resposta na faixa de passagem 


\subsubsection{3 - sensor de temperatura}

A informação da saída do LM35 será filtrada com um filtro passa-baixas, que pode causar alguma distorção indesejada na faixa de passagem, atenuando o sinal; essa atenuação, como para o sensor de pressão, não pode ser superior a meio LSB (least significant bit). Da mesma maneira, na faixa de bloqueio o filtro deve ter uma atenuação que elimine o sinal para o conversor A/D. Assim:

$$
\begin{aligned}
& A_{\max }=\frac{1}{2} \cdot \frac{1}{256} \approx 0,015 \mathrm{~dB} \\
& A_{\min }=54,19 \mathrm{~dB} . \\
& \varepsilon=\sqrt{10^{\frac{\mathrm{A}_{\max }}{10}}-1}
\end{aligned}
$$

Com os dados apresentados, $\Omega_{n}=6$ e $\varepsilon=0,0588$.

Para estes valores, um filtro Chebyshev de ordem $\mathrm{N}$ daria as seguintes atenuações A na faixa de bloqueio:

$$
\begin{aligned}
& \mathrm{N}=3 \rightarrow \mathrm{A}=33,94 \mathrm{~dB} \\
& \mathrm{~N}=4 \rightarrow \mathrm{A}=55,46 \mathrm{~dB}
\end{aligned}
$$

Logo, um filtro Chebyshev de quarta ordem é suficiente para filtrar a faixa de freqüências do sinal com a atenuação especificada. Pode-se notar que a aproximação de $A_{\max }$ feita no caso do sensor de pressão aqui faz diferença: para $A_{\max }=0,01 \mathrm{~dB}$, um filtro Chebyshev de ordem 4 daria uma atenuação na faixa de bloqueio de 53,69dB, ligeiramente abaixo das especificações.

Fazendo os cálculos para um filtro Butterworth, chega-se a:

$$
\begin{aligned}
& N=4 \rightarrow A=37,64 d B \\
& N=5 \rightarrow A=53,20 d B \\
& N=6 \rightarrow A=68,77 d B
\end{aligned}
$$


Por isso, foi escolhido para este caso também um modelo Chebyshev. Os pólos $p_{i}$ normalizados da função de transferência do filtro são os seguintes:

$$
\begin{aligned}
& p_{1}, p_{4}=(-0,38297 \pm \mathrm{j} 1,30706) \\
& p_{2}, p_{3}=(-0,92458 \pm \mathrm{j} 0,54140)
\end{aligned}
$$

O resultado é a função de transferência:

$$
H(s)=\frac{1,8551 \omega_{P B}^{2}}{s^{2}+0,76594 \omega_{P B} s+1,8551 \omega_{P B}^{2}} \cdot \frac{1,1479 \omega_{P B}^{2}}{s^{2}+1,8492 \omega_{P B} s+1,1479 \omega_{P B}^{2}}
$$

A resposta em freqüência desta função de transferência é apresentada abaixo (Figura 3.6).

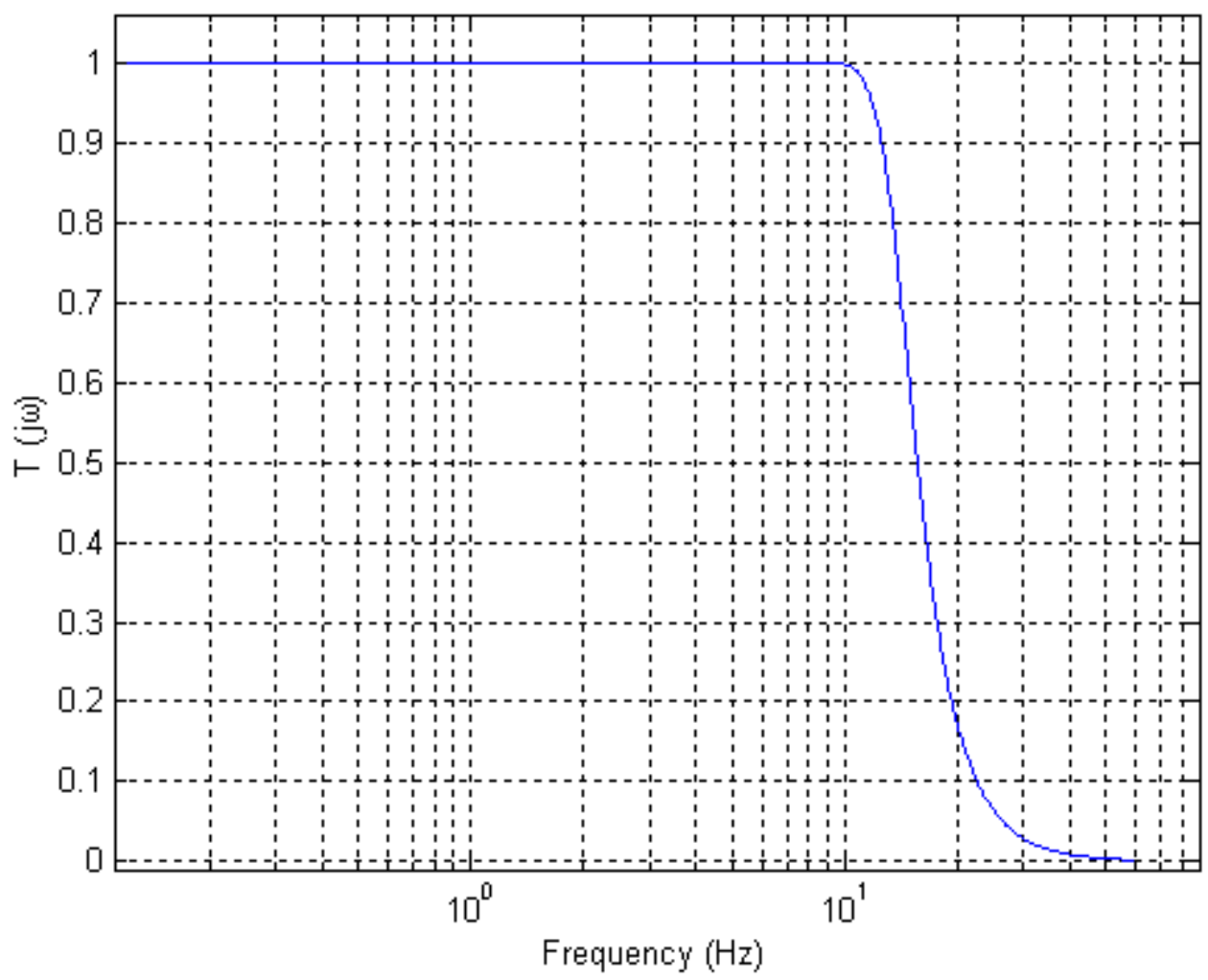

Figura 3.6 - resposta em freqüência da filtragem do sensor de temperatura 


\section{4- PROJETO ELÉTRICO}

Neste capítulo são apresentadas as topologias escolhidas para o projeto dos circuitos e os valores calculados.

\section{1 - topologias}

São apresentadas as topologias para os amplificadores de instrumentação, biquads SC, biquads SI e o circuito de teste da bateria.

\subsection{1 - amplificador de instrumentação}

Os sensores podem fornecer sinais de saída pequenos, e ter - como é o caso do LM35 - uma baixa impedância de saída. É útil, portanto, usar um amplificador de instrumentação, que tem alta impedância de entrada e alta CMRR. É útil também para minimizar problemas de diferença, caso haja, entre os terminais terra dos circuitos dos sensores e dos circuitos do $S o C$.

Uma proposta de conseguir-se um circuito cada vez menor e com menos dissipação térmica é o amplificador de instrumentação em modo de corrente da Figura 4.1.

No diagrama do IA, mostrado na figura, AO1, AO2 e AO3 são amplificadores operacionais; pM e nM são espelhos de corrente. Esta configuração é uma alternativa ao IA convencional - construído com 7 resistores, sendo 3 pares que devem estar casados proposta por Toumazou e Lidgey em 1989, construída com um transportador de corrente (current conveyor, também chamado de "transferidor de corrente"). Nesta configuração, usa-se técnica de sensoriamento da corrente de alimentação como substituição da necessidade de alguns dos resistores [19-20]. 


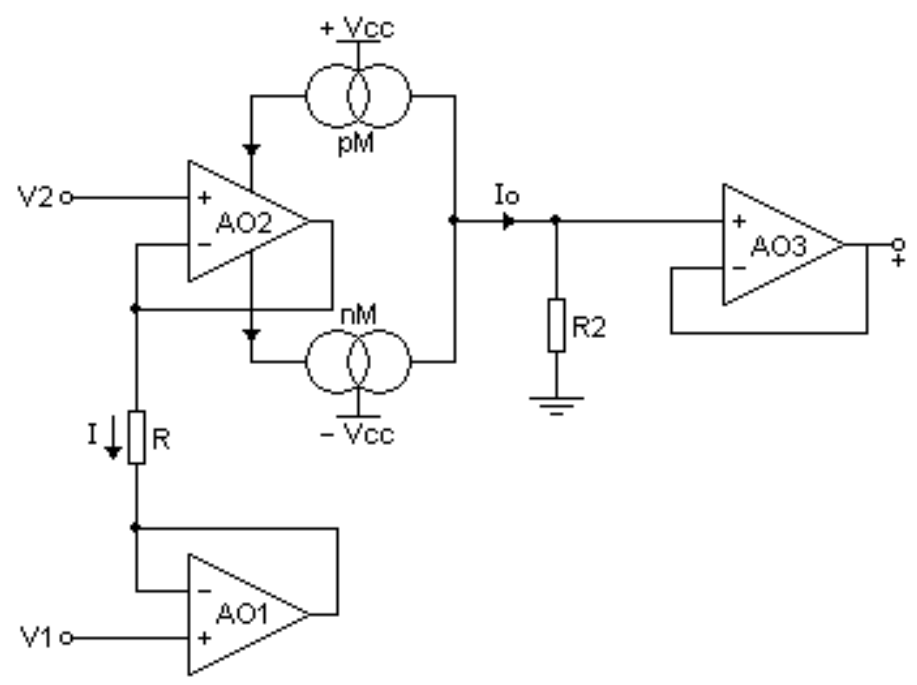

Figura 4.1 - amplificador de instrumentação em modo de corrente

Os amp-ops AO1 e AO2 atuam como seguidores de tensão; assim, a corrente $I$ fluindo pelo resistor $R$ é dada pelas tensões de entrada, na forma:

$$
I=(V 2-V 1) / R
$$

A técnica de sensoriamento da corrente de alimentação do amplificador operacional é baseada no fato de que as correntes de entrada do amp-op são muito pequenas (idealmente nulas), de modo que, pela lei de Kirchhoff, vê-se que a corrente de saída de AO2 (que é a corrente $I$ ) é a diferença entre a corrente de alimentação entrando e a corrente de alimentação saindo do amp-op. Os espelhos de corrente copiam as correntes de alimentação, e assim a corrente de saída do primeiro estágio do IA é dada pela recombinação das correntes dos espelhos, ou seja:

$$
I=I_{p}-I_{n}=I_{o}
$$

Vê-se, assim, que o primeiro estágio do IA (formado pelos amp-ops AO1 e $\mathrm{AO} 2$, e pelos espelhos de corrente $\mathrm{pM}$ e $\mathrm{nM}$ ) tem como saída um sinal de corrente proporcional à diferença entre as tensões de entrada. Nota-se também que se as entradas de tensão forem iguais, não circulará corrente sobre $R$ e a saída é nula, representando 
CMRR infinita para o primeiro estágio (considerando amp-ops idênticos). Este mesmo resultado, no IA convencional, está ligado também ao casamento preciso dos resistores.

O segundo estágio do IA é composto pela resistência $R 2$ e o amplificador operacional AO3. O amplificador é um seguidor da tensão $V_{R 2}$ sobre $R 2$ (i.e., $\left.V_{R 2}=R 2 . I_{o}\right)$. Usando a relação (4.1-1), a tensão na saída do IA é, portanto, dada por:

$$
V_{o}=\left(\frac{R 2}{R}\right)(V 2-V 1)
$$

O projeto do amplificador de instrumentação (IA) foi realizado em três etapas: projeto dos amplificadores operacionais, projeto dos espelhos de corrente e o dimensionamento do amplificador (isto é, da relação entre as resistências).

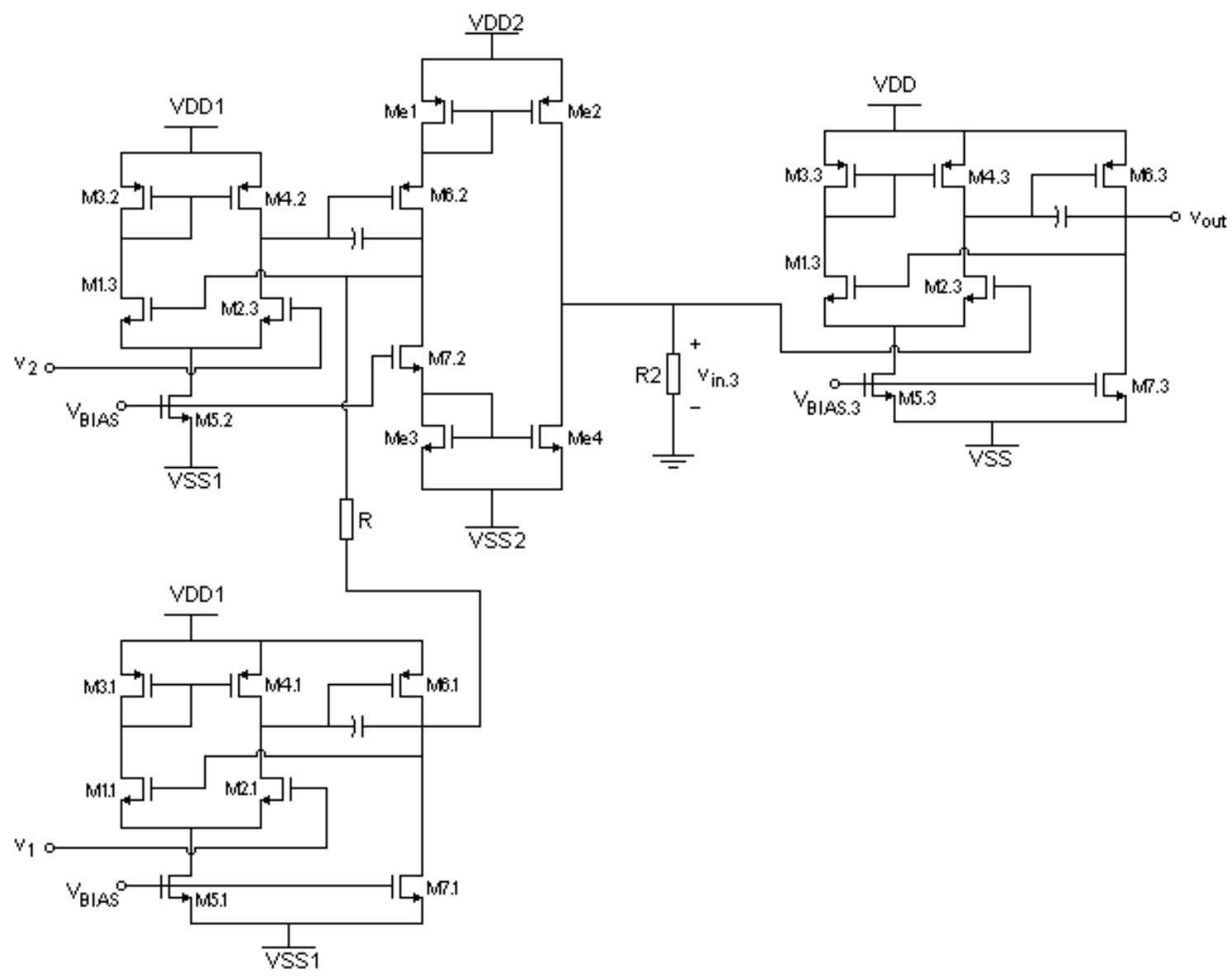

Figura 4.2 - topologia do amplificador de instrumentação 
A topologia básica resultante é a mostrada na Figura 4.2, que será melhor explicada pelos itens a seguir. Para cada circuito, pode haver alguma variação, que será apresentada quando pertinente.

\subsubsection{1 - amplificadores operacionais}

O procedimento de projeto do amplificador operacional, proposto por Allen e Holberg [4] é apresentado neste item, e os resultados específicos de cada projeto são apresentados separadamente, em seguida. As especificações dos parâmetros da tecnologia são as mostradas na tabela 3.1 .

O projeto é baseado na topologia mostrada na Figura 4.3(b), mostrada abaixo ao lado do símbolo do amplificador operacional - Figura 4.3(a).

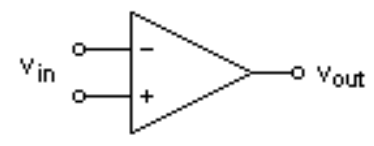

(a)

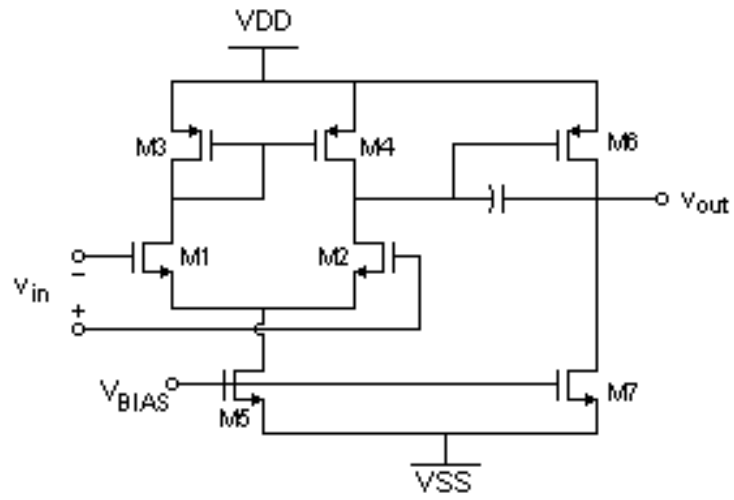

(b)

Figura 4.3 - amplificador operacional: (a) símbolo e (b) topologia

O dimensionamento dos transistores dos amplificadores operacionais foi feito tendo como base inicialmente um comprimento $L=0,35 \mu \mathrm{m}$, para que ocupem uma área pequena. A princípio, os transistores M1 e M2 são iguais, assim como os transistores M3 e M4. O capacitor $C_{C}$, entre a saída e a porta de M6, tem a função de realizar a compensação Miller do amp-op, aproximando o pólo mais próximo da origem e afastando o pólo seguinte. Supondo o zero distante (aproximadamente $10 G B$ ), pode ser mostrado [4] que, para uma margem de fase de $60^{\circ}$, pode-se dimensionar $C_{C}$ a partir de uma capacitância de carga prevista $C_{L}$, pela relação $C_{C}=0,22 . C_{L}$. 
A corrente $I_{5}$, fluindo pelo transistor M5, pode ser calculada pelo produto entre a exigência de slew-rate e a capacitância de compensação. (ou seja, $I_{5}=S R . C_{C}$ ). A slewrate, SR, foi calculada seguindo uma sugestão para quando uma especificação de slewrate não é dada [4], e considerando uma capacitância de carga padrão de $10 \mathrm{pF}$.

O comportamento do transistor na saturação é dado pela equação (4.1-4):

$$
I_{D}=K^{\prime}\left(\frac{W}{2 L}\right)\left(V_{G S}-V_{T}\right)^{2}\left(1+\lambda v_{D S}\right)
$$

onde $\lambda$ é idealmente nulo. Esta equação será utilizada repetidas vezes, inclusive sob outras formas - para se calcular $S_{i}=(W / L)_{i},\left(V_{G S^{-}} V_{T}\right)$, etc.

De acordo com as tensões necessárias sobre os transistores M1 e M3 para mantêlos na saturação, e admitindo que, devido ao espelho de corrente composto por M3 e M4,

$$
I_{3}=I_{4}=\frac{I_{5}}{2}
$$

as dimensões do transistor M3 (e, consequentemente, M4) são calculadas com a corrente $I_{5}$ e a especificação de uma tensão máxima de entrada, $V_{i n}(\max )$, chegando-se à seguinte equação (4.1-6).

$$
V_{\text {in }}(\max )=V_{D D}-\sqrt{\frac{I_{5}}{\beta_{3}}}-\left|V_{T 03}\right|(\max )+V_{T 1}(\min )
$$

Com as especificações de tensões e $I_{5}$ calculada como descrito acima, tira-se da equação (4.1-6) o a razão de aspecto de $\mathrm{M} 3$, ou seja, $S_{3}=(W / L)_{3}$.

Convém fazer uma observação sobre a alimentação do amp-op: as referências de tensão utilizadas sistema são de $\pm 3,3 \mathrm{~V}$; a tensão de alimentação do amp-op, entretanto, deve ser menor do que a tensão aplicada nos espelhos de corrente (já que haverá uma queda de tensão entre a referência e a alimentação do amp-op, devido ao espelho). Por isso, o IA terá duas referências de tensão positivas: $V_{D D 2}=3,3 \mathrm{~V}$ e $V_{D D 1}$, pouco menor que $3,3 \mathrm{~V}$. $V_{D D 1}$ deve ser tal a diferença $\left(V_{D D 2}-V_{D D 1}\right)$ seja suficiente para manter os 
transistores dos espelhos de corrente (Me.1 e Me.2) saturados. A análise é análoga para Me.3 e Me.4 e para as referências negativas, $V_{S S 1}$ e $V_{S S 2}$, que são simétricas às positivas.

O transistor M1 (M2) é dimensionado pela equação:

$$
S=(W / L)=\frac{g_{m}^{2}}{2 \cdot K^{\prime} \cdot I}
$$

Onde supõe-se $g_{m 1}=g_{m 2}=g_{m I}$ (transcondutância do primeiro estágio), que pode ser calculada como a multiplicação da capacitância de compensação pelo produto banda-ganho desejado do amp-op, ou seja:

$$
g_{m I}=G B \cdot C_{C}
$$

onde GB(gain bandwidth, freqüência de ganho unitário) é calculada pela freqüência de corte e ganho DC desejados.

Dimensionado M1, com a especificação da tensão de entrada mínima calcula-se a tensão sobre M5, de forma semelhante à empregada no dimensionamento de M3:

$$
V_{D S 5}=V_{i n}(\min )-V_{S S}-\sqrt{\frac{I_{5}}{\beta_{1}}}-V_{T 1}(\max )
$$

O dimensionamento de M5 foi realizado então, de acordo com a equação (4.1-4) manipulada para ser resolvida para S, conforme mostrado na equação (4.1.-10).

$$
S=(W / L)=\frac{2 . I}{K^{\prime}\left(V_{D S}\right)^{2}}
$$

Todos os passos apresentados até agora (e seguintes) podem ser realizados iterativamente, uma vez que uma escolha pode dar um resultado indesejado, levando a alterações em decisões anteriores, até que todos os resultados estejam adequados. Combinando a relação (4.1-8) com a localização do pólo $p_{L}$ de saída, $\left|p_{L}\right|=g_{m \sigma} / C_{L}$ (supondo $g_{m I I}=g_{m 6}$ ), e supondo que, para a margem de fase de $60^{\circ}$, o pólo esteja a 2,2.GB (suposição que levou à relação entre $C_{C}$ e $C_{L}$ ) chega-se a: 


$$
\begin{aligned}
g_{m 6}= & 2,2 G B \cdot C_{L} \\
& \rightarrow g_{m 6}=2,2 \cdot g_{m 2}\left(C_{L} / C_{C}\right)
\end{aligned}
$$

Há duas abordagens possíveis para o cálculo da razão $(W / L)_{6} \quad$ (e, consequentemente, da corrente $I_{6}$ ): a primeira é basear-se na operação do espelho M3/M4; a segunda é basear-se na tensão de saída e no cálculo da tensão de saturação $V_{D S 6}(\mathrm{sat})$.

Pela primeira abordagem, as dimensões de M6 podem ser encontradas pela relacionando-se M6 e M4 por:

$$
S_{6}=S_{4}\left(g_{m 6} / g_{m 4}\right)
$$

Pela segunda abordagem, calcula-se $S_{6}$ pela equação (4.1-10) aplicada a M6, onde $V_{S D 6}($ sat $) \leq V_{D D}-V_{\text {out }}(\max )$.

Calculado $S_{6}=(W / L)_{6}$, a corrente $I_{6}$ fluindo por M6 é dada por:

$$
I_{6}=\frac{g_{m 6}^{2}}{2 K_{6}^{\prime} S_{6}}
$$

Feitas as duas abordagens, checa-se a adequação dos resultados de ambas às especificações, principalmente de saída de tensão. No caso de as duas respostas serem adequadas, pode-se seguir com as duas possibilidades para posterior análise. A não ser que resulte em erros ou valores indesejados à frente, a primeira abordagem é preferível, pois mantém o funcionamento do espelho de corrente do primeiro estágio. Para melhor compreensão, os valores de $S_{6}$ e $I_{6}$ calculados pela primeira e segunda abordagem serão chamados de $S_{6 a}$ e $S_{6 b}$, e $I_{6 a}$ e $I_{6 b}$, respectivamente.

Finalmente, as dimensões do transistor M7 se relacionam às do transistor M5, similarmente à relação entre $S_{6}$ e $S_{4}$, da forma:

$$
S_{7}=(W / L)_{7}=S_{5}\left(I_{6} / I_{5}\right)
$$


A tensão de polarização $V_{B I A S}$ equivale, em relação à alimentação negativa, à tensão porta-fonte de M5, $V_{G S 5}$, e pode ser encontrada considerando a equação do comportamento do transistor na saturação (4.1-4). A este ponto, todos os valores necessários para o dimensionamento do amp-op já foram definidos ou calculados.

\subsubsection{1 - espelhos de corrente}

A Figura 4.4 mostra espelhos de corrente, simples e cascode. Ambos os tipos foram usados em diferentes partes do projeto. No diagrama do amplificador de instrumentação (Figura 4.1), pM é um espelho de corrente PMOS, e nM é um espelho de corrente NMOS. Os dispositivos dos espelhos de corrente foram dimensionados a partir da diferença entre as alimentações $V_{D D 1}$ e $V_{D D 2}$ (ou $V_{S S 1}$ e $V_{S S 2}$ ) e da corrente de saída de $\mathrm{AO} 2$, isto é, $I_{6.2}$.

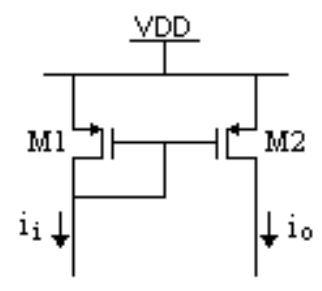

(a)

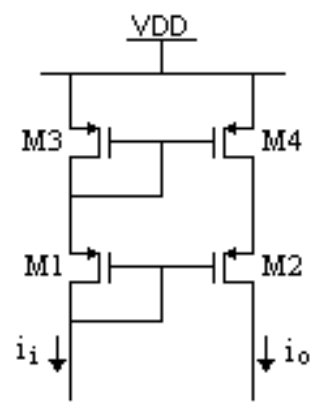

(c)

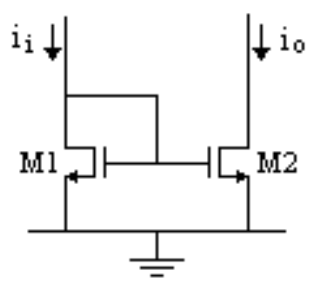

(b)

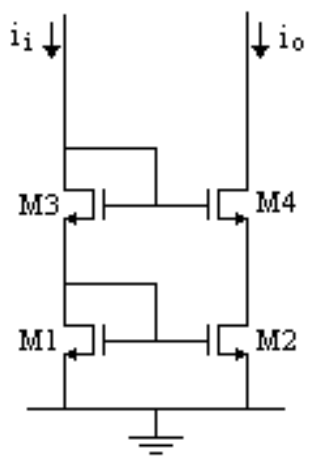

(d)

Figura 4.4 - espelhos de corrente (a) PMOS simples; (b) NMOS simples; (c) PMOS cascode; e (d) NMOS cascode

Podemos dividir a tensão $V_{G S}$ de um dispositivo em duas partes: a tensão de limiar $V_{T}$ e a excedente, chamado de $V_{O N}$ (eq. 4.1-15). Assim, podemos expressar o 
valor mínimo de $v_{D S}$ necessário para manter o dispositivo saturado por $V_{O N}$, como mostrado pela expressão (4.1-16).

$$
\begin{aligned}
& V_{G S}=V_{O N}+V_{T} \\
& v_{D S}(\text { sat })=V_{G S}-V_{T}=V_{O N}
\end{aligned}
$$

Relacionando-se as equações (4.1-15) e (4.1-16) à eq. (4.1-4) e observando que, no espelho, a tensão $v_{G S}$ em Me.1 se iguala à diferença $\left(V_{D D 2}-V_{D D 1}\right)$, podem-se calcular as dimensões dos dispositivos dos espelhos pela eq. (4.1-17).

$$
\begin{aligned}
V_{O N}^{2}= & \frac{2 \cdot I_{D}}{\beta} \\
& \rightarrow S=(W / L)=\frac{2 \cdot I_{D}}{K^{\prime} \cdot V_{O N}^{2}}
\end{aligned}
$$

Para espelhos cascode, o processo é o mesmo, mas notando que $V_{D D 2}-V_{D D 1}=$ $2 V_{T}+2 V_{O N}$.

Considera-se, a princípio, todos os pares dos espelhos de corrente sendo de transistores idênticos. É possível que a corrente copiada seja multiplicada por uma constante, multiplicando a relação $W / L$ dos transistores da saída por essa constante. No espelho de corrente mostrado na Figura 4.4(a), por exemplo, se for desejado um ganho de corrente $\alpha$, faz-se $S 2=(W / L)_{2}=\alpha .(W / L)_{1}$. De forma geral:

$$
i_{D 1}\left(\frac{W_{2}}{L_{2}}\right)=i_{D 2}\left(\frac{W_{1}}{L_{1}}\right)
$$

\subsubsection{3 - resistências}

Para o dimensionamento das resistências, os seguintes fatores são considerados:

a) ganho desejado, uma vez que a saída de tensão se relaciona às resistências pela eq. (4.1-3); 
b) entrada de tensão de $\mathrm{AO} 3$ - a tensão máxima de entrada de AO3 limita R2, uma vez que $v_{i n .3}=R 2 . I_{o}$. (Lembrando que pode ser aplicado um ganho à corrente de saída do primeiro estágio, $I_{o}$, pelos espelhos de corrente.);

c) tensão sobre R, uma vez que os amplificadores operacionais têm limitações para a corrente de saída;

d) possibilidade de realização - dependendo da escolha da implementação das resistências (podem ser resistores externos ao chip, de polissilício, resistores ativos, etc.) algumas limitações podem surgir, inclusive quanto a valores máximo e mínimo de resistência e precisão.

Resistores na tecnologia utilizada podem ser fabricados no próprio material semicondutor. A resistência é dada pelas dimensões do dispositivo (Figura 4.5).

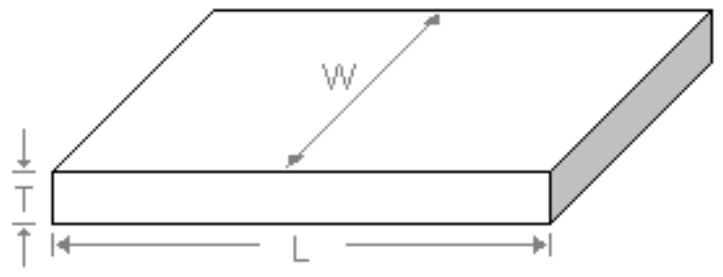

Figura 4.5 - dimensões de um bloco de material semicondutor

Para uma dada tecnologia de fabricação, $\rho$ e $T$ são geralmente fixos, e se define a resistência de camada (sheet resistance) como

$$
\rho_{s}=\frac{\rho}{T}
$$

Considerando um bloco de material resistivo, com resistividade $\rho$ dada em $\Omega$.cm, a resistência em $\Omega$ é dada por

$$
R=\frac{\rho L}{A}=\frac{\rho L}{W \cdot T}=\rho_{s} \frac{L}{W}
$$


onde $A$ é a área perpendicular ao fluxo de corrente (a área hachurada na Figura 4.5).

Dividindo uma área plana retangular em pedaços de dimensões $W=L$, cada pedaço será um quadrado (supondo não haver sobras). Assim, pode-se dizer que uma área com $W / L=n$ é composta por $n$ quadrados, independentemente dos valores absolutos de $W$ e $L$. A resistência do material resistivo da Figura 4.5 varia linearmente $\operatorname{com}(L / W)$, por isso $\rho_{s}$ é dada geralmente em $\Omega / \square$, ou "ohm por quadrado", mesmo que a razão não seja um número inteiro. A resistência de um bloco é obtida, portanto, dimensionando-se a largura $W$ e o comprimento $L$ do resistor.

Observa-se também que há tamanhos mínimos para cada uma dessas dimensões, portanto o tamanho em relação à resistência tem certa variação. Uma resistência muito grande pode ser obtida com $W$ mínimo e $L$ grande, enquanto uma resistência pequena pode ser obtida com $L$ mínimo e $W$ grande; ambas terão área relativamente grande, dependendo de quão grande são $W$ e $L$.

\subsubsection{4 - conversor tensão-corrente}

Inicialmente, os conversores tensão-corrente a serem utilizados no projeto eram baseados na topologia abaixo (Figura 4.6).

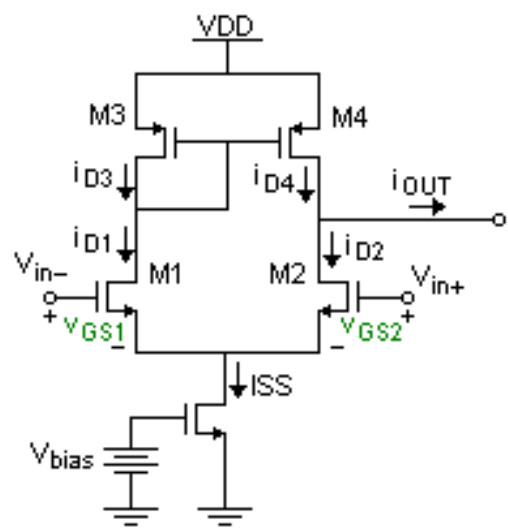

Figura 4.6 - conversor V-I

O princípio é o mesmo explicado para o transportador de corrente: as correntes $i_{D 1}$ e $i_{D 2}$ são iguais, se as tensões nos transistores M1-M2 e M3-M4 forem iguais. Se há uma diferença de tensão aplicada entre os terminais $V_{i n+}$ e $V_{i n \text {-, }}$ as correntes $i_{D 1}$ e $i_{D 2}$ se tornam diferentes; como $i_{D 3}$ e $i_{D 4}$ se mantém iguais, devido ao espelhamento, a diferença de corrente - proporcional à diferença de tensão - é escoada na forma da corrente $i_{\text {OUT }}$. 
No entanto, preferiu-se o uso de conversores baseados nos current conveyors, conforme explicado a seguir.

Esta outra utilidade dos current conveyors também é baseada no sensoriamento da corrente de alimentação (Figura 4.7).

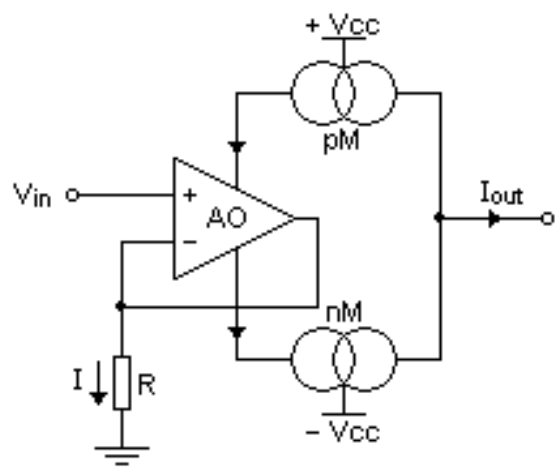

Figura 4.7 - conversor V-I baseado em sensoriamento da corrente de alimentação

Embora componha um conversor maior e mais complexo do que o da Figura 4.6, o conversor acima tem a vantagem de poder ser incorporado ao amp-op de saída do amplificador de instrumentação (AO3), chegando-se ao diagrama abaixo.

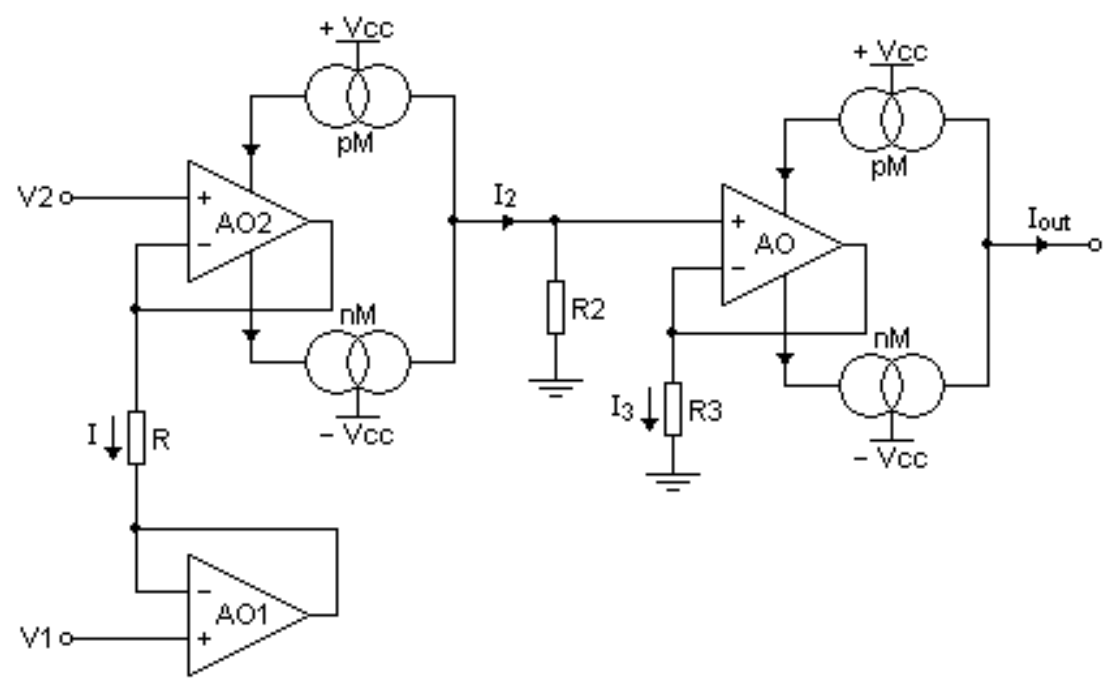

Figura 4.8 - amplificador de instrumentação utilizando conversor V-I da Figura 4.7 
Dessa forma, a corrente de saída será proporcional à tensão em $R 3$, que por sua vez corresponde a $R 2\left(I_{2} / I_{3}\right)$. Com esse uso, a principal desvantagem do conversor $\mathrm{V}$-I da Figura 4.7 se torna a necessidade de uma resistência (real ou simulada). Se tal desvantagem se tornar impeditiva, podem-se usar os conversores simples da Figura 4.6.

\subsection{2 - biquads SC}

Conforme descrito anteriormente na seção 2.4.2, é possível utilizar modelos de circuitos que correspondem a funções de transferência de filtros biquadráticos. Com capacitores chaveados, as funções de transferência genéricas são dadas por [4]:

$$
T\left(s_{n}\right)=-\frac{\left[\alpha_{3} s_{n}^{2}+\frac{s_{n} \alpha_{4}}{T_{n}}+\frac{\alpha_{1} \alpha_{5}}{T_{n}^{2}}\right]}{s_{n}^{2}+\frac{s_{n} \alpha_{6}}{T_{n}}+\frac{\alpha_{2} \alpha_{5}}{T_{n}^{2}}}
$$

para Q baixo; e

$$
T\left(s_{n}\right)=-\frac{\left[\alpha_{6} s_{n}^{2}+\frac{s_{n} \alpha_{3} \alpha_{5}}{T_{n}}+\frac{\alpha_{1} \alpha_{5}}{T_{n}^{2}}\right]}{s_{n}^{2}+\frac{s_{n} \alpha_{4} \alpha_{5}}{T_{n}}+\frac{\alpha_{2} \alpha_{5}}{T_{n}^{2}}}
$$

para Q alto.

Comparando-se a função de transferência de cada estágio com as equações acima, pode-se calcular, com $T_{n}=\omega_{P B} / f_{c}$ (onde $f_{c}$ é a freqüência do relógio usado para controlar o chaveamento do circuito), os coeficientes $\alpha$ de cada estágio. Estes coeficientes se relacionam diretamente aos circuitos de integradores SC de Q baixo (Figura 4.9) ou alto (Figura 4.10), mostrados abaixo [4], e assim se obtêm os biquads SC correspondentes a cada estágio. 


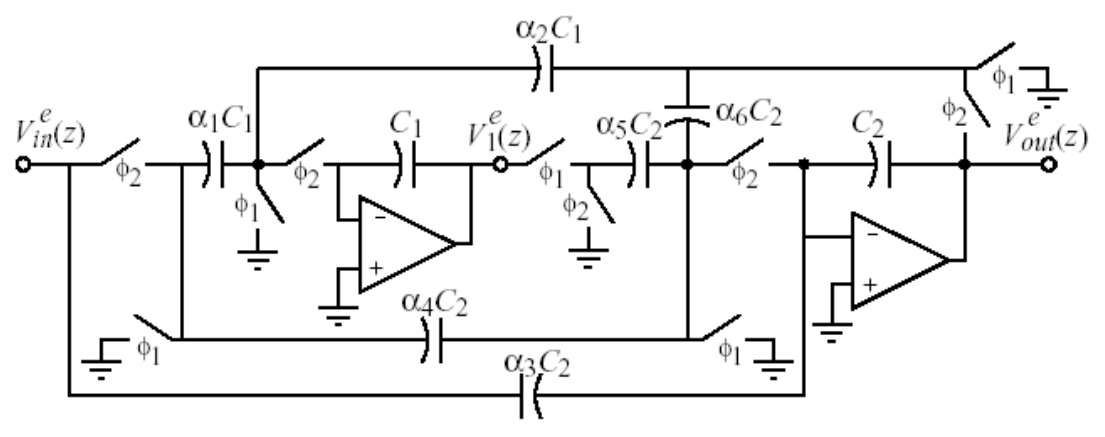

Figura 4.9 - circuito de biquad SC para Q baixo

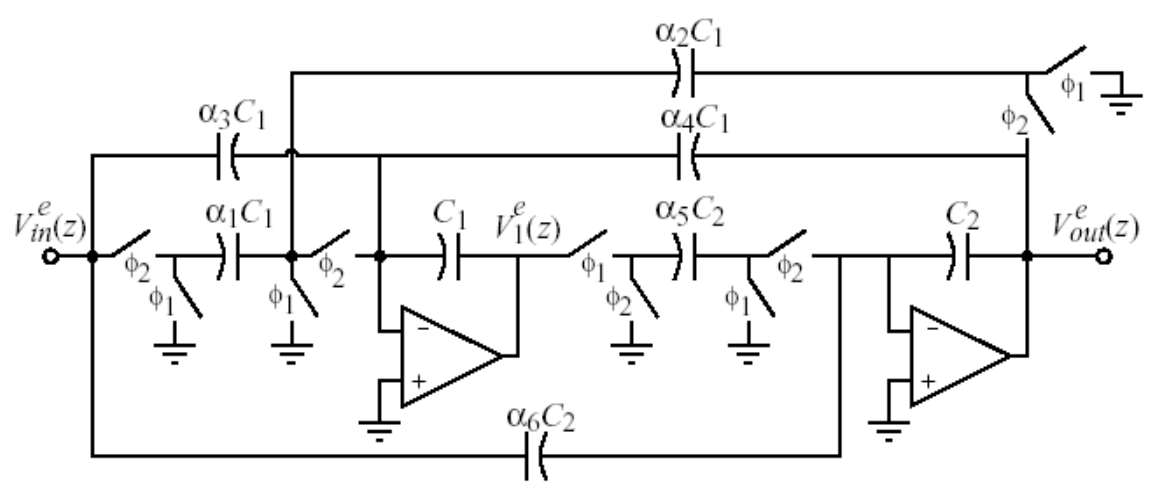

Figura 4.10 - circuito de biquad SC para Q alto

Os valores das capacitâncias (isto é, os coeficientes $\alpha$ ) são dimensionados de acordo com a função de transferência a ser implementada. A Figura 4.11 abaixo mostra um biquad passa-baixas, com Q baixo, genérico, utilizado várias vezes no projeto. A ausência dos caminhos por $\alpha_{3}$ e $\alpha_{4}$ se dá pela ausência dos coeficientes no numerador de $T\left(s_{n}\right)$.

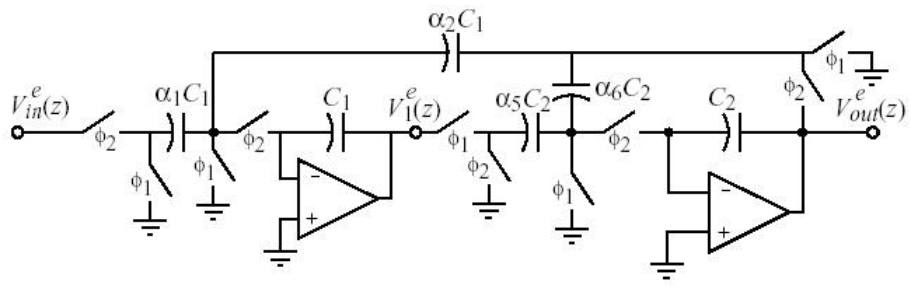

Figura 4.11 - passa-baixas SC com Q baixo 


\subsection{3 - biquads SI}

Circuitos a corrente chaveada usam amostras de corrente, enquanto circuitos a capacitores chaveados usam amostras de tensão. Ambos são discretos no tempo. Uma analogia se sugere, e pode ser facilmente feita considerando-se correntes, em lugar das tensões de entrada e saída da função de transferência do circuito SC, para se obter a função de transferência de um circuito SI. Mas a implementação dos circuitos é obviamente diferente.

Um método foi proposto por Fiez, Lee e Allstot [22, 23] para se implementarem filtros biquadráticos a corrente chaveada a partir de circuitos SC. Para isso, o bloco fundamental é o integrador SI, mostrado abaixo (Figura 4.12) [22].

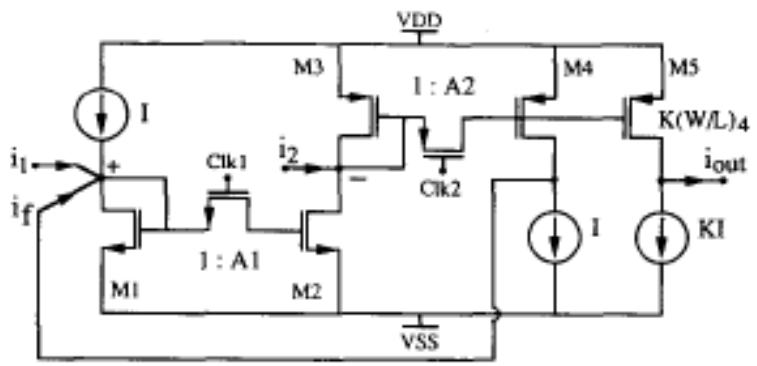

Figura 4.12 - integrador SI

(Para se ter melhor desempenho, pode-se usar espelhos de corrente do tipo cascode; são usados para melhorar a razão entre impedâncias de entrada e saída, e a faixa dinâmica.)

A idéia é que, sendo o ganho $K$ de um espelho de corrente no integrador SI análogo à razão $C_{1} / C_{2}$ do integrador SC (mostrado na Figura 2.26), pode-se desenhar o primeiro a partir do último. Esta relação é baseada na função de transferência de cada integrador no domínio da transformada $z$ [4, 23, 47], uma ferramenta para representação de sinais discretos, utilizada para circuitos SI e SC devido ao chaveamento do percurso do sinal.

Para implementar-se o integrador SI, basta então definir calcular os ganhos $K$ mapeando-se as capacitâncias no circuito SC. Para o circuito passa-baixas com baixo 
valor de Q (Figura 4.11), o diagrama que mostra a conversão para SI é da forma mostrada na Figura 4.13(a):

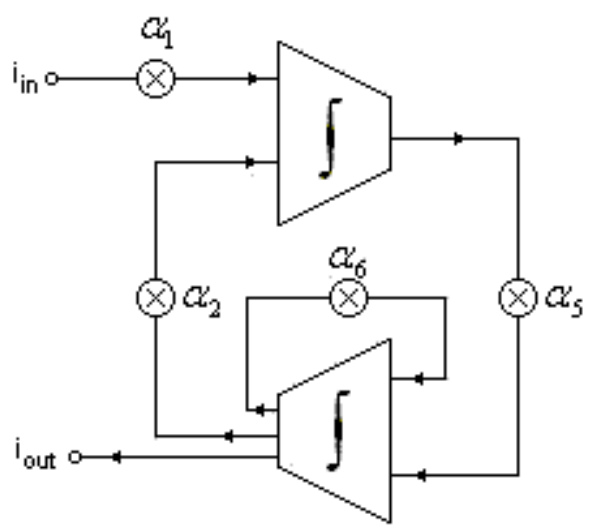

(a)

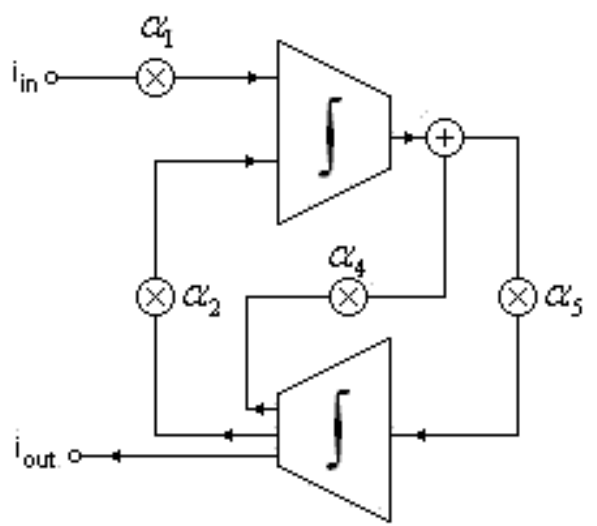

(b)

Figura 4.13 - diagrama de conversão para SI, a) de um circuito passa-baixas SC de $Q$ baixo; e b) de um passa-baixas $S C$ de $Q$ alto.

Convertendo o circuito da Figura 4.11 com o diagrama da Figura 4.13(a), resulta o seguinte circuito SI (Figura 4.14):

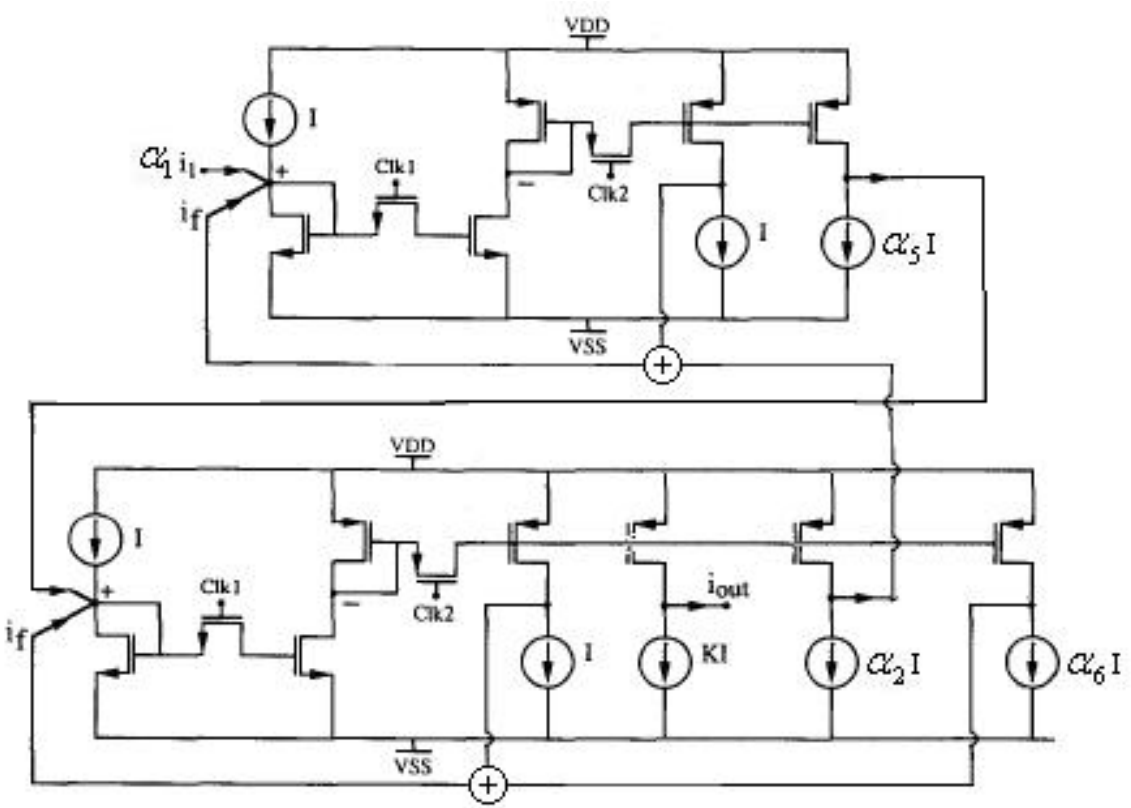

Figura 4.14 - passa-baixas SI com Q baixo 
Analogamente ao que é feito em circuitos SC, os dispositivos são dimensionados considerando-se a maior razão entre os coeficientes e adotando-se uma escala adequada em relação ao menor (ou maior) tamanho. Leva-se em conta também o desempenho dos espelhos de corrente. O erro nos espelhos de corrente é dado por:

$$
\frac{\Delta I}{I_{\text {in }}}=\frac{\left(I_{\text {out }}-I_{\text {in }}\right)}{I_{\text {in }}}=\frac{\Delta \beta}{\beta}-\Delta V_{T}\left(\frac{2 \beta}{I_{\text {in }}}\right)^{1 / 2}
$$

para dispositivos na saturação; esta condição é a limitação de I em espelhos de corrente simples, como o mostrado acima.

Para que $\Delta \mathrm{I}$ não seja grande demais, são necessários dispositivos com alta impedância de saída e bem casados [29]. Estas exigências definem o dimensionamento dos componentes em cada caso.

\subsection{4 - monitoramento da bateria}

Os procedimentos descritos anteriormente para a aferição do estado da bateria devem ser executados. O SoH em si é útil e interessante para o sistema do SoC, mas não é necessário; as baterias sendo monitoradas devem ser usadas até precisarem de recarga, e como o $\mathrm{SoH}$ é em certo grau subjetivo, sua definição completa deve ser feita (se feita) separadamente para levar em conta as características das pilhas escolhidas e condições de uso. De qualquer forma, serão necessárias leituras de tensão, corrente e temperatura. Todas estas leituras já podem ser feitas a partir da leitura do próprio sensor de temperatura (apesar de que esta pode ser uma medida imprecisa, já que a temperatura da pilha em si é afetada pelo efeito Joule e pelas condições da instalação) e do teste de OCV anteriormente apresentado, útil portanto tanto para estimar o $\mathrm{SoH}$ quanto o SofCh.

No circuito do teste de OCV, o parâmetro a ser definido é a resistência externa $R_{\text {ext. }}$ Esta resistência depende do objetivo do teste. É recomendado, para testes de descarga $[33,39]$, que se tenha uma corrente de aproximadamente $60 \mathrm{~mA}$. Como a tensão nominal de cada pilha é de 1,2V teria-se por cálculo direto da lei de Ohm que o resistor para o teste de uma pilha deve ser $R_{e x t}=20 \Omega$. Para o teste da bateria inteira (quatro pilhas em série), de tensão $4,8 \mathrm{~V}$, teria-se $R_{\text {ext }}=80 \Omega$. 
Dependendo do tamanho e dissipação de potência (devido ao calor gerado), resistores não são práticos para o uso interno em chips microeletrônicos e devem ser externos. A bibliografia [33, 39] recomenda as leituras de células individuais e das baterias, mas não necessariamente das várias combinações possíveis. Seria mais interessante então utilizar apenas um resistor de $20 \Omega$ e um de $80 \Omega$ e que os testes individuais das pilhas fossem feitos separadamente.

Os testes iniciais do sistema de alimentação do SoC utilizaram resistores de $22 \Omega$ e $82 \Omega$, respectivamente. Essa diferença se deu pela necessidade de ter resistores que sejam comercialmente fabricados. Esta pequena diferença não afeta significativamente o teste, mas devem ser levadas em conta quaisquer diferenças caso os resistores usados sejam de valores diferentes dos acima.

Estes valores de $20 \Omega$ e $80 \Omega$, no entanto, são utilizados em testes onde a bateria é de fato descarregada. É de interesse do projeto do $S o C$ que a carga utilizada no monitoramento da bateria seja menor, justamente para que se evite sua descarga. Portanto, são mais adequadas resistências maiores, da ordem de centenas ou milhares de ohms, utilizando uma corrente menor do que a de $60 \mathrm{~mA}$ do teste de descarga.

Há outra questão problemática relativa a este teste no contexto do $S o C$ : sendo a bateria a fonte de alimentação do sistema no chip, seria melhor que o teste fosse realizado sem desligá-la. Entretanto, o teste OCV descrito anteriormente depende de uma leitura da tensão sem que corrente flua através da resistência interna $R_{\text {in }}$ da bateria. Além disso, para realizar a medição com elementos ativos, há o problema de a tensão a ser medida (de até 4,8V) ser bem superior à tensão de alimentação $(3,3 \mathrm{~V})$ disponível para tais dispositivos. Uma divisão de tensão simples pode ser realizada, mas significaria também corrente através de $R_{i n}$. Para contornar esses problemas, é sugerida uma variação do teste $\mathrm{OCV}$, ilustrada na Figura 4.15. (Embora não se meça tensão de circuito aberto, o nome será mantido por referência.)

A chave $s 1$ representa simplesmente a conexão do circuito de teste aos terminais da bateria, estando fechada durante todo o teste. As resistências $R_{d}, R_{1}$ e $R_{2}$ são conhecidas; $R_{d}$ é utilizada para a divisão de tensão, enquanto $R_{l}$ e $R_{2}$ são utilizadas para a medição indireta de $V_{b a t}$ e $R_{\text {in }}$. $V_{\text {out }}$ é a saída de tensão medida no teste. 


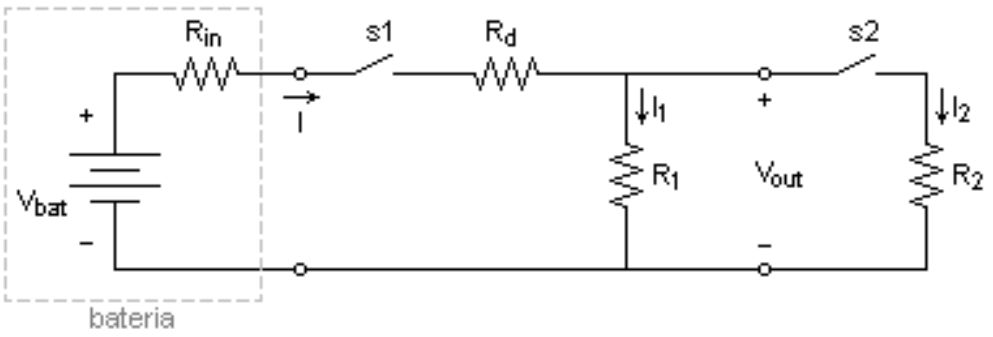

Figura 4.15 - teste de tensão de circuito aberto (OCV) alterado

Com a chave $s 2$ aberta, a tensão $V_{\text {out }}$ é descrita por:

$$
V_{\text {out }}=I \cdot R_{1}=V_{b a t}-I \cdot\left(R_{\text {in }}+R_{d}\right)
$$

Medindo-se a tensão $V_{\text {out }}$, calcula-se a corrente $I$. Na segunda etapa do teste, a chave $s 2$ é fechada, e tem-se:

$$
V_{\text {out }}^{\prime}=I_{1} \cdot R_{1}=I_{2} \cdot R_{2}=V_{\text {bat }}^{\prime}-I^{\prime} \cdot\left(R_{\text {in }}+R_{d}\right)
$$

Com $R_{1}$ e $R_{2}$ conhecidos e $V_{\text {out }}$ medida, calcula-se $I_{1}, I_{2}$ e pode-se achar a corrente $I^{\prime}$, pela equação (4.1-24):

$$
I^{\prime}=I_{1}+I_{2}
$$

Considerando que $V_{b a t}$ e $R_{\text {in }}$ são valores fixos para a bateria durante o teste (apesar de variarem ao longo de sua vida útil), as equações (4.1-24) e (4.1-25) podem ser combinadas da seguinte maneira:

$$
\begin{aligned}
V_{\text {bat }}= & V_{\text {out }}+I \cdot\left(R_{\text {in }}+R_{d}\right)=V_{\text {out }}^{\prime}+I^{\prime} \cdot\left(R_{\text {in }}+R_{d}\right) \\
& \Rightarrow V_{\text {out }}-V_{\text {out }}^{\prime}+\left(I-I^{\prime}\right) R_{d}=\left(I^{\prime}-I\right) R_{\text {in }}
\end{aligned}
$$

A equação (4.1-27) pode ser resolvida para $R_{i n}$, uma vez que todas as demais variáveis já foram calculadas ou medidas. Feito este cálculo, encontra-se o valor de $V_{\text {bat }}$. 


\subsubsection{1 - chave analógica}

Nas equações descritas acima, supõe-se uma chave ideal, isto é, com resistência nula quando fechada e resistência infinita quando aberta. A chave real usada no teste provavelmente não terá nenhuma dessas duas características. (Uma chave manual poderia ter resistência infinita quando aberta, mas não faria sentido usá-la, o contexto do SoC.)

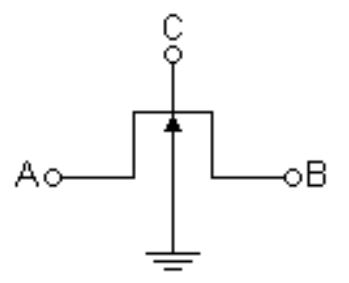

Figura 4.16 - transistor NMOS como chave

Um transistor MOS pode ser usado como chave, como ilustrado na Figura 4.16 com um NMOS. O substrato é conectado ao potencial mais negativo. O terminal $\mathrm{C}-\mathrm{a}$ porta do transistor - representa o controle da chave. Se a tensão em C for suficientemente alta, o transistor não satura e opera na região de triodo, modelada pela equação (4.1-28). A tensão $v_{D S}$, apesar de não-nula, é suposta pequena o bastante para que o transistor não atinja a saturação.

$$
\left.i_{D}=\frac{K^{\prime} W}{L}\left[\left(v_{G S}-V_{T}\right) v_{D S}-\frac{v_{D S}^{2}}{2}\right)\right]
$$

Nessa condição, diz-se que a chave está fechada (estado ON). A resistência $r_{O N}$ da chave é dada por:

$$
r_{O N}=\frac{L}{K^{\prime} W\left(V_{G S}-V_{T}-V_{D S}\right)}
$$

Para muitas aplicações, a resistência $r_{O N}$ é suficientemente baixa para que não afete o comportamento do circuito. No caso do OCV alterado, a resistência deve ser 
levada em conta como uma resistência em série com $R_{2}$, o que pode ser representado por uma chave ideal em série com $R 2=R 2^{\prime}+r_{O N}$. Isto gera algum problema pois a resistência $r_{O N}$ não é exatamente constante, se a tensão nos seus terminais varia. Este efeito pode ser minimizado pelo dimensionamento da chave, utilizando-se corrente baixa e fazendo-se $R 2$ ' grande em relação a $r_{O N}$.

Quando a tensão em $\mathrm{C}$ estiver no nível baixo (no potencial mais negativo), o transistor está em corte. Idealmente, a resistência nesta situação é infinita, mas no caso real há correntes de fuga, resultando em resistência menor. Geralmente, no entanto, não é o estado OFF da chave que influencia negativamente o circuito, mas sim a transição de um estado para o outro. Quando a chave passa do estado ON (conduzindo) para o estado OFF (em corte), a carga acumulada nas capacitâncias internas do transistor, devido ao sinal de controle na porta, tem como caminho de saída o circuito ao qual a chave está ligada. Esse efeito é um problema maior em circuitos onde a chave é controlada por um sinal pulsado (tipicamente, um relógio - daí o nome). Depende de vários fatores, como o desenho do transistor, suas dimensões, a velocidade e a forma de onda e na porta, etc. Apesar de haver algum nível de previsibilidade (por exemplo, freqüência de chaveamento maior piora o efeito do clock feedthrough, assim como maiores dimensões do transistor), é um efeito muito difícil de ser descrito analiticamente, por isso é calculado por meios computacionais.

\section{2 - Cálculos dos dispositivos}

O resultado do dimensionamento dos dispositivos utilizados nas topologias apresentadas são mostrados a seguir, bem como os principais cálculos envolvidos. A seção está subdividida primeiramente para os amplificadores de instrumentação de cada subcircuito - sensor de temperatura (4.2.1), sensor de pressão (4.2.2) e monitoramento da bateria (4.2.3) - com os cálculos dos conversores V-I incluídos em cada seção. Os cálculos dos filtros apresentados na subseção 4.2.4.

\subsection{1 - subcircuito: sensor de temperatura}

A primeira parte do subcircuito envolve ajustes de amplitude realizados por um amplificador de instrumentação, que consiste de três partes: amplificadores 
operacionais, espelho de corrente e resistências. O resultado do cálculo dos dispositivos está mostrado a seguir.

\subsubsection{1 - amplificadores operacionais}

Os cálculos foram realizados conforme explicado no item 4.1.1.1. As especificações da tecnologia são aquelas mostradas na tabela 3.1. Sobre o uso destes parâmetros, é necessária uma observação:

As tensões $V_{S B}$ e o parâmetro de modulação do comprimento do canal, $\lambda$, dependem às vezes de valores obtidos durante o cálculo, sobre os quais podem exercer também alguma influência. Nesses casos, tal valor foi calculado primeiramente sem levar em conta o parâmetro (isto é, como se $V_{S B}=0$ ou como se não houvesse modulação do comprimento do canal) e daí foram realizados cálculos iterativos até encontrarem-se os valores devidos.

As especificações baseadas no funcionamento do amp-op e características do sinal são as seguintes:

$$
\begin{aligned}
& A_{V} \geq 70 \mathrm{~dB} \\
& V_{D D}=2,5 \mathrm{~V} ; V_{S S}=-2,5 \mathrm{~V} \\
& -1,0 \mathrm{~V} \leq V_{\text {in }} \leq 1,5 \mathrm{~V} \\
& -1,0 \mathrm{~V} \leq V_{\text {out }} \leq 1,5 \mathrm{~V} \\
& C_{L}=10 \mathrm{pF} \\
& G B=32 \mathrm{kHz} \\
& S R=0,5 \mathrm{~V} / \mu \mathrm{S}
\end{aligned}
$$

Os resultados dos cálculos são os seguintes:

$C_{C}=2,4 \mathrm{pF}$

Dimensões dos transistores:

$$
\begin{aligned}
& S_{1}=S_{2}=34,2 \cdot 10^{-3} \\
& S_{3}=S_{4}=1,14 \\
& S_{5}=0,35 \\
& S_{6 a}=3,11 \\
& S_{6 b}=0,42 \\
& S_{7 a}=0,47 \\
& S_{7 b}=3,5
\end{aligned}
$$


Correntes:

$$
\begin{aligned}
& I_{1}=I_{3}=0,6 \mu \mathrm{A} \\
& I_{2}=I_{4}=0,6 \mu \mathrm{A} \\
& I_{5}=1,2 \mu \mathrm{A} \\
& I_{6 a}=I_{7 a}=1,62 \mu \mathrm{A} \\
& I_{6 b}=I_{7 b}=12,0 \mu \mathrm{A}
\end{aligned}
$$

Tensões:

$$
\begin{aligned}
& V_{D S 5}=200 \mathrm{mV} \\
& V_{G S 5}=V_{B I A S}-V_{S S}=910 \mathrm{mV}
\end{aligned}
$$

A razão $(W / L)$ calculada para os transistores na verdade só pode assumir determinados valores, uma vez que as dimensões e sua precisão são limitadas pelo processo de fabricação. Assim, um transistor com $S=1$ e $L=0,35 \mu$ m na realidade tem as dimensões $L=0,35 \mu \mathrm{m}$ e $W=0,4$ (mínima), resultando em $S=1,14$; alternativamente, poderia fazer-se $L=W=0,4 \mu \mathrm{m}$. Nos resultados acima, mantiveram-se os valores sem a aproximação.

Outra observação é que, devido a essas limitações, razões de aspecto $S$ menores que a unitária resultam em $L>0,4 \mu \mathrm{m}$. É possível, durante o projeto, evitar estas relações, ampliando razões $S<1$ para $S=1$ e refazendo os cálculos, por exemplo. Esta alternativa também foi calculada; seu resultado é uma leve diminuição na área total do amplificador, mas um maior consumo de potência e relaxamento das especificações. $\mathrm{O}$ aumento de $L$ também traz algumas vantagens, como a diminuição da modulação do comprimento do canal $(\lambda)$ e redução do ruído $1 / f$ (flicker noise).

As alimentações foram dimensionadas prevendo o uso de espelhos de corrente. A capacitância de compensação foi dimensionada com uma pequena margem do valor mínimo estimado anteriormente. $\mathrm{O}$ ganho $A_{V}$ e a capacitância de carga $C_{L}$ foram tomados de valores típicos.

Para os valores calculados acima, a potência dissipada estimada é:

$$
\begin{aligned}
P_{\text {diss }}= & \left(I_{5}+I_{6}\right)\left(V_{D D}+\left|V_{S S}\right|\right) \\
& =(1,2+1,62) \cdot 10^{-6} \cdot(2,5+2,5)=14,1 \mu \mathrm{W}
\end{aligned}
$$

A área total $A$ (soma das áreas individuais) dos transistores é dada por: 


$$
A=\sum(W . L)_{i}=10,8 \mu \mathrm{m}^{2}
$$

E o ganho direto é calculado como

$$
A_{V}=\frac{2 \cdot g_{m 2} \cdot g_{m 6}}{I_{5}\left(\lambda_{2}+\lambda_{4}\right) I_{6}\left(\lambda_{6}+\lambda_{7}\right)}
$$

Com os valores de $\lambda$ mostrados abaixo

$$
\begin{aligned}
& \lambda_{2}=0,007 \\
& \lambda_{4}=0,08 \\
& \lambda_{6}=0,08 \\
& \lambda_{7}=0,01
\end{aligned}
$$

resulta em $A_{V} \approx 78 \mathrm{~dB}$.

\subsubsection{2 - espelhos de corrente}

Os espelhos de corrente foram projetados de acordo com as equações (4.1-17) e (4.1-18).

A tensão $V_{G S}$ do transistor Me.3, do espelho NMOS, equivale à diferença entre as alimentações $V_{S S 2} \mathrm{e} V_{S S 1}$. Para o espelho PMOS, $V_{G S}$ do transistor Me.1 equivale à diferença entre as alimentações $V_{D D 2} \mathrm{e} V_{D D 1}$. Com o valor de $V_{T}$ definido pela tecnologia e a corrente calculada, chega-se a:

$$
\begin{aligned}
& S_{e .1}=S_{e .2}=0,09 \\
& S_{e .3}=S_{e .4}=0,03
\end{aligned}
$$

Como o sinal deste subcircuito já tem uma faixa de tensão relativamente grande, a faixa de tensãod e entrada do segundo estágio foi feita igual à do primeiro estágio. Por esse motivo e pelo uso do $\mathrm{AO} 3$ como conversor de corrente, como explicado anteriormente, os três amplificadores serão iguais.

Chegou a ser considerada a idéia de se dispensar o amp-op AO3, usando apenas a saída de corrente do primeiro estágio; no entanto, resultados de simulações com essa configuração não foram satisfatórios. 


\subsubsection{3 - resistências}

Para o sensor de temperatura, a máxima tensão sobre a resistência $R$ será de 1,5V. Daí, pode-se estabelecer uma limitação de corrente $I_{(\max )}=0,5 \cdot I_{6}$ e calcular a resistência $R$ pela Lei de Ohm. Chegou-se a $R=R 2=1,85 \mathrm{M} \Omega$

A limitação de corrente deve ser tal que a corrente sobre $R$ não seja pequena demais (mais suscetível a ruídos e variações) nem drene corrente demais de $I_{6}$ (para não alterar a operação dos transistores). Esta limitação de $I_{(\max )}=0,5 . I_{6}$ foi estimada considerando tais aspectos.

A resistência pode ser dimensionada então pela equação (4.1-20). A camada mais indicada em termos de precisão e ruído é a camada POLY2. A resistividade dessa camada é de $50 \Omega / \square$, portanto:

$$
L / W=1,85 \cdot 10^{6} / 50=37.10^{3}
$$

que é uma razão realizável com $W=0,65 \mu \mathrm{m}$ e $L=24 \mathrm{~mm}$.

\subsection{2 - subcircuito: sensor de pressão}

A primeira parte do subcircuito é semelhante à do circuito do sensor de pressão. O resultado do cálculo dos dispositivos está mostrado a seguir.

\subsubsection{1 - amplificadores operacionais}

O projeto dos amplificadores operacionais deste circuito se deu de forma semelhante ao descrito para o subcircuito do sensor de temperatura. Algumas especificações, no entanto, são diferentes. Para o amplificador operacional AO3:

$$
\begin{aligned}
& A_{V} \geq 70 \mathrm{~dB} \\
& V_{D D}=2,5 \mathrm{~V} ; V_{S S}=-2,5 \mathrm{~V} \\
& 0 \mathrm{~V} \leq V_{\text {in }} \leq 1,5 \mathrm{~V} \\
& 0 \mathrm{~V} \leq V_{\text {out }} \leq 1,5 \mathrm{~V} \\
& C_{L}=10 \mathrm{pF} \\
& G B=3,16 \mathrm{MHz} \\
& S R=3,13 \mathrm{~V} / \mu \mathrm{S}
\end{aligned}
$$

Os resultados dos cálculos são os seguintes:

$$
C_{C}=2,4 \mathrm{pF}
$$


Dimensões dos transistores:

$$
\begin{aligned}
& S_{1}=S_{2}=1,78 \\
& S_{3}=S_{4}=1,14 \\
& S_{5}=0,054 \\
& S_{6 a}=22,48 \\
& S_{6 b}=7,53 \\
& S_{7 a}=0,49 \\
& S_{7 b}=1,46
\end{aligned}
$$

\section{Correntes:}

$$
\begin{aligned}
& I_{1}=I_{3}=3,75 \mu \mathrm{A} \\
& I_{2}=I_{4}=3,75 \mu \mathrm{A} \\
& I_{5}=7,5 \mu \mathrm{A} \\
& I_{6 a}=I_{7 a}=73,17 \mu \mathrm{A} \\
& I_{6 b}=I_{7 b}=218,4 \mu \mathrm{A}
\end{aligned}
$$

Tensões:

$$
\begin{aligned}
& V_{D S 5}=1,28 \mathrm{~V} \\
& V_{G S 5}=V_{B I A S}-V_{S S}=2,14 \mathrm{~V}
\end{aligned}
$$

Com os valores acima, calculou-se:

$$
\begin{aligned}
& P_{\text {diss }}=403 \mu \mathrm{W} \\
& A=6,8 \mu \mathrm{m}^{2} \\
& A_{v} \approx 80 \mathrm{~dB}
\end{aligned}
$$

O amp-op AO3 foi projetado com uma entrada de tensão que já prevê um ganho dado pelo primeiro estágio, para se aproveitar melhor a faixa de tensão possível para o amp-op. Esta escolha vai influenciar os cálculos do primeiro estágio e das resistências.

Os amplificadores AO1 e AO2 (iguais) podem ser diferentes de $\mathrm{AO} 3$, projetados para uma faixa de entrada menor. Seu projeto resultou nos seguintes valores:

$$
\begin{aligned}
& A_{V} \geq 70 \mathrm{~dB} \\
& V_{D D}=1,4 \mathrm{~V} ; V_{S S}=-1,4 \mathrm{~V} \\
& 0 \mathrm{~V} \leq V_{\text {in }} \leq 0,2 \mathrm{~V} \\
& 0 \mathrm{~V} \leq V_{\text {out }} \leq 0,2 \mathrm{~V} \\
& C_{L}=10 \mathrm{pF} \\
& G B=3,16 \mathrm{MHz}
\end{aligned}
$$




$$
\begin{aligned}
& S R=1,75 \mathrm{~V} / \mu \mathrm{S} \\
& C_{C}=2,4 \mathrm{pF}
\end{aligned}
$$

Dimensões dos transistores:

$$
\begin{aligned}
& S_{1}=S_{2}=3,18 \\
& S_{3}=S_{4}=1,14 \\
& S_{5}=0,84 \\
& S_{6 a}=29,82 \\
& S_{6 b}=18,83 \\
& S_{7 a}=11,03 \\
& S_{7 b}=17,67
\end{aligned}
$$

\section{Correntes:}

$$
\begin{aligned}
& I_{1}=I_{3}=2,1 \mu \mathrm{A} \\
& I_{2}=I_{4}=2,1 \mu \mathrm{A} \\
& I_{5}=4,2 \mu \mathrm{A} \\
& I_{6 a}=I_{7 a}=55,16 \mu \mathrm{A} \\
& I_{6 b}=I_{7 b}=87,35 \mu \mathrm{A}
\end{aligned}
$$

Tensões:

$$
\begin{aligned}
& V_{D S 5}=242 \mathrm{mV} \\
& V_{G S 5}=V_{B I A S}-V_{S S}=1,27 \mathrm{~V}
\end{aligned}
$$

Com os valores acima, calculou-se:

$$
\begin{aligned}
& P_{\text {diss }}=166,2 \mu \mathrm{W} \\
& A=6,3 \mu \mathrm{m}^{2} \\
& A_{v} \approx 80 \mathrm{~dB}
\end{aligned}
$$

Nota-se que as alimentações $V_{D D 1}$ e $V_{S S l}$ nesse caso foram projetadas para serem bastante menores que $\pm 3,3 \mathrm{~V}$. Isso foi feito pois, considerando que a faixa de entrada do sinal é bem pequena, há a possibilidade de se usar espelhos de corrente do tipo cascode. Assim, em cada espelho haverá um par de transistores com $V_{S B} \neq 0$. Portanto, foram calculados os valores de $V_{T}$ de cada transistor nos espelhos, fazendo-se uma solução de compromisso com as tensões necessárias ao próprio amp-op. 


\subsubsection{2 - espelhos de corrente}

A partir das equações (4.1-17) e (4.1-18), os transistores do espelho de corrente do amp-op AO3 têm as seguintes razões de aspecto:

$$
\begin{aligned}
& S_{e .1}=S_{e .2}=3,94 \\
& S_{e .3}=S_{e .4}=1,35
\end{aligned}
$$

Para os espelhos do amp-op AO2, chegou-se aos seguintes valores, para os espelho pM e nM (Figura 4.17(a) e (b), respectivamente):

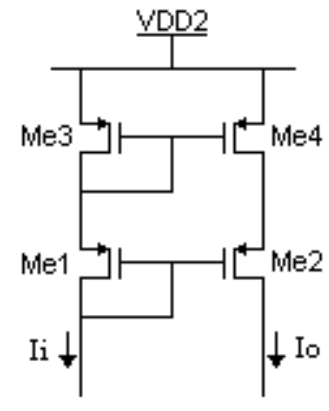

(a)

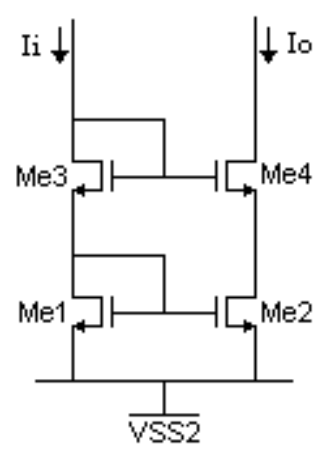

(b)

Figura 4.17 - espelhos de corrente cascode: (a) pM e (b) nM

Para pM:

$$
\begin{aligned}
& S e 1=S e 2=1,90 \\
& S e 3=S e 4=2,35 \\
& V_{O N I}=190 \mathrm{mV} \\
& V_{O N 3}=150 \mathrm{mV}
\end{aligned}
$$

Para nM:

$$
\begin{aligned}
& S e 1=S e 2=0,80 \\
& S e 3=S e 4=0,65 \\
& V_{O N I}=300 \mathrm{mV} \\
& V_{O N 3}=170 \mathrm{mV}
\end{aligned}
$$




\subsubsection{3 - resistências}

Para o sensor de pressão, a máxima tensão do sinal (que deve ser a maior tensão sobre a resistência $R$ ) será de $111,4 \mathrm{mV}$. Daí, pode-se estabelecer uma limitação aproximada de corrente $I_{(\max )}=10 \mu \mathrm{A}$, chegando-se a aproximadamente $R=11,5 \mathrm{k} \Omega$.

A resistência pode ser dimensionada, portanto, como:

$L / W=11,5.10^{3} / 50=230$

que é uma razão realizável com $W=0,65 \mu \mathrm{m}$ e $L=149,5 \mu \mathrm{m}$.

O ganho de tensão pode ser calculado a partir da tensão de entrada e a corrente por $R$ :

$$
R 2=1,5 / 10^{-6}=150 \mathrm{k} \Omega .
$$

Na camada POLY2, as dimensões são $W=0,65 \mu \mathrm{m}$ e $L=1950 \mu \mathrm{m}$. (Neste caso, a aproximação de $I$ já foi pensada com a possibilidade de se usar um resistor comercial para $R 2$.)

Os amp-ops $\mathrm{AO} 1$ e $\mathrm{AO} 2$ deste circuito podem ser, por simplicidade, iguais a AO3. Esta não deve ser a melhor opção, já que a entrada de $\mathrm{AO} 3$ varia na faixa de 1,5V, enquanto o sinal de pressão varia menos de $200 \mathrm{mV}$. Para esta configuração, as resistências seriam um pouco menores $(R=7,5 \mathrm{k} \Omega$ e $R 2=101 \mathrm{k} \Omega)$.

\subsection{3 - subcircuito: monitoramento da bateria}

Serão apresentados a seguir os cálculos para o dimensionamento do teste OCV alterado (seção 4.2.3.1), e para o amplificador de instrumentação (seção 4.2.3.2)

\subsubsection{1 - teste OCV}

Chamando de $\operatorname{Req}$ a resistência equivalente de $R_{1}$ e $R_{2}$ em paralelo, para que a tensão sobre $R_{l}$ e $R_{2}$ seja igual a $1,2 \mathrm{~V}$, a resistência $R_{d}$ e $R e q$ devem se relacionar como

$$
R_{d}=3 R_{e q}=3\left(R_{1} / / R_{2}\right)
$$

Escolheu-se, por simplicidade e para limitar a dissipação de potência no teste, $R_{e q}=24 \mathrm{k} \Omega$. Assim, limita-se a corrente $I$ circulando no circuito de teste a $50 \mu \mathrm{A}$, e temse $R_{d}=72 \mathrm{k} \Omega$. As resistências $R_{1}$ e $R_{2}$ podem ser iguais, encontrando-se, para esse valor 
de $R_{e q}, R_{l}=R_{2}=48 \mathrm{k} \Omega$. Entretanto, devido às preocupações em relação à chave analógica, explicadas no item 4.1.4.1, preferiu-se fazer $R_{1}<R_{2}$. Foram escolhidos $R_{1}=30 \mathrm{k} \Omega$ e $R_{2}=$ $120 \mathrm{k} \Omega$. Logo, $I_{1}=40 \mu \mathrm{A}$, e $I_{2}=10 \mu \mathrm{A}$.

Para o cálculo da resistência $r_{O N}$, considerou-se o substrato conectado ao terminal terra, portanto $V_{S B}=1,2 \mathrm{~V}$. Daí, foi seguido o seguinte procedimento:

1) cálculo de $V_{T}$ com o valor de $V_{S B}$;

2) cálculo de $r_{O N}$ com as tensões encontradas;

3) cálculo da tensão $V_{D S}$ a partir da resistência e da corrente fluindo pela chave

Daí, o valor de $V_{S B}$ é recalculado levando em conta a queda de tensão $V_{D S}$, e o procedimento é repetido, até se encontrar a resistência $r_{O N}$ para a operação. Então, foi calculada a resistência $R 2^{\prime}$ para ter-se $R_{2}=120 \mathrm{k} \Omega$.

Chegou-se a:

$$
\begin{aligned}
& r_{O N}=4 \mathrm{k} \Omega \\
& R 2^{\prime}=116 \mathrm{k} \Omega .
\end{aligned}
$$

Os valores acima foram calculados para $V_{\text {out }}=1,2 \mathrm{~V}$. Foi feito um cálculo dos mesmos valores para a resolução mínima (menor que $0,2 \mathrm{~V}$ ) e verificou-se que o erro relacionado à variação de $r_{O N}$ com a variação da tensão é aproximadamente a $7.10^{-3}$, que satisfaz à exigência especificada para a precisão do sinal amostrado.

A escolha da relação entre $R_{d}$ e $R_{e q}$ se justifica pela possibilidade de usar o mesmo circuito para a medição da tensão da bateria ou de apenas uma pilha. Assim, permite-se um teste como esboçado na figura abaixo (4.18)

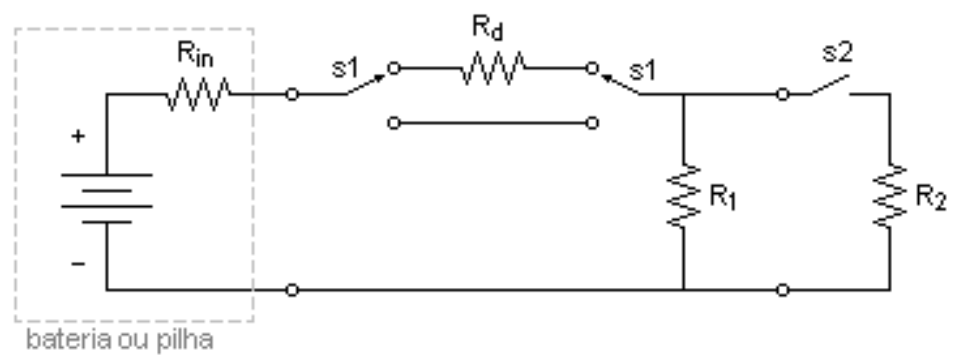

Figura 4.18 - monitoramento da tensão da bateria 
A chave $s 1$ permitiria escolher se a medição sendo feita é de uma bateria ou de uma pilha individual. Não há conhecimento o bastante no momento sobre o sistema de alimentação e a disposição das baterias no nó para se propor alguma solução mais detalhada neste ponto.

\subsubsection{2 - amplificador de instrumentação}

A tensão medida pelo teste acima passará por processamentos semelhantes aos dos sinais dos outros dois subcircuitos. O processamento realizado pelo amplificador de instrumentação pode ser feito com um IA como o do subcircuito do sensor de temperatura (ou o de pressão, se não usados $\mathrm{AO} 1$ e $\mathrm{AO} 2$ diferentes), devido às características muito semelhantes dos dois sinais, tanto em amplitude quanto em freqüência.

\subsection{4 - filtros}

A seguir estão apresentados os valores de $Q$, calculados comparando-se a equação (2.4-11) com a função de transferência do estágio, para cada estágio dos 3 filtros projetados (monitoramento da bateria, sensor de temperatura LM35 e sensor de pressão):

\begin{tabular}{|l|c|c|c|c|}
\hline & Estágio 1 & Estágio 2 & Estágio 3 & Estágio 4 \\
\hline Bateria & 0,54 & 1,31 & - & - \\
\hline LM35 & 0,58 & 1,78 & - & - \\
\hline Pressão & 0,55 & 0,92 & 1,79 & 5,80 \\
\hline
\end{tabular}

Tabela 4.1 - fator Q para cada filtro

Os valores de $\alpha$ obtidos para cada sistema estão listados (tabela 4.2). O segundo índice indica o estágio. Em alguns casos, apesar de $Q<5$, foram calculados os coeficientes pelo modelo de alto Q também. Isto às vezes é feito em circuitos SC para se reduzir a capacitância total do circuito, mas implica alguns riscos. Estes casos estão indicados por $\alpha_{\mathrm{ijh}}$; o índice $h$ indica o cálculo considerando Q alto. 


\begin{tabular}{|l|l|l|l|l|l|l|}
\hline Circuito & $\boldsymbol{\alpha}_{\mathbf{1}}$ & $\boldsymbol{\alpha}_{\mathbf{2}}$ & $\boldsymbol{\alpha}_{\mathbf{3}}$ & $\boldsymbol{\alpha}_{\mathbf{4}}$ & $\boldsymbol{\alpha}_{\mathbf{5}}$ & $\boldsymbol{\alpha}_{\mathbf{6}}$ \\
\hline Bateria & $\alpha_{11}=0,06434$ & $\alpha_{21}=0,06434$ & $\alpha_{31}=0$ & $\alpha_{41}=0$ & $\alpha_{51}=0,06434$ & $\alpha_{61}=0,11889$ \\
& $\alpha_{12}=0,06434$ & $\alpha_{22}=0,06434$ & $\alpha_{32}=0$ & $\alpha_{42}=0$ & $\alpha_{52}=0,06434$ & $\alpha_{62}=0,04924$ \\
& $\alpha_{12 \mathrm{~h}}=0,06434$ & $\alpha_{22 \mathrm{~h}}=0,06434$ & $\alpha_{32 \mathrm{~h}}=0$ & $\alpha_{42 \mathrm{~h}}=0,7654$ & $\alpha_{52 \mathrm{~h}}=0,06434$ & $\alpha_{62 \mathrm{~h}}=0$ \\
\hline LM35 & $\alpha_{11}=0,06893$ & $\alpha_{21}=0,06893$ & $\alpha_{31}=0$ & $\alpha_{41}=0$ & $\alpha_{51}=0,06893$ & $\alpha_{61}=0,11898$ \\
& $\alpha_{12}=0,08762$ & $\alpha_{22}=0,08762$ & $\alpha_{32}=0$ & $\alpha_{42}=0$ & $\alpha_{52}=0,08762$ & $\alpha_{62}=0,04928$ \\
& $\alpha_{11 \mathrm{~h}}=0,08762$ & $\alpha_{21 \mathrm{~h}}=0,08762$ & $\alpha_{31 \mathrm{~h}}=0$ & $\alpha_{41 \mathrm{~h}}=0,56244$ & $\alpha_{51 \mathrm{~h}}=0,08762$ & $\alpha_{61 \mathrm{~h}}=0$ \\
\hline Pressão & $\alpha_{11}=0,05239$ & $\alpha_{21}=0,05239$ & $\alpha_{31}=0$ & $\alpha_{41}=0$ & $\alpha_{51}=0,5239$ & $\alpha_{61}=0,09529$ \\
& $\alpha_{12}=0,07401$ & $\alpha_{22}=0,07401$ & $\alpha_{32}=0$ & $\alpha_{42}=0$ & $\alpha_{52}=0,07401$ & $\alpha_{62}=0,08078$ \\
& $\alpha_{13}=0,09759$ & $\alpha_{23}=0,09759$ & $\alpha_{33}=0$ & $\alpha_{43}=0$ & $\alpha_{53}=0,09759$ & $\alpha_{63}=0,05398$ \\
& $\alpha_{14}=0.10989$ & $\alpha_{24}=0.10989$ & $\alpha_{34}=0$ & $\alpha_{44}=0.17248$ & $\alpha_{54}=0.10989$ & $\alpha_{64}=0$ \\
\hline
\end{tabular}

Tabela 4.2 - coeficientes $\alpha$ dos biquads SC

Para os circuitos do LM35 e para o monitoramento da bateria, onde a banda do sinal a ser considerada é de $10 \mathrm{~Hz}$, a freqüência do relógio escolhida foi $976,56 \mathrm{~Hz}$ (igual a $1 / 2^{14} \cdot 16 \mathrm{MHz}$ ). Para o circuito do sensor de pressão, cujo sinal pode chegar a $1 \mathrm{kHz}$, a freqüência do relógio escolhida foi $62,5 \mathrm{kHz}\left(1 / 2^{8} .16 \mathrm{MHz}\right)$.

O dimensionamento dos filtros SI foi realizado a princípio para se ter uma saída uma corrente desejada e para manter os transistores operando na saturação. Então, tanto transistores quanto fontes de corrente eram dimensionado proporcionalmente aos coeficientes $\alpha$, calculados anteriormente. Entretanto, devido aos baixos valores de $\alpha$, ter a corrente de saída de $10 \mu \mathrm{A}$ (especificação do conversor $\mathrm{A} / \mathrm{D}$ ) resultava em correntes de entrada mínimas. Então, os cálculos foram realizados considerando, para cada circuito, as relações entre os $\alpha$ 's, a corrente de saída e de entrada. Os resultados estão mostrados na tabela 4.3, de acordo com a Figura 4.13. 


\begin{tabular}{|c|l|l|l|l|l|l|l|l|}
\cline { 2 - 9 } \multicolumn{1}{c|}{} & \multicolumn{3}{c|}{ Bateria } & \multicolumn{2}{c|}{ Temperatura } & \multicolumn{4}{c|}{ Pressão } \\
\cline { 2 - 9 } \multicolumn{1}{c|}{} & $\begin{array}{c}\text { Estágio } \\
\mathbf{1}\end{array}$ & $\begin{array}{c}\text { Estágio } \\
\mathbf{2}\end{array}$ & $\begin{array}{c}\text { Estágio } \\
\mathbf{1}\end{array}$ & $\begin{array}{c}\text { Estágio } \\
\mathbf{2}\end{array}$ & $\begin{array}{c}\text { Estágio } \\
\mathbf{1}\end{array}$ & $\begin{array}{c}\text { Estágio } \\
\mathbf{2}\end{array}$ & $\begin{array}{c}\text { Estágio } \\
\mathbf{3}\end{array}$ & $\begin{array}{c}\text { Estágio } \\
\mathbf{4 ( H )}\end{array}$ \\
\hline Iout & $40 \mu \mathrm{A}$ & $40 \mu \mathrm{A}$ & $40 \mu \mathrm{A}$ & $40 \mu \mathrm{A}$ & $40 \mu \mathrm{A}$ & $40 \mu \mathrm{A}$ & $40 \mu \mathrm{A}$ & $10 \mu \mathrm{A}$ \\
\hline I & $80 \mu \mathrm{A}$ & $80 \mu \mathrm{A}$ & $80 \mu \mathrm{A}$ & $80 \mu \mathrm{A}$ & $80 \mu \mathrm{A}$ & $80 \mu \mathrm{A}$ & $80 \mu \mathrm{A}$ & $20 \mu \mathrm{A}$ \\
\hline S1.1 & 0,94 & 0,94 & 0,94 & 0,94 & 0,94 & 0,94 & 0,94 & 0,24 \\
\hline S2.1 & 0,94 & 0,94 & 0,94 & 0,94 & 0,94 & 0,94 & 0,94 & 0,24 \\
\hline S3.1 & 2,28 & 2,28 & 2,28 & 2,28 & 2,28 & 2,28 & 2,28 & 0,57 \\
\hline S4.1 & 2,28 & 2,28 & 2,28 & 2,28 & 2,28 & 2,28 & 2,28 & 0,57 \\
\hline S5.1 & 0,15 & 0,15 & 0,16 & 0,20 & 0,12 & 0,17 & 0,22 & 0,063 \\
\hline S1.2 & 0,94 & 0,94 & 0,94 & 0,94 & 0,94 & 0,94 & 0,94 & 0,24 \\
\hline S2.2 & 0,94 & 0,94 & 0,94 & 0,94 & 0,94 & 0,94 & 0,94 & 0,24 \\
\hline S3.2 & 2,28 & 2,28 & 2,28 & 2,28 & 2,28 & 2,28 & 2,28 & 0,57 \\
\hline S4.2 & 2,28 & 2,28 & 2,28 & 2,28 & 2,28 & 2,28 & 2,28 & 0,57 \\
\hline S5.2 & 0,15 & 0,15 & 0,16 & 0,20 & 0,12 & 0,17 & 0,22 & 0,063 \\
\hline S6.2 & 0,27 & 0,028 & 0,27 & 0,11 & 0,22 & 0,18 & 0,12 & 0,098 \\
\hline S7.2 & $0,15^{*}$ & 2,28 & $0,20^{*}$ & 2,28 & $0,17^{*}$ & $0,22^{*}$ & $0,25^{*}$ & 0,57 \\
\hline lin & $2,57 \mu \mathrm{A}$ & & $2,72 \mu \mathrm{A}$ & & & & & $1,1 \mu \mathrm{A}$ \\
\hline
\end{tabular}

Os valores de S7 marcados com * já são apresentados com o dimensionamento adequado para a entrada do estágio seguinte.

Tabela 4.3 - dimensões e correntes dos filtros SI

\section{3 - Procedimentos de teste}

Os testes desses circuitos foram feitos principalmente por simulações computacionais, que utilizam um modelo para o comportamento do transistor bastante complexo e aprofundado. O fabricante usa o mesmo modelo para a simulação do comportamento de seus dispositivos.

Esse modelo, chamado BSIM3v3 (de Berkeley Short-Channel IGFET Model), leva em conta vários fenômenos não abordados pelo modelo utilizado para os cálculos dos dispositivos do projeto, apresentados na seção anterior (chamado de SPICE LEVEL 1), que é um modelo apropriado para cálculos à mão; dá uma boa idéia do comportamento dos transistores e permite uma compreensão intuitiva de vários fenômenos. O modelo SPICE (Simulation Program with Integrated Circuits Emphasis) LEVEL 1 não considera, entretanto, alguns fenômenos que só são relevantes em 
geometrias bastante reduzidas, tipicamente abaixo de $1 \mu \mathrm{m}$ - o que é o caso da maioria dos dispositivos deste projeto.

O modelo BSIM3v3 é, portanto, mais apropriado e prevê mais precisamente o comportamento do circuito real. Entretanto, o cálculo preliminar utilizando o BSIM3v3 é inviável - enquanto o SPICE LEVEL 1 modela o transistor por 5 parâmetros (os da tabela 3.1), no BSIM3v3 são 154 parâmetros [41]. O procedimento que foi feito (que é o feito usualmente para projetos com características similares) para o desenho dos circuitos foi o cálculo preliminar com o modelo simplificado, seguido de simulações com o modelo avançado. As simulações permitem análise de comportamento DC, para verificarem-se os pontos de operação dos dispositivos; análise transiente, que simula o comportamento dos circuitos excitados por um sinal de entrada AC; e outras análises diversas de vários aspectos do sistema.

Foi utilizado o ambiente de projeto da Cadence Design Systems, que tem entre suas ferramentas o simulador Spectre e o editor de esquemáticos Virtuoso. Ambos dispõem de bibliotecas de arquivos que descrevem as características de fabricação da tecnologia utilizada pela Austria Microsystems. Os softwares estão disponíveis, no Departamento de Engenharia Elétrica da Universidade de Brasília, no LPCI Laboratório de Projeto de Circuitos Integrados, e no LTSD - Laboratório de Tratamento de Superfícies e Dispositivos. Após a fabricação do chip, serão feitos testes de funcionamento e características do SoC, para verificar os principais aspectos previstos nas simulações. 


\section{5 - RESULTADOS E DISCUSSÃO}

Os resultados obtidos são computacionais, como explicado acima. Serão expostos neste capítulo algumas imagens dos esquemáticos dos circuitos e das simulações, obtidas nos laboratórios, e serão discutidos esses resultados.

\section{1 - simulações}

As simulações foram feitas por blocos, para que se analisasse cada parte separadamente e fosse possível ter uma idéia mais clara da influência de cada bloco no sistema. Em situações como as alimentações dos amplificadores operacionais de tensão mais baixa que as alimentações do sistema, os amplificadores foram simulados com fontes próximas das ideais, e as referências de tensão simuladas separadamente. Só então são feitas as simulações com todos os blocos.

\subsection{1 - amplificador operacional}

A simulação do amp-op do subcircuito do sensor de pressão (AO3) ilustra bem a questão da diferença entre o modelo simplificado e o modelo BSIM3v3. Com as referências e dimensões calculadas (Figura 5.1), a análise DC mostrou o amp-op operando quase da maneira prevista, com alguma diferença em tensões, em geral menores que 0,2V. Essas diferenças, entretanto, foram suficientes para alterar significativamente o comportamento do amp-op, uma vez que o transistor M5 operava na região de não-saturação. A Figura 5.2, obtida do simulador, mostra essa operação. 


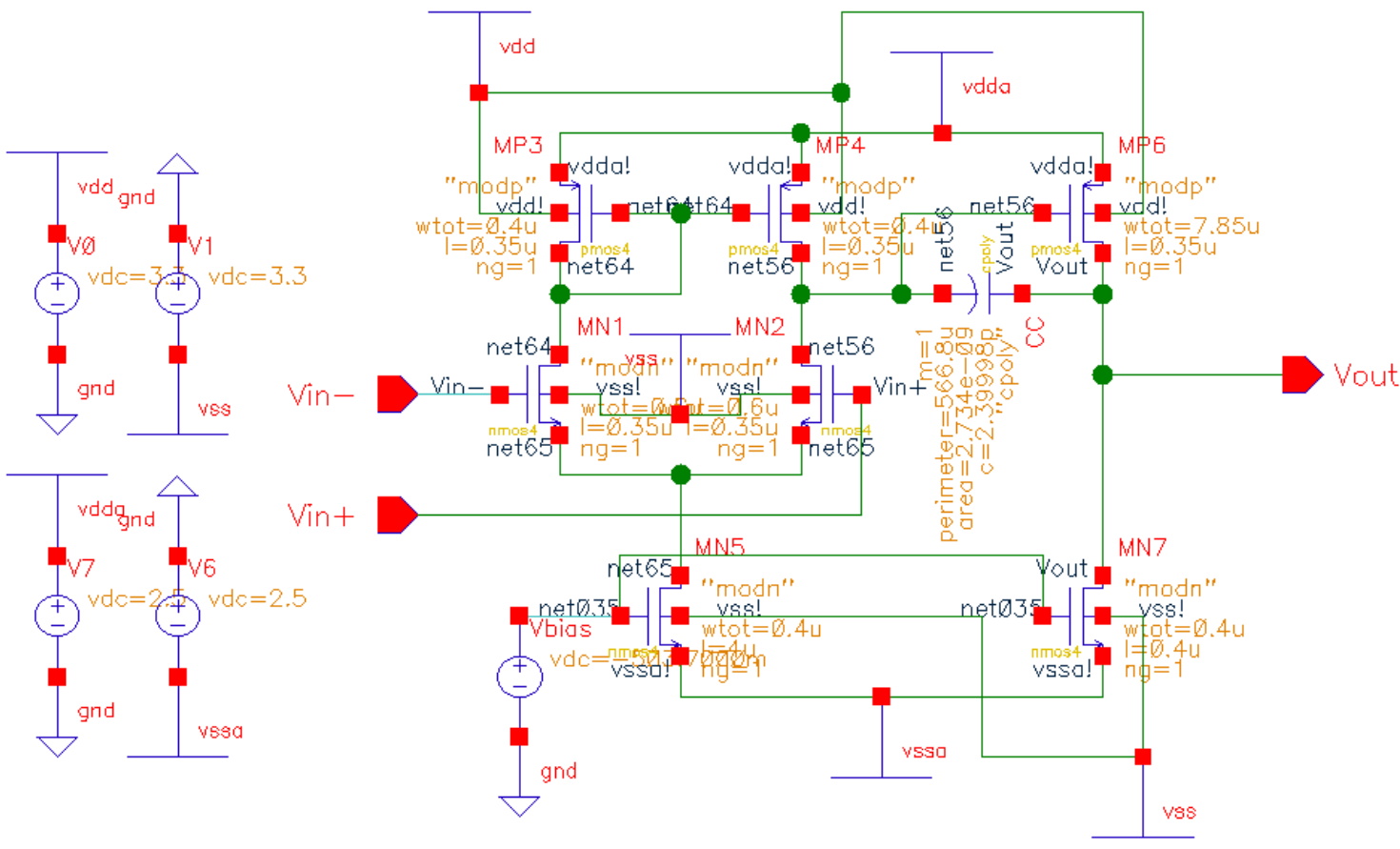

Figura 5.1 - Esquemático do amp-op (Virtuoso Schematic Editor)

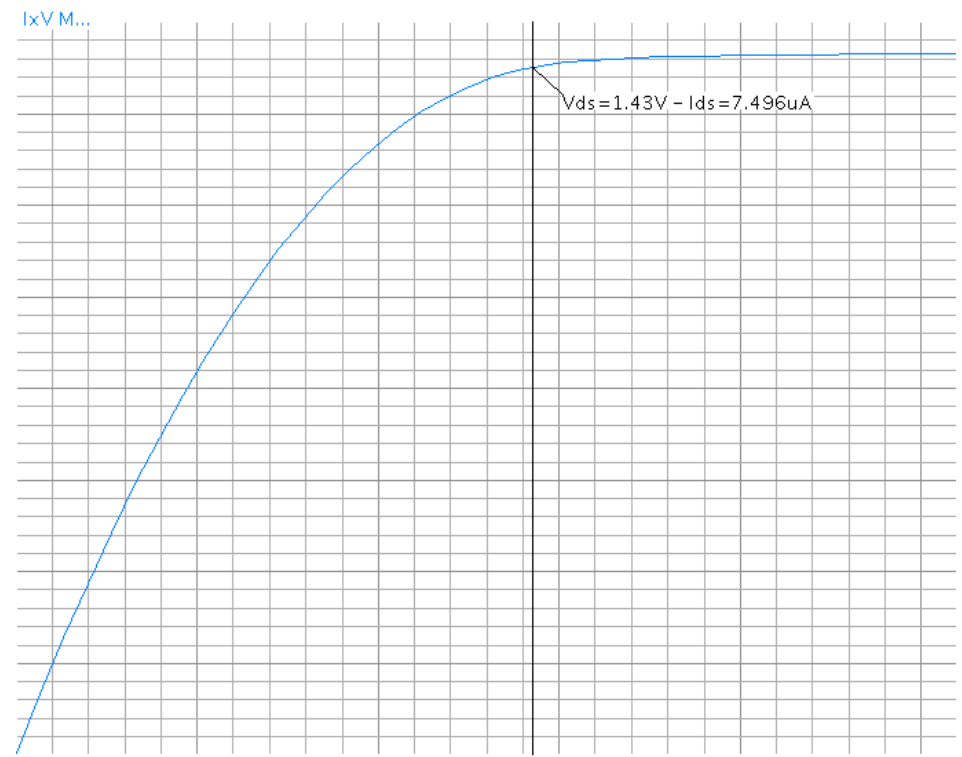

Figura 5.2 - operação de M5, não saturado

A Figura 5.1 mostra o esquemático do $\mathrm{AO} 3$ calculado, conforme desenhado no editor de esquemáticos Virtuoso (as cores estão alteradas). As fontes de tensão à esquerda representam as duas referências de tensão, $V_{D D 1}=\mathrm{vdda}=2,5 \mathrm{~V}$ e $V_{D D 2}=\mathrm{vdd}=$ 
3,3V. Pode-se notar que, para a análise DC, o circuito não é excitado com um sinal de entrada.

Com o auxílio do simulador, foram então ajustados algumas dimensões e pontos de operação. A figura abaixo (5.3) mostra alguns dos valores de tensão e corrente pertinentes da análise DC do amp-op, já corrigido.

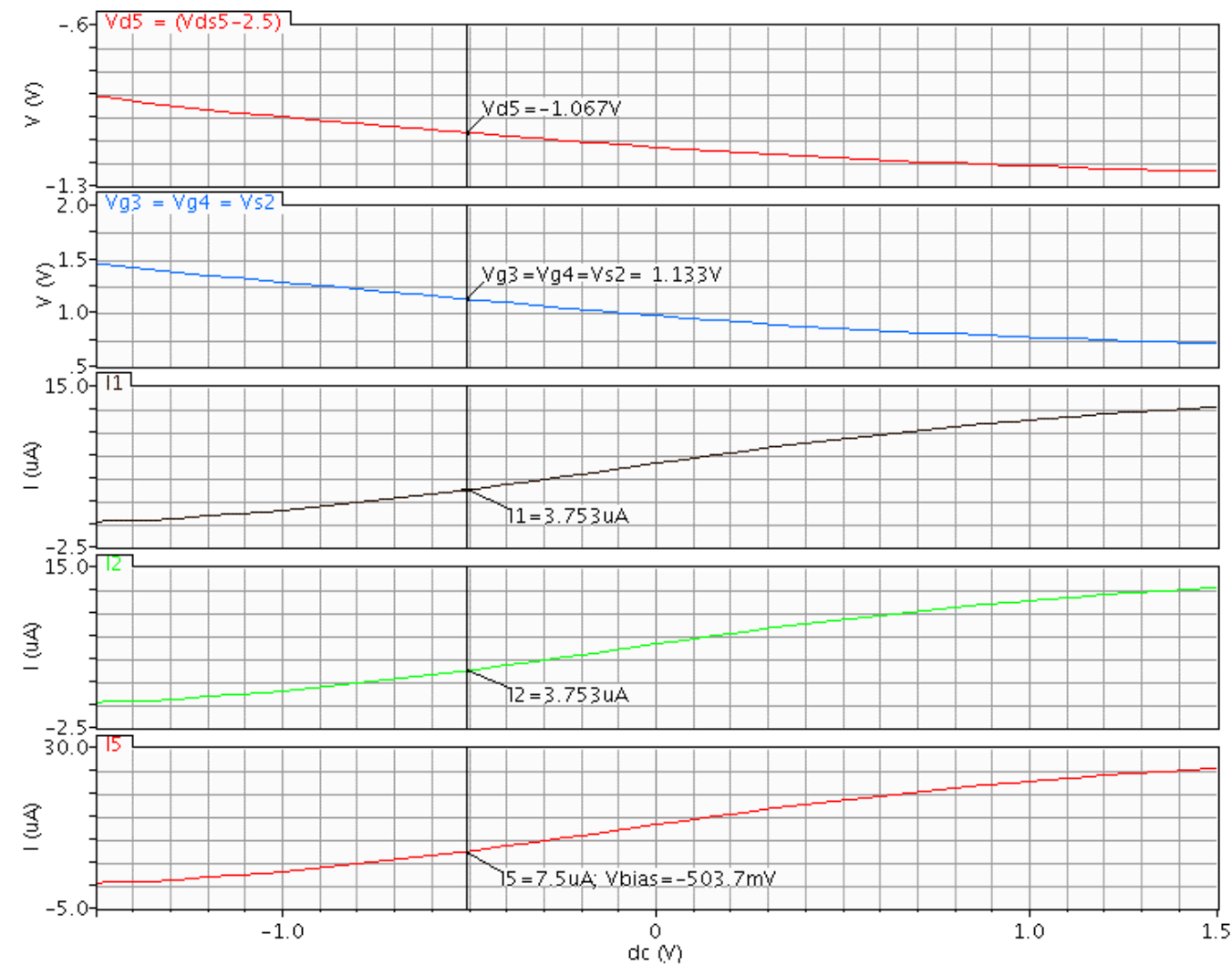

Figura 5.3 - alguns valores de tensão e corrente na operação do amp-op

Esta simulação mostrou, entre outros aspectos, a simetria entre $I_{1}$ e $I_{2}$. A tensão $V_{D S 5}$, calculada em $1,28 \mathrm{~V}$, foi obtida na simulação, para a operação desejada, como 1,43V . A tensão $V_{B I A S}$, calculada em $-360 \mathrm{mV}$ (em relação ao terra), foi corrigida pela simulação para $-503.7 \mathrm{mV}$.

Foram realizados então testes para as principais características do amp-op. Estes estão apresentados a seguir, com breves descrições. São alguns dos testes que visam à caracterização de amplificadores operacionais, por simulações, medições, ou ambos. No caso, foram aplicados somente os de simulação. 


\subsubsection{1 - malha aberta}

A simulação do ganho de malha aberta - e outras características de malha aberta - é feita, para que a saída não sature, aplicando-se um sinal muito pequeno na entrada, já que o ganho diferencial de malha aberta é, espera-se, muito grande.

O primeiro passo para este tipo de teste é encontrar a tensão $V_{O S}$ que, aplicada à entrada, como mostra a Figura 5.4, mantém a saída em malha aberta na região linear (i.e., evita que a saída sature).

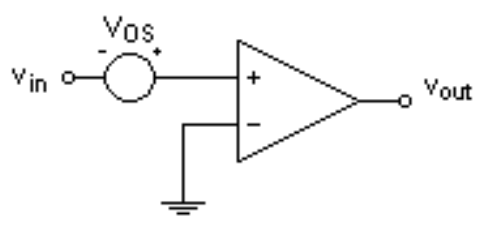

Figura 5.4 - aplicação de $V_{O S}$

Considerando $V_{O S}$, a tensão de saída $V_{o u t}$ do amp-op, em malha aberta, fica

$$
V_{\text {out }}=A_{v}\left(V_{2}-V_{1}+V_{O S}\right)
$$

$V_{O S}$ foi encontrada variando-se a tensão na entrada e monitorando-se a saída, como mostra a Figura 5.5.

O ganho diferencial de malha aberta $A_{v}$ foi encontrado, então, aplicando-se uma tensão pequena $( \pm 1 \mu \mathrm{V}, 1 \mathrm{~Hz})$, em série com $V_{O S}$, à entrada não-inversora e medindo-se a saída (Figura 5.6); o ganho é a relação entre a entrada e a saída. A primeira tentativa resultou em um ganho menor que o especificado. Alguma diferença do comportamento era prevista, devido às diferenças de modelagem já explicadas. 


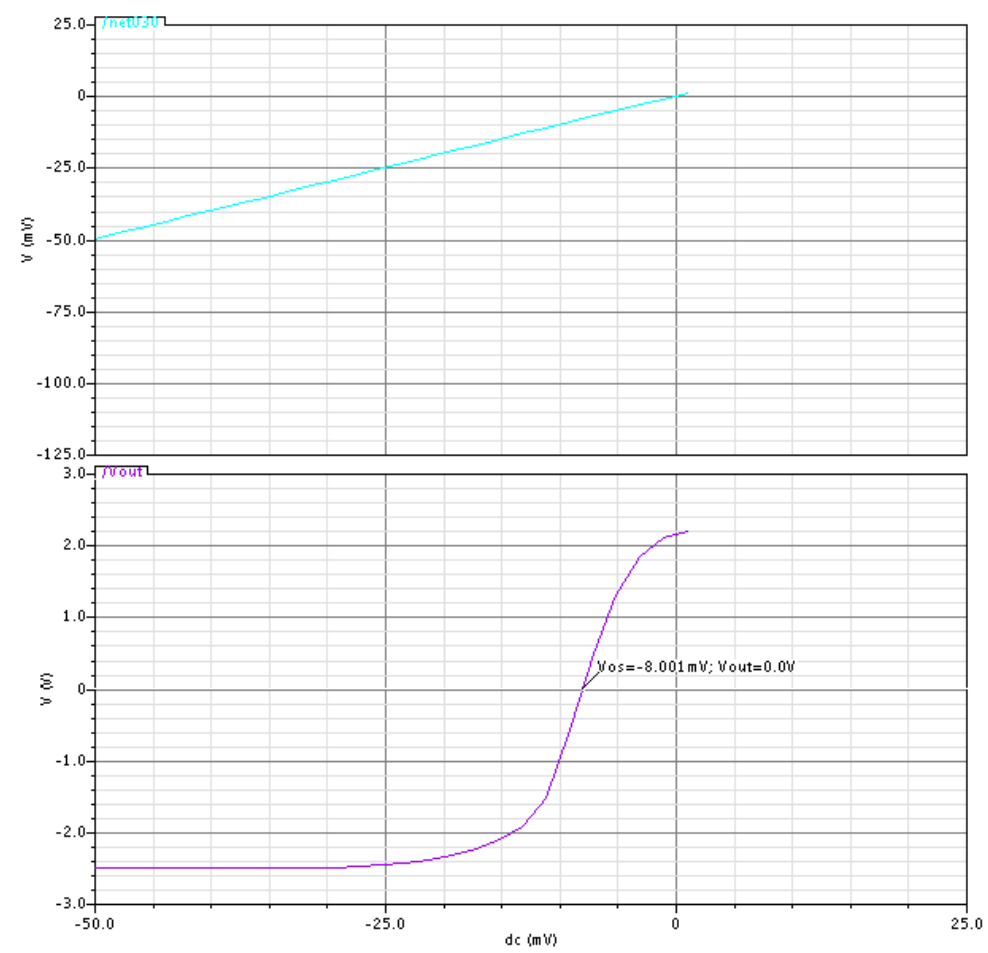

Figura 5.5 - simulação para encontrar $\mathrm{V}_{\mathrm{OS}}$

Foram então feitas alterações no amp-op, ampliando-se proporcionalmente $W$ e $L$ de alguns transistores. O aumento proporcional mantém as razões $S$, enquanto o aumento de $L$ permite o aumento do ganho em malha aberta. A tensão $V_{O S}$ foi então medida novamente, e chegou-se a:

$$
\begin{aligned}
& V_{O S}=62,64 \mu \mathrm{V} \\
& A_{v}=\frac{(4,71+4,70) \cdot 10^{-3}}{2 \cdot 10^{-6}}=73,4 \mathrm{~dB}
\end{aligned}
$$




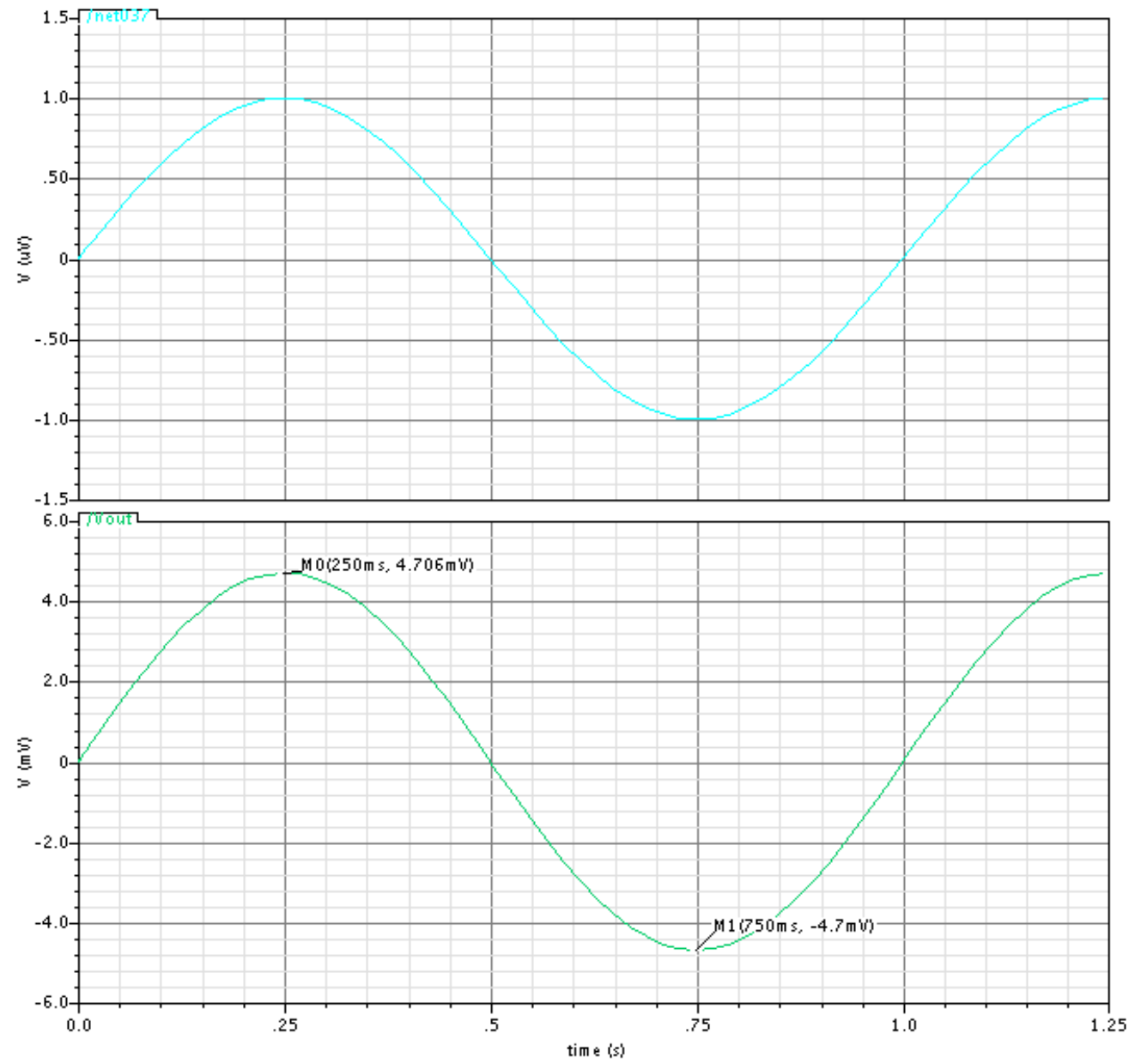

Figura 5.6 - medida do ganho diferencial de malha aberta

O ganho de modo-comum $A_{c}$ foi encontrado de maneira semelhante, mas aplicando-se o sinal de entrada tanto à entrada não-inversora quanto à entrada inversora. Chegou-se a $A_{c}=-14,3 \mathrm{~dB}$ (Figura 5.7). Com esses valores, calcula-se a CMRR do ampop:

$$
\begin{aligned}
C M R R & =\frac{A_{v}}{A_{c}}=\left(A v-A_{c}\right)[\mathrm{dB}] \\
& =87,7 \mathrm{~dB}
\end{aligned}
$$




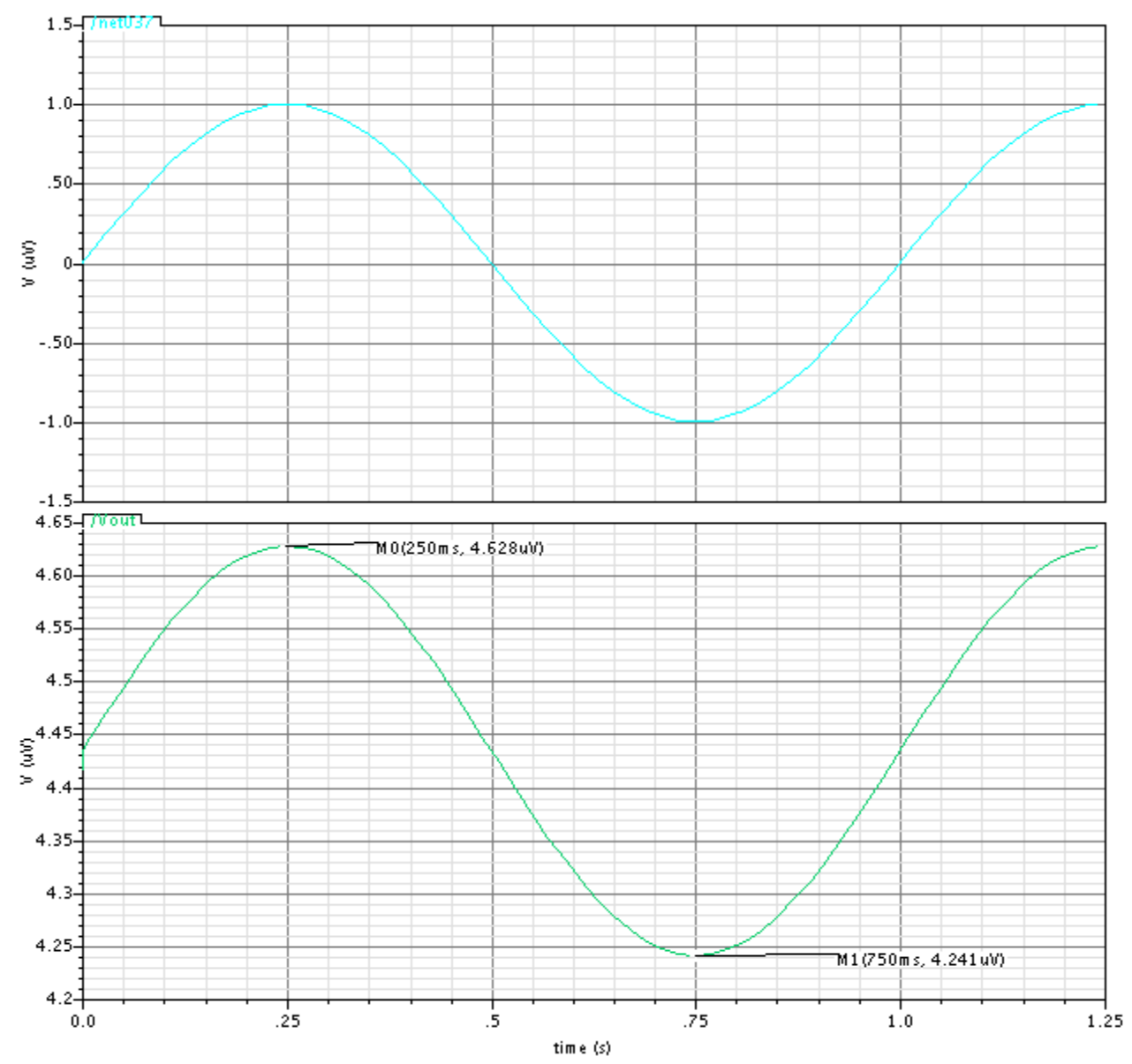

Figura 5.7 - medida do ganho em modo comum

\subsubsection{2 - impedância de saída}

Com um sinal pequeno na entrada, variou-se uma carga de saída $R_{L}$ e foi medida a tensão sobre $R_{L}$; calculada a transferência de potência para vários pontos, a resistência de saída $R_{O U T}$ é igual a $R_{L}$ quando a transferência de potência é máxima. Durante a medição a intervalos razoáveis, tem-se a noção de a transferência de potência estar diminuindo ou aumentando; pode-se assim ir limitando o intervalo até encontrar o valor desejado.

A tabela 5.1 mostra alguns dos valores medidos para a obtenção de $R_{\text {OUT }}$. Entre os valores de $71 \mathrm{k} \Omega$ e $72 \mathrm{k} \Omega$, um cálculo com mais precisão mostra que

$$
R_{O U T}=72 \mathrm{k} \Omega \text {. }
$$




\begin{tabular}{|l|l|l|}
\hline \multicolumn{1}{|c|}{$\mathbf{R}_{\mathbf{L}}(\mathbf{\Omega})$} & \multicolumn{1}{c|}{$\mathbf{V}_{\mathbf{L}}(\mathbf{V})$} & \multicolumn{1}{c|}{$\mathbf{P}(\mathbf{W})$} \\
\hline $1 \mathrm{k}$ & $216,3 \mu$ & $46,8.10^{-12}$ \\
\hline $10 \mathrm{k}$ & $1,925 \mathrm{~m}$ & $3,71.10^{-10}$ \\
\hline $50 \mathrm{k}$ & $6,461 \mathrm{~m}$ & $8,35.10^{-10}$ \\
\hline $70 \mathrm{k}$ & $7,769 \mathrm{~m}$ & $8,622.10^{-10}$ \\
\hline $\mathbf{7 1 k}$ & $\mathbf{7 , 8 2 5 m}$ & $\mathbf{8 , 6 2 4 . 1 0 ^ { - 1 0 }}$ \\
\hline $\mathbf{7 2 k}$ & $\mathbf{7 , 8 8 0 m}$ & $\mathbf{8 , 6 2 4 . 1 0 ^ { - 1 0 }}$ \\
\hline $73 \mathrm{k}$ & $7,934 \mathrm{~m}$ & $8,623.10^{-10}$ \\
\hline $75 \mathrm{k}$ & $8,040 \mathrm{~m}$ & $8,619.10^{-10}$ \\
\hline $90 \mathrm{k}$ & $8,753 \mathrm{~m}$ & $8,51.10^{-10}$ \\
\hline $100 \mathrm{k}$ & $9,159 \mathrm{~m}$ & $8,39.10^{-10}$ \\
\hline $150 \mathrm{k}$ & $10,64 \mathrm{~m}$ & $7,55.10^{-10}$ \\
\hline $200 \mathrm{k}$ & $11,58 \mathrm{~m}$ & $6,71.10^{-10}$ \\
\hline
\end{tabular}

Tabela 5.1 - medição de RoUT

\subsubsection{3 - faixa de modo comum}

A ICMR (input common-mode range) foi medida com o amp-op configurado como seguidor de tensão, variando a entrada de tensão e medindo a saída para verificar se havia distorção. A tabela 5.2 mostra alguns valores de entrada e seu efeito sobre a tensão de saída máxima (CMR +) e mínima (CMR -).

\begin{tabular}{|c|l|l|}
\hline Entrada & \multicolumn{1}{|c|}{ CMR + } & \multicolumn{1}{c|}{ CMR - } \\
\hline $\pm 1 \mathrm{~V}$ & não distorce & não distorce \\
\hline $\pm 1,2 \mathrm{~V}$ & não distorce & não distorce \\
\hline $\pm 1,5 \mathrm{~V}$ & não distorce & diferença de $1 \mathrm{mV}$ \\
\hline $\pm 2,0 \mathrm{~V}$ & diferença de $1 \mathrm{mV}$ & diferença de $3 \mathrm{mV}$ \\
\hline $\pm 2,2 \mathrm{~V}$ & diferença de $2 \mathrm{mV}$ & distorce (Figura 5.8) \\
\hline $\pm 2,4 \mathrm{~V}$ & distorce (Figura 5.9) & distorce (Figura 5.9) \\
\hline
\end{tabular}

Tabela 5.2 - medição da CMR 
As figuras indicadas são mostradas abaixo. A onda verde representa a saída e a onda azul, a entrada.

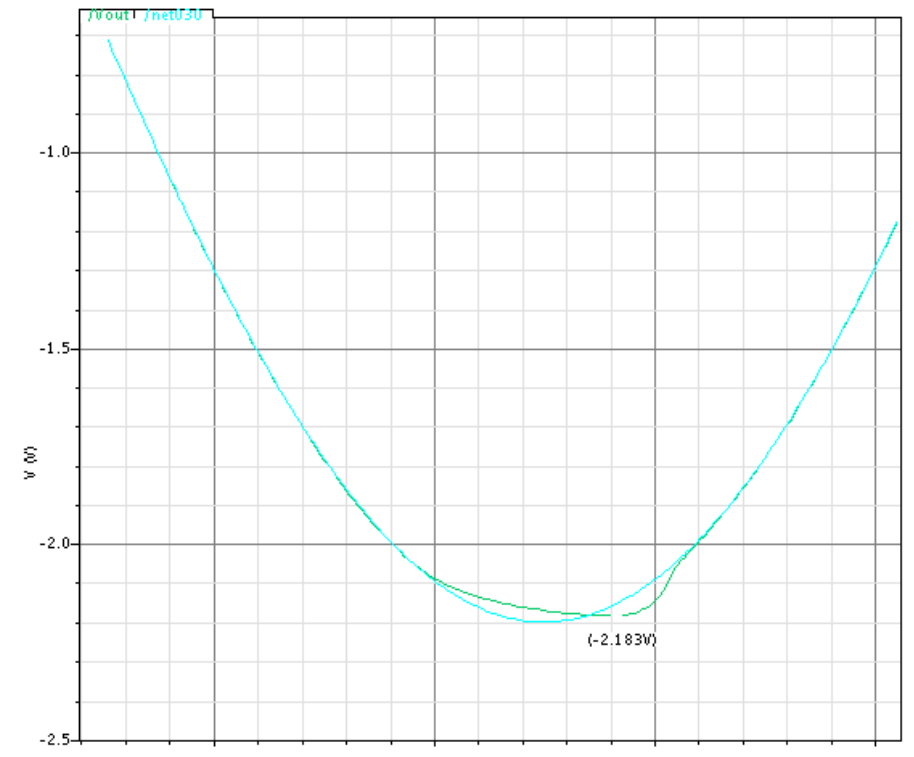

Figura 5.8 - distorção da saída para entrada de -2,2V

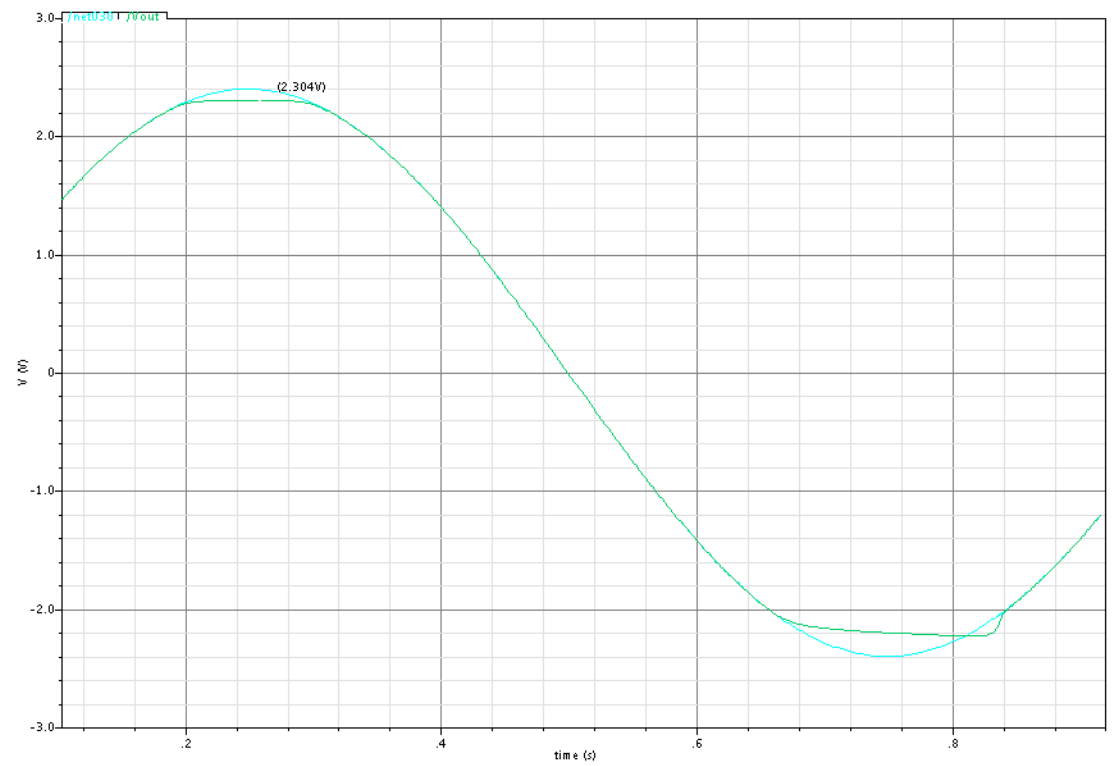

Figura 5.9 - distorção da saída para entrada de $\pm 2,4 \mathrm{~V}$ 
Para a configuração de ganho unitário, como acima, a entrada limita a linearidade da curva de transferência. Já para configurações com ganho alto, a linearidade é correspondente à faixa de saída de tensão do amplificador [4]. Para a medição da faixa de saída, portanto, foi usada uma configuração inversora de ganho 10 (Figura 5.10). Foram utilizados $R_{L}=10 \mathrm{k} \Omega$ e $R=500 \mathrm{k} \Omega$ (com $R_{L}$ baseado nas resistências utilizadas nos amplificadores de instrumentação). A Figura 5.11 ilustra a faixa de tensão de saída, com ampliações feitas nas regiões onde a faixa linear termina.

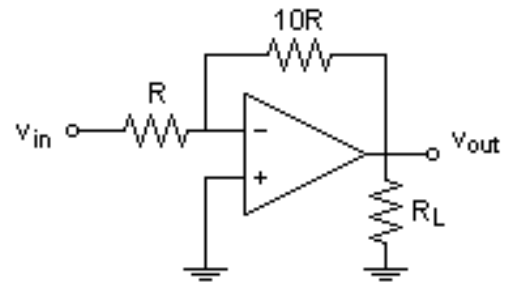

Figura 5.10 - amplificador inversor de ganho 10
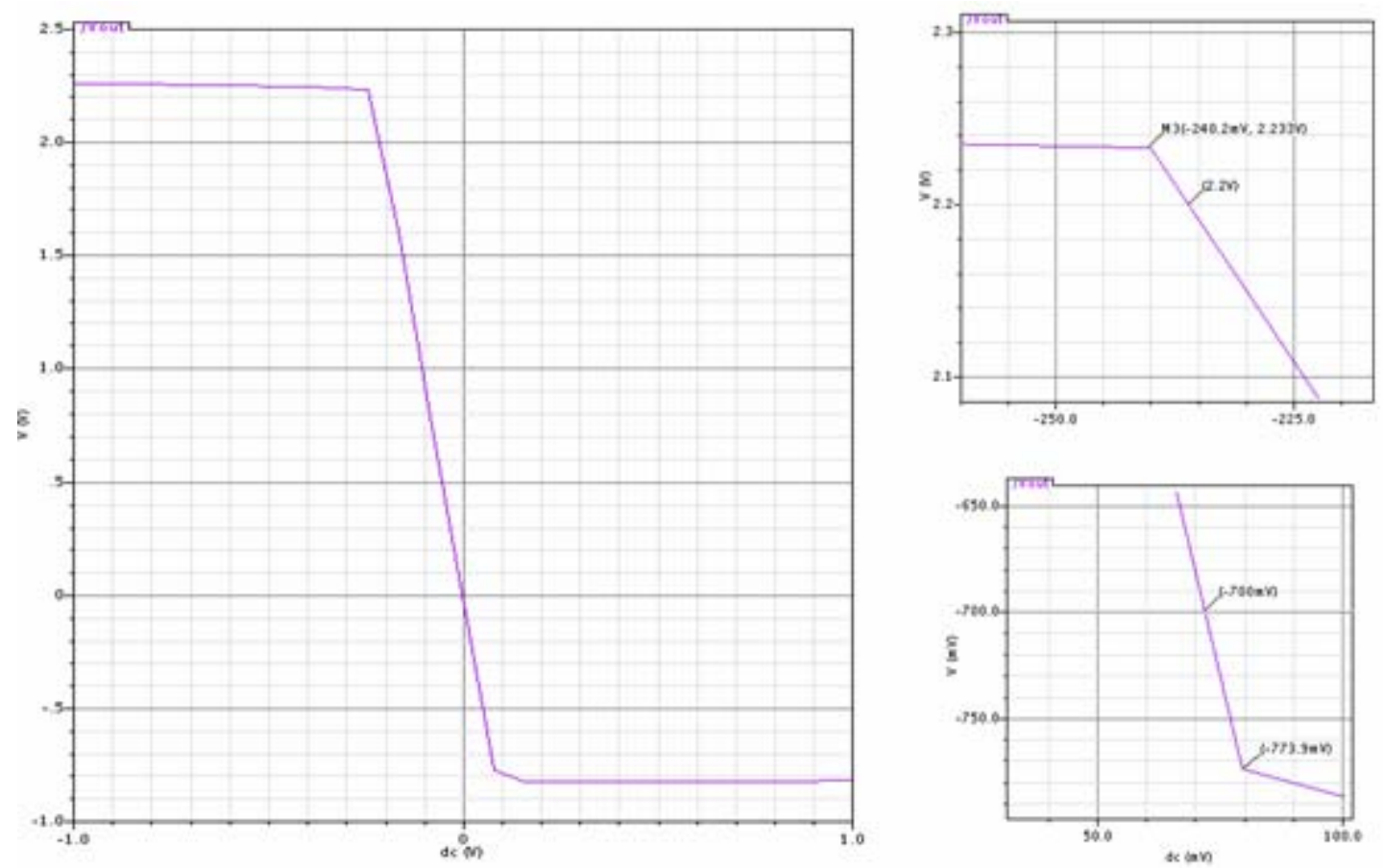

Figura 5.11 - faixa de tensão de saída 
Com este procedimento, chegou-se aos seguintes valores de CMR:

$-1,2 \mathrm{~V} \leq V_{\text {in }} \leq 2,0 \mathrm{~V}$

$-0,75 \leq V_{\text {out }} \leq 2,2 \mathrm{~V}$

\subsubsection{4 - PSRR}

A PSRR (power supply rejection ratio) é uma medida da variação da resposta do amp-op em conseqüência de uma variação na alimentação. Sua simulação é feita acrescentando uma pequena tensão à alimentação (ou seja, conectando uma fonte de tensão de pequena amplitude em série série entre a alimentação e o amplificador). Fazem-se medições diferentes para a variação de $V_{S S}\left(\mathrm{PSRR}^{-}\right)$e a variação de $V_{D D}$ $\left(\mathrm{PSRR}^{+}\right)$. As figuras 5.12 e 5.13 mostram as medições de PSSR $^{+}$e PSRR', respectivamente.

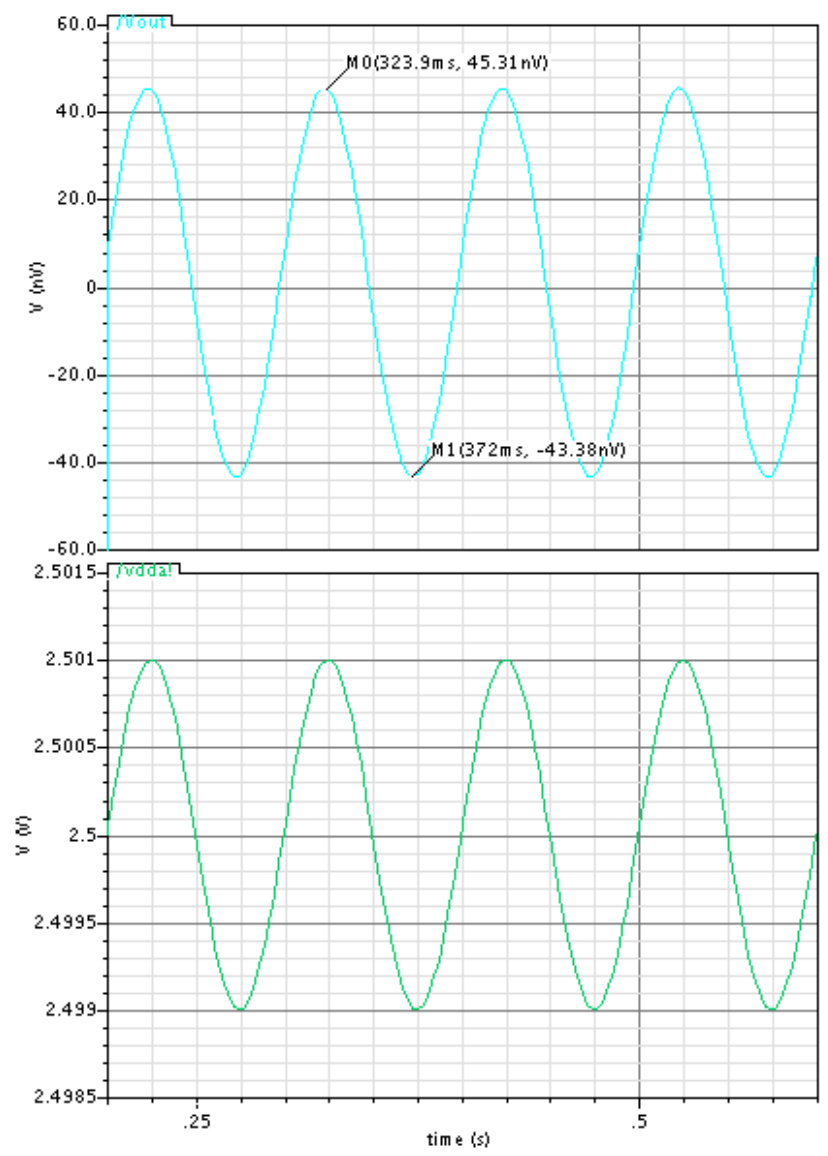

Figura 5.12 - simulação da PSSR 


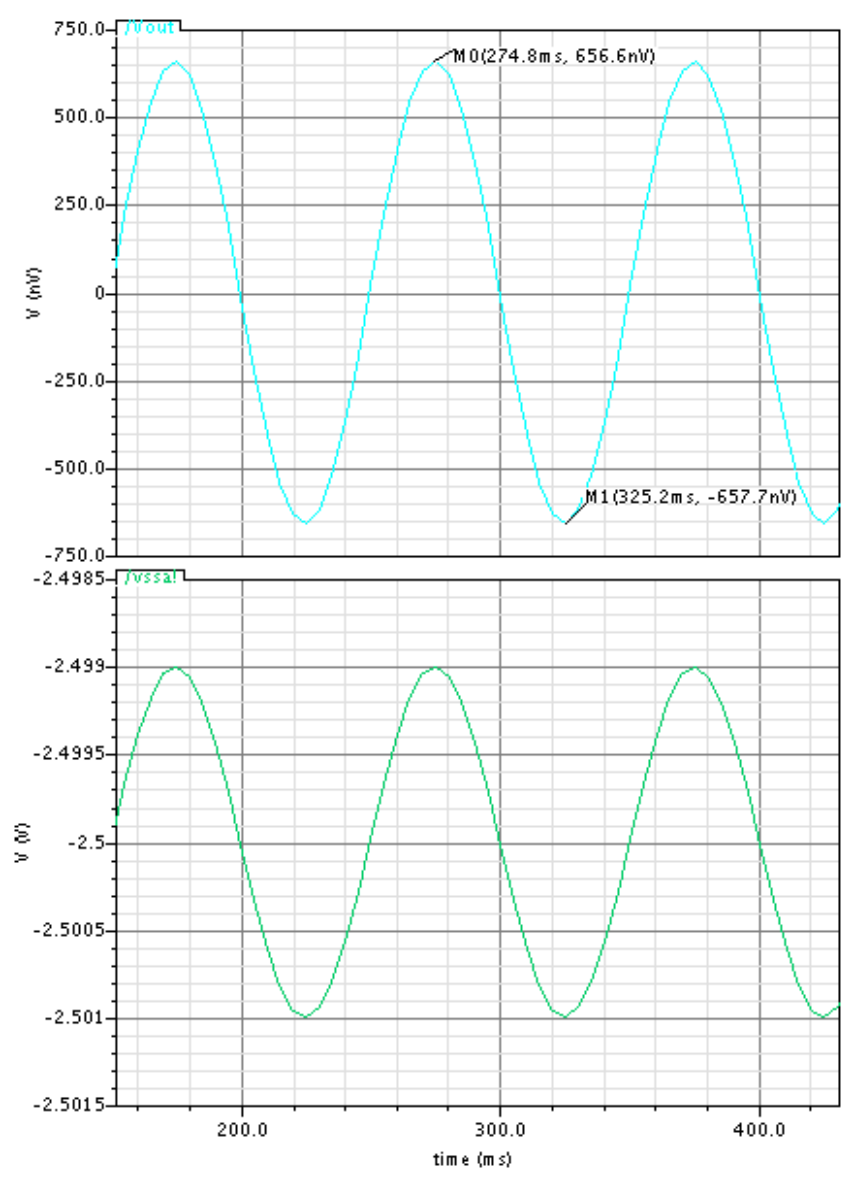

Figura 5.13 - simulação da PSRR

Os valores medidos de PSRR foram:

$$
\begin{aligned}
& \mathrm{PSRR}^{+}=87 \mathrm{~dB} \\
& \mathrm{PSRR}^{-}=64 \mathrm{~dB}
\end{aligned}
$$

\subsubsection{5 - resposta em freqüência}

A resposta em freqüência do amplificador foi medida pontualmente, variando-se a freqüência de entrada e medindo-se o ganho diferencial. A tabela 5.3 mostra alguns dos valores de $A_{v}$ medidos para dada freqüência $f$. 


\begin{tabular}{|c|c|c|c|c|c|c|c|c|c|}
\hline $\boldsymbol{f}(\mathbf{H z})$ & 1 & 10 & 100 & $1 \mathrm{k}$ & $10 \mathrm{k}$ & $100 \mathrm{k}$ & $1 \mathrm{M}$ & $1,9 \mathrm{M}$ & $3 \mathrm{M}$ \\
\hline $\boldsymbol{A}_{\mathbf{v}}(\mathbf{d B})$ & 73,4 & 73,4 & 73,4 & 66,5 & 51,5 & 25,6 & 11,6 & 0 & $-3,9$ \\
\hline
\end{tabular}

Tabela 5.3 - ganho de malha aberta em função da freqüência

A resposta em freqüência não correspondeu à especificação. Era prevista uma freqüência de ganho unitário de aproximadamente $3 \mathrm{MHz}$; a medida foi $1,9 \mathrm{MHz}$. Além disso, há já alguma atenuação na freqüência de $1 \mathrm{kHz}$. Essa diferença pode ser corrigida refazendo-se a compensação, com uma aproximação mais precisa, e uma análise do impacto disso no circuito, para que não haja comprometimento de outras especificações.

\subsubsection{1 - slew rate e tempo de acomodação}

As medições dessas duas características são feitas de modo similar; o amplificador, configurado como seguidor de tensão, é excitado com um sinal do tipo degrau e é observada a saída de tensão. Para a medição da slew rate, o degrau tem uma amplitude relativamente alta, para que se possa observar a capacidade do amplificador de acompanhar o sinal. A slew rate é medida pela inclinação da reta de subida da tensão.

Para medir o tempo de acomodação, o degrau tem amplitude pequena, e se observa a ultrapassagem e o tempo até que a saída se estabilize dentro de determinada faixa. A figura abaixo (5.14) mostra a medição da slew-rate para um degrau de 2,0V.

A $S R$ prevista era de 3,1V/ $\mu$ s; a medida foi $S R=3,0 \mathrm{~V} / \mu \mathrm{s}$, bem próxima. A $S R$ desejada foi calculada por uma aproximação, explicada no capítulo 4. Caso haja a neceissdade de correção, as mesmas considerações sobre a correção da freqüência de ganho unitário se aplicam aqui. 


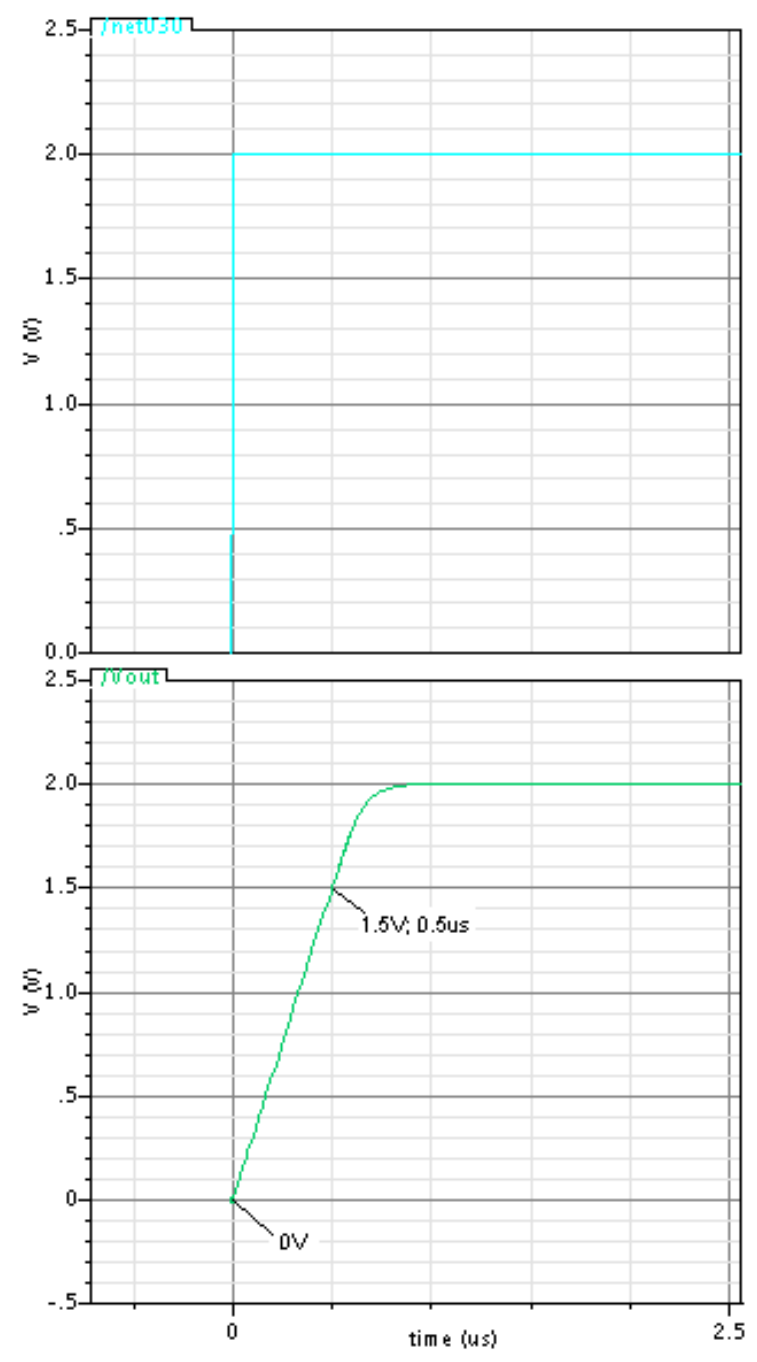

Figura 5.14 - teste da slew rate

A Figura 5.15 mostra a medição do tempo de acomodação para um degrau de 0,4V. A oscilação do sinal não chegou a alcançar uma amplitude significativa. 


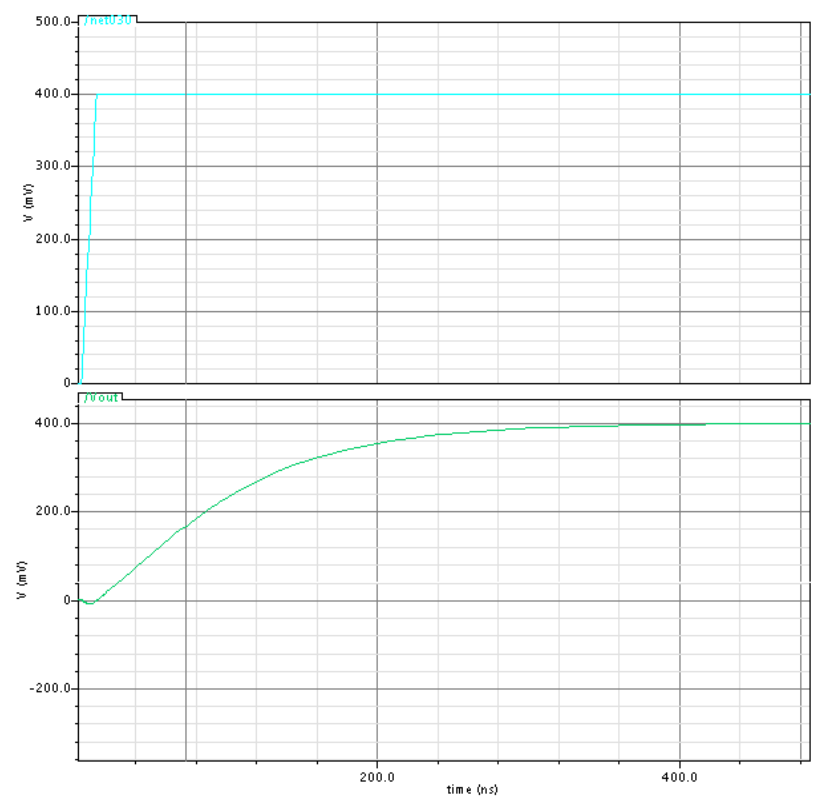

Figura 5.15 - teste do tempo de acomodação

Considerando como o tempo de acomodação $T_{s}$ o tempo até a saída atingir o valor final, tem-se

$$
T_{s}=0,44 \mu \mathrm{s}
$$

\subsection{2 - outros blocos}

Outros blocos dos circuitos em geral não chegaram a ser satisfatoriamente testados. Foram realizadas medições de transistores (a Figura 5.16 mostra as curvas IV de um transistor NMOS com $S=2,28$ e o circuito usado para tais medições), para auxiliar a compreensão do comportamento dos circuitos, e de blocos pequenos, como os espelhos nM e pM (Figura 5.17) destinados ao amp-op com alimentação de $\pm 1,4 \mathrm{~V}-\mathrm{a}$ alimentação e a configuração dos espelhos foram ajustadas com os resultados das simulações (as simulações revelaram a inviabilidade de um espelho pM cascode para as condições desejadas). 


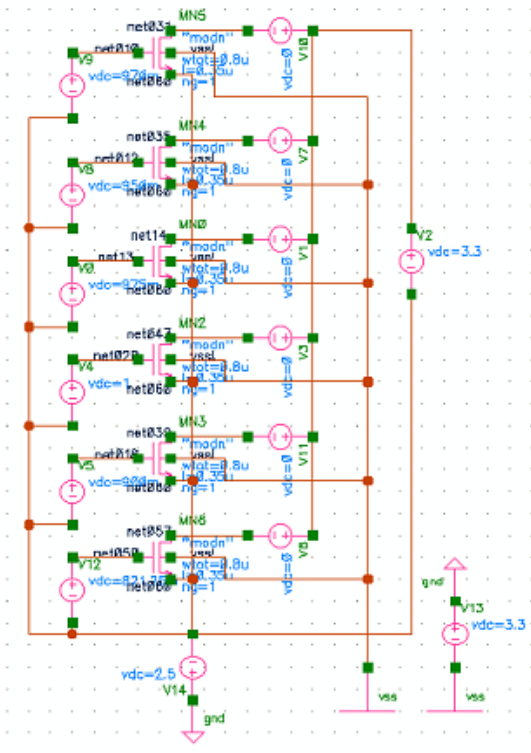

(a)

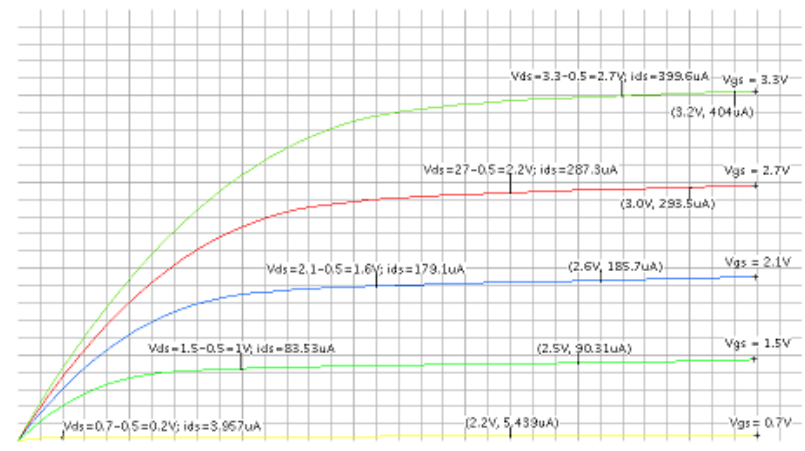

(b)

Figura 5.16 - (a) circuito para simulação das (b) curvas características de um MOSFET
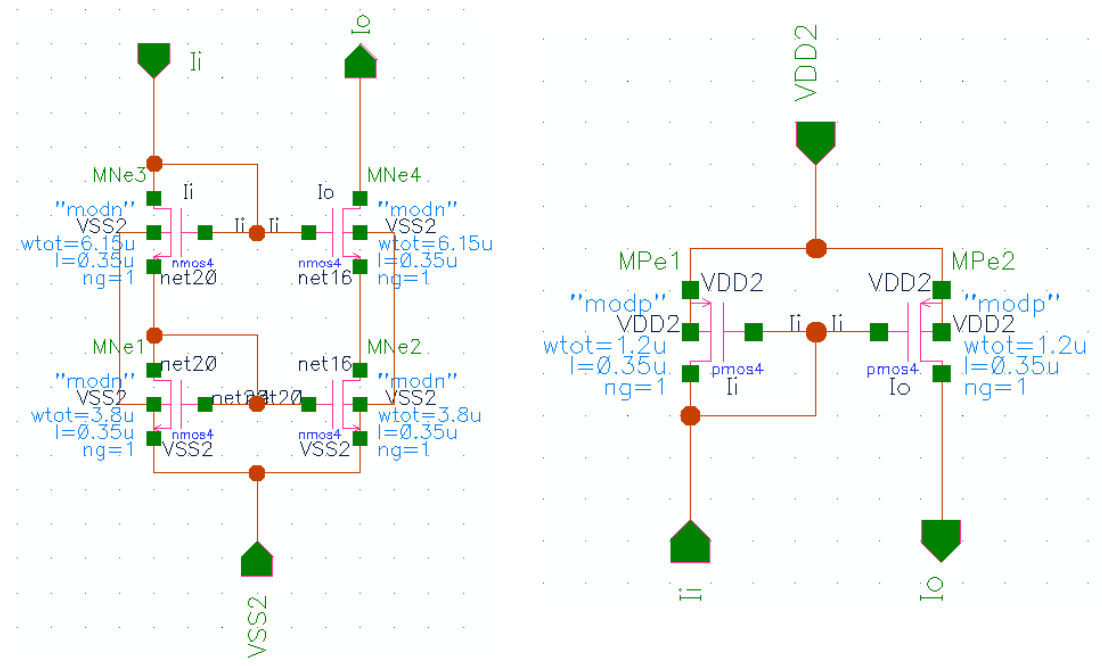

Figura 517 - espelhos de corrente NMOS (cascode) e PMOS

Outros circuitos chegaram a ser construídos, mas dependem do amp-op como bloco funcional, por isso tiveram seus testes deixados para depois do amplificador operacional. Figuras 5.18 e 5.19 mostram circuitos com o amp-op como bloco funcional; aqui, o amp-op não tem o símbolo padrão, mas um símbolo construído no simulador. 


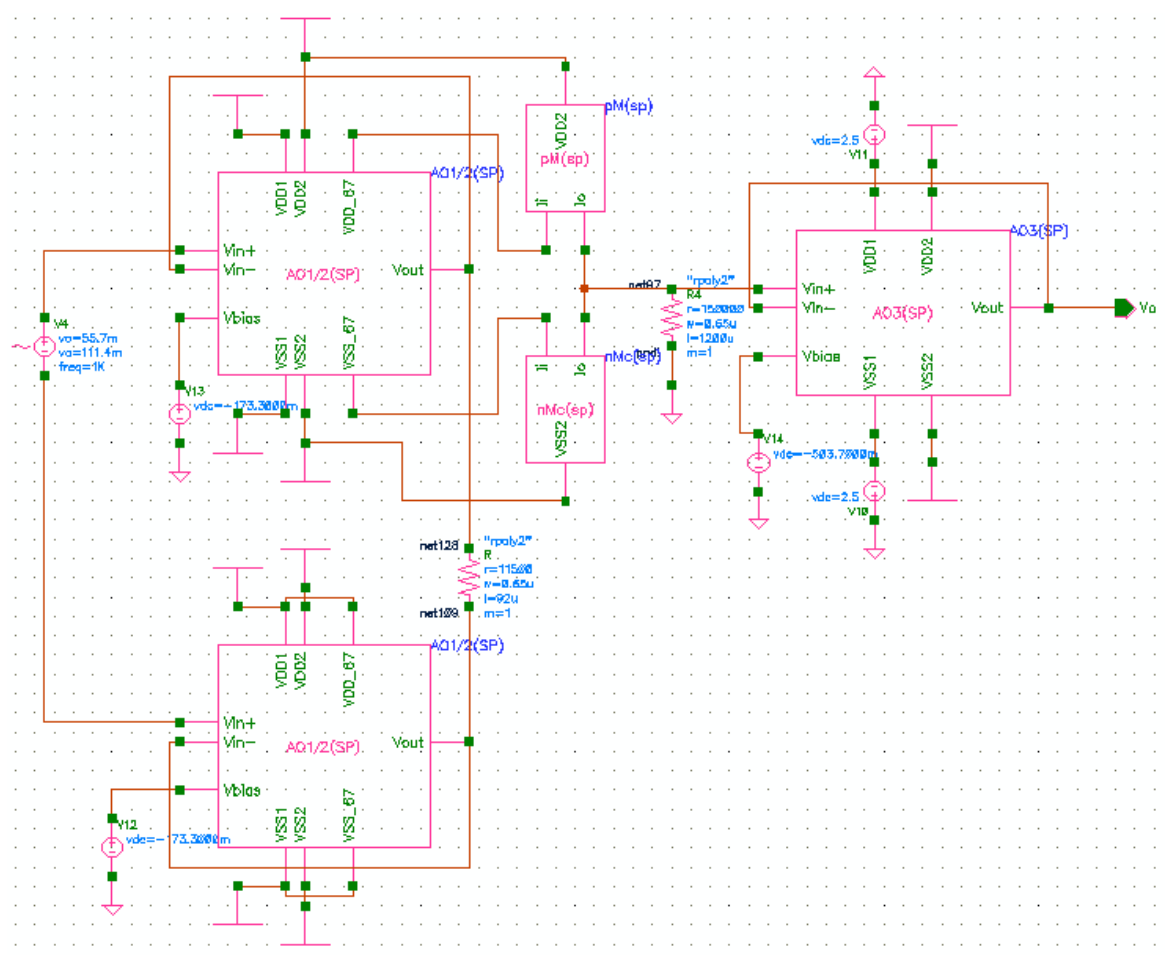

Figura 5.18 - amplificador de instrumentação

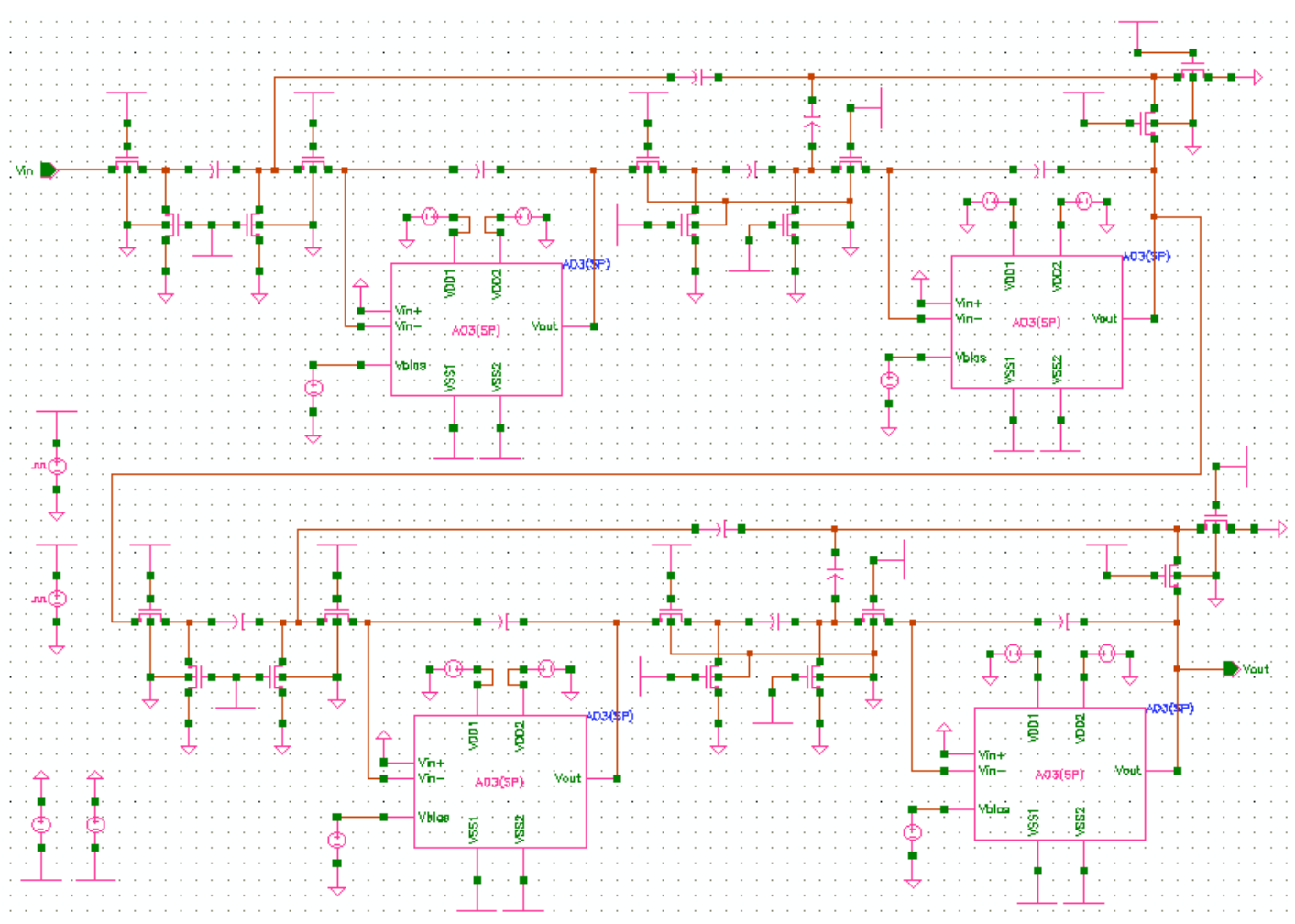

Figura 5.19 - filtro SC biquadrático 


\section{2 - Discussão}

Os resultados apresentados na seção anterior já foram comentados individualmente. A tabela 5.4 resume os resultados medidos para o amp-op.

\begin{tabular}{|l|l|l|}
\hline parâmetro & desejado & simulado \\
\hline$A_{v}$ & $\geq 70 \mathrm{~dB}$ & $73 \mathrm{~dB}$ \\
\hline CMRR & $\geq 60 \mathrm{~dB}$ & $90 \mathrm{~dB}$ \\
\hline ICMR & $0 \mathrm{~V} \leq \mathrm{V}_{\text {in }} \leq 1,5 \mathrm{~V}$ & $-1,2 \mathrm{~V} \leq \mathrm{V}_{\text {in }} \leq 2,0 \mathrm{~V}$ \\
\hline Faixa de saída & $0 \mathrm{~V} \leq \mathrm{V}_{\text {out }} \leq 1,5 \mathrm{~V}$ & $-0,75 \leq \mathrm{V}_{\text {out }} \leq 2,2 \mathrm{~V}$ \\
\hline SR & $3,1 \mathrm{~V} / \mu \mathrm{s}$ & $3,0 \mathrm{~V} / \mu \mathrm{s}$ \\
\hline$T_{\mathrm{s}}$ & $\leq 8 \mu \mathrm{s}$ & $\leq 1 \mu \mathrm{s}$ \\
\hline GB & $3,2 \mathrm{MHz}$ & $1,9 \mathrm{MHz}$ \\
\hline PSRR & $\geq 60 \mathrm{~dB}$ & $\geq 63 \mathrm{~dB}$ \\
\hline
\end{tabular}

Tabela 5.4 - resumo dos resultados da simulação do amp-op

O amplificador operacional resultante das simulações é ligeiramente diferente do calculado. Isso já era previsto (como explicado na seção anterior), mas mesmo com as diferenças foi possível projetar o amp-op relativamente funcional, embora os ajustes finos, feitos com a simulação, tenham tomado um tempo significativo.

Nota-se dos resultados que o amp-op pode ser utilizado para todos os subcircuitos (embora necessite de ajuste na compensação, para o circuito do sensor de pressão), por isso se deu mais destaque a seu projeto e teste. É um bloco importante dos circuitos aqui propostos e de diversos outros que podem ter utilidade em sistemas parecidos ou até mesmo em futuras aplicações no SoC. 


\section{$\underline{6-\text { CONCLUSÃO }}$}

Foi proposta uma interface analógica de condicionamento de sinais para um conversor $\mathrm{A} / \mathrm{D}$, a partir de uma bateria e sensores de temperatura e pressão. O sistema não foi completamente testado e ainda necessita de ajustes e validações; foi projetado e testado um amplificador operacional que será incluído em várias ocasiões no sistema, como bloco funcional. O amplificador operacional sofrerá correções para integrar um dos subcircuitos, e os outros blocos do circuito serão projetados em seguida.

É necessário ainda realizar os ajustes necessários e as simulações para validar a interface projetada. Feito isso, será desenhado o layout do sistema, para que se possa integrar a interface analógica na fabricação dos próximos protótipos do chip, e então realizar testes reais.

Futuramente, será necessário o projeto de um sistema de controle que permita ao microprocessador coordenar o funcionamento dos circuitos - chaveamento, multiplexação, etc. Pode ser necessário também, futuramente, atualizar o sistema em relação a novas especificações, uma vez que não só o SoC, mas também o SCI estão sendo desenvolvidos por grupos diversos. 


\section{BIBLIOGRAFIA}

[1] "Especificações para o Sistema de Controle de Irrigação (Livro Branco)". Instituto do Milênio; SCMN, 2003.

[2] “0.35 $\mu \mathrm{m}$ CMOS C35 Process Parameters (Document Number: ENG -182)”. Rev. \#2.0, Austria Microsystems, 2003.

[3] “0.35 um CMOS C35 Design Rules (Document: ENG-183)”. Rev. \#: 4.0, Austria Microsystems, 2004.

[4] Allen, P.E. e HOLBERG, D.R.: CMOS Analog Circuit Design. Oxford University Press, 2002.

[5] GREgORIAN, R. e TEMES, G. C.: Analog MOS Integrated Circuits for Signal Processing. Wiley-Interscience, 1986.

[6] SEDRA, A.S. e SMITH, K.C.: Microeletrônica. Makron Books, 2000.

[7] PÁlLAS-ARENY, R. e WEBSTER, J.G.: Sensors and signal conditioning. Wiley Interscience, 1991.

[8] WILliaMS, A. B.: Active filter design. Artech House, 1975.

[9] WHITE, R.M.: "A Sensor Classification Scheme", in Microsensors. IEEE Press, 1991.

[10] MIDDELHOEK, S. e HOOGERWERF, A.C.: "Smart Sensors: When and Where?", in Microsensors. IEEE Press, 1991.

[11] SENTURIA, S. D. e SMITH, R.L.: "Microsensor Packaging and System Partitioning”, in Microsensors. IEEE Press, 1991.

[12] "LM35 Precision Centigrade Temperature Sensors" datasheet. National Semiconductor, $2000 . \quad$ Disponível em $<$ http://www.datasheetcatalog.com/datasheets_pdf/L/M/3/5/LM35.shtml $>$. Acesso em 30/07/2006.

[13] "Tensiomètre Electronique à capteur profond", datasheet. SDEC France. Disponível em: $\quad<$ http://www.sdec-france.com/produits.php?numprod=7\&lg=an>. Acesso em 30/07/2006.

[14] FARES, A.: “Components of Soil Water Potential”. Disponível em: $<$ http://www.ctahr.hawaii.edu/faresa/sp04-lecture4.ppt $>$. Acesso em 16/03/2006.

[15] “Description of Water Potential Components", Agronomy and Horticulture Department, New Mexico State University. Disponível em: 
$<$ http://www.aghort.nmsu.edu/soils/soil_physics/tutorials/wp/wp_comp.html $>$. Acesso em 16/03/2006.

[16] "Pressure Gauges \& Switches", Omega Engineering. Disponível em: $<$ http://www.omega.com/literature/transactions/volume3/pressure.html $>$. Acesso em $16 / 03 / 2006$.

[17] VANDOREN, A. H.: Data Acquisition Systems. Reston Publishing, 1982.

[18] WARRING, R. H. e GIBILISCO, S.: Fundamentals of Transducers. Tab Books, 1985.

[19] TOUMAZOU, C. e LIDGEY, F.: Novel current-mode instrumentation amplifier. IEEE Electronics Letters, vol. 25, nº 3, 02/1989, pp. 228-230.

[20] TOUMAZOU, C. e LIDGEY, F.: Current-mode analogue signal processing. IEEE 1991 Bipolar Circuits and Technology Meeting, pp.224-229.

[21] LANCANETTE, K.: A Basic Introduction to Filters - Active, Passive, and Switched-Capacitor, National Semiconductor Application Note 779, National Semiconductor, 1995.

[22] FIEZ, T. e Allstot, D.: A CMOS Switched-Current Filter Technique. IEEE International Solid-State Circuits Conference, 1990, pp.206-207.

[23] FIEZ, T., LEE, B. e ALLSTOT, D.J.: CMOS switched-current biquadratic filters. IEEE International Symposium on Circuits and Systems (ISCAS), 1990, pp. 2300-2303.

[24] MIN, B.M. e KIM, S.W.: New Clock-Feecthrough Compensation Scheme for Switched-Current Circuits. IEEE Transactions on Circuits and Systems - II: Analog and Digital Signal Processing, vol. 45, nº 11, 11/1998.

[25] LOEliger, T. e GUGGenBÜHL, W.: Cascode Circuits for Switched Current Copiers. Analog Integrated Circuits and Signal Processing, vol. 19, pp. 115127, May 1999.

[26] BRAMBLE, S.: Demystifying Analog Filter Design. Sensors Magazine Online, 2002. Disponível em $<$ http://archives.sensorsmag.com/articles/0202/filter/>. Acesso em $30 / 07 / 2006$.

[27] YAGER, C. e LABER, C.: "Switched-Capacitor Filters Beat Active Filters at Their Own Game". TechOnLine. Disponível em $<$ http://www.techonline.com/community/home/7534>. Acesso em 30/07/2006.

[28] GHAUSI, M.S. e LAKER, K.R.: Modern Filter Design - Active RC and Switched Capacitor. Prentice-Hall, 1981. 
[29] NAIRN, D.G. e SALAMA, C. A T.: Current -Mode Algorithmic Analog- toDigital Converters. IEEE Journal of Solid-State Circuits, vol. 25, no 4, 08/1990, pp997-1004.

[30] TAVARES, F.M.L.: “Conversor Analógico/Digital Cíclico Baseado em Dispositivos de Corrente Chaveada CMOS para Sistema de Controle de Irrigação em Chip”. Departamento de Engenharia Elétrica, Universidade de Brasília, 2005.

[31] HNATEK, E. R.: A User's Handbook of D/A and A/D Converters. WileyInterscience, 1976.

[32] WANG, J.S. e WEY, C.L.: "A 12-bit 100-ns/bit 1.9-mW CMOS SwitchedCurrent Cyclic A/D Converter". IEEE Transactions on Circuits and Systems - II: Analog and Digital Signal Processing, vol. 46, n 5, 1999, pp.507-516.

[33] VIEGAS, M.A.G.: Projeto da fonte de alimentação para o nó remoto do Sistema de Controle de Irrigação (SCI). Departamento de Engenharia Elétrica, Universidade de Brasília, 2003.

[34] "Battery testing", MPower Solutions. Disponível em $<$ http://www.mpoweruk.com/testing.htm $>$. Acesso em 30/07/2006.

[35] ATWATER, T.B.: State-of-Charge Indicators. IEEE Military Communication Conference, 1994.

[36] PANG, S.; FARRELL, J.; DU, J.; e BARTH, M.: Battery State-of-Charge Estimation. Proceedings of the American Control Conference, 2001.

[37] CHIASSON, J. e VAIRAMOHAN, B.: Estimating the State of Charge of a Battery. Proceedings of the American Control Conference, 2003.

[38] HEYDECKE, J. e KIEHNE, H.A.: Portable NiCd- and Ni-MH-Batteries for Telecom Applications. IEEE Proceedings of the International Telecommunications Energy Conference, 1995, pp. 758-765.

[39] "IEEE Recommended Practice for Maintenance, Testing, and Replacement of Nickel-Cadmium Storage Batteries". ANSI/IEEE, 1988.

[40] COSTA, J.D.: Ambiente de projeto CADENCE. Departamento de Engenharia Elétrica - Universidade de Brasília, 2005.

[41] MANERA, L. e SWART, J.: Modelos de Simulações - SPICE e BSIM. Centro de Componentes Semicondutores - Universidade Estadual de Campinas. Disponível em $<$ http://www.ccs.unicamp.br/cursos/ee941/downloadppt/modelos_spice.ppt $>$. Acesso em 20/07/2006. 
[42] STAN, M.R.: “CADENCE Tutorials". Disponível em $<$ http://www.ee.virginia.edu/ mrs8n/cadence/Cadencetutorials.html $>$. Acesso em 30/07/2006.

[43] "Signal Processing Toolbox", The Mathworks. Disponível em $<$ http://www.mathworks.com/products/signal/>. Acesso em 02/08/2006. [44] LATHI, B.P.: Modern Digital and Analog Communication Systems. Oxford University Press, 1998.

[45] DORF, R.C. e BISHOP, R.H.: Sistemas de Controle Moderno. LTC Editora, 1998.

[46] DORF, R.C e SVOBODA, J.A.: Introduction To Electric Circuits. John Wiley \& Sons, 2001.

[47] OPPENHEIM, A.V. e WILlSKY, A.S.: Signals and Systems. Prentice Hall, 1996.

[48] KOLI, K. e HALONEN, K.A.I.: “CMRR Enhancement Techniques for Current-Mode Instrumentation Amplifiers". IEEE Transactions on Circuits and Systems-I: Fundamental Theory and Applications, vol. 47, nº 5, 05/2000. 
Anexo 1 - datasheet resumido LM35

\begin{tabular}{|c|c|}
\hline 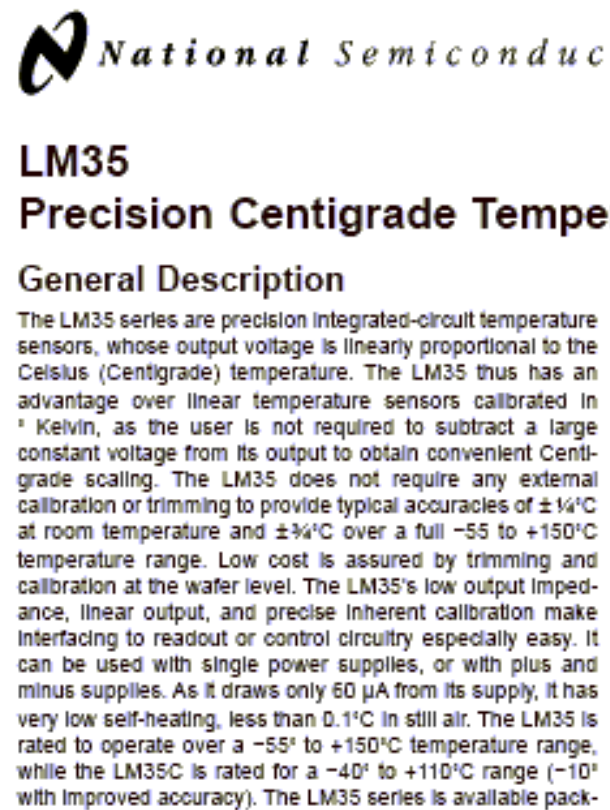 & 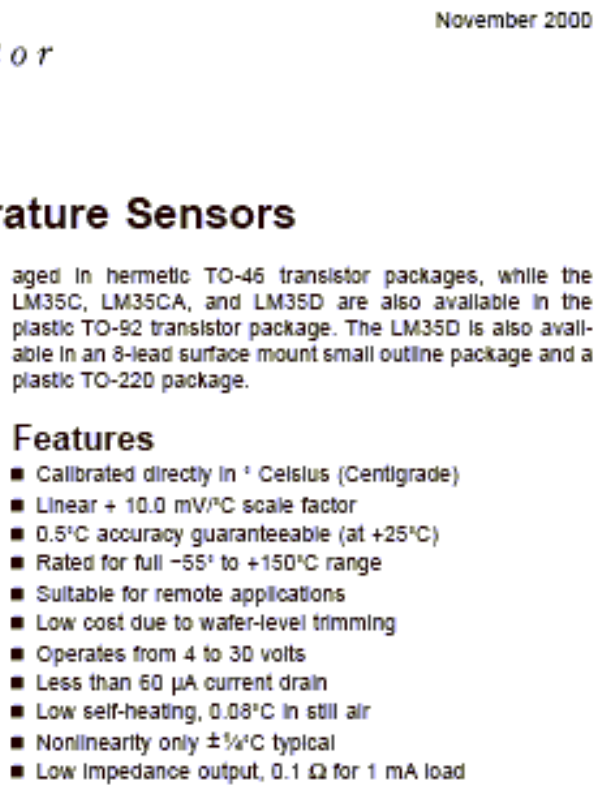 \\
\hline
\end{tabular}


Anexo 2 - datasheet resumido STCP 850

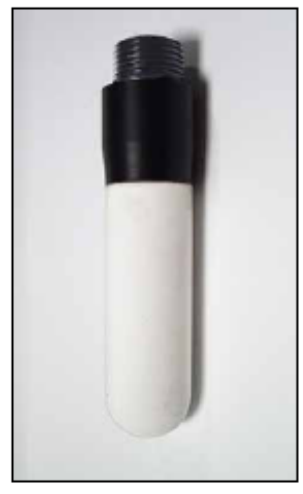

Equipement de base livré : - Tensiomètre STCP850 équipé complet.

Une seringue de préparation de tensiomètre (Réf. TENS22750). Voi page 48.

- Sachet d'embout de protection $(x 4)$ (Réf : TENS22001).

Longueur de câble électrique standard ( 3 mètres).

Accessoires à prévoir (option)

Tarière d'installation (Voir page 76)

pour tensiomètre.

- Liquide anti-algues

Standard equipment:

- One Tensiometer STCP850, complete with its ceramic cup.

- One preparation syringe (ref:. TENS22750).

- One pack of 4 yellow stoppers (ref.: TENS22001)

4 wire cable, length $3 \mathrm{~m}$

Accessories:

- Helix auger for tensiometers' installation (see page 76).

- anti-seaweed liquid
Caractéristiques électriques / Electric characteristics

Sortie en tension $(0-100 \mathrm{mV})$

-Sortie quadrifilaire. (Quatre fils).

-Consommation en courant : $2 \mathrm{~mA}$.

pour $\mathrm{Vcc}=10,00$ Volts

-Rësistance d'entrêe : $7,5 \mathrm{~K} \cdot$ :

-Résistance de sortie : $2,5 \mathrm{~K} \cdot$,

-Rêponse du capteur : du type tension

non amplifiée.

-Temps de réponse : $1 \mathrm{msec}$

-Tension de sortie du signal : en milli-

volts.

-Tension d'offeet : $0 \pm 1,5 \mathrm{mV}$.

-Hystërésis : $\pm 0,2 \%$ de la pleine échel-

-Temps de réponse : $1 \mathrm{msec}$.

- Pression max. admissible sur capteur

+ 1 bar $(+1000 \mathrm{Hpa})$.

-Tests aux chocs : qualifíe à 150

(testé jusqu'à $800 \mathrm{~g}$ ).

-Stabilité après une année : $\pm 0,5 \%$ de

la pleine échelle.

-Compensé en température : de $-10^{\circ} \mathrm{C}$

aे $+50^{\circ} \mathrm{C}$.

-Temperature de stockage : $-40^{\circ}$ à +

$60^{\circ} \mathrm{C}$ (sans eau).

-Temperrature d'utilisation: $-10^{\circ}$ à +

$50^{\circ} \mathrm{C}$. (avec anti-gel).
Voltage OutPut $(0-100 \mathrm{mV})$

-4 wire output.

Current consumption: $2 \mathrm{~mA}$ with a

direct current of 10,00 Volts.

Input resistor: $7,5 \mathrm{~K}$. .

Output resistor : $2,5 \mathrm{~K}$.

Sensor's output : voltage type as 0

to $100 \mathrm{mV}$ (non amplified).

- Response time : $1 \mathrm{msec}$.

- Voltage output : millivolts.

Offset : $0 \pm 1,5 \mathrm{mV}$.

- Hysteresis : $0,2 \%$ of full scale.

Maximum pressure acceoted by the

sensor +1 bar (1000 HPa).

Shock tests : guaranteed for $150 \mathrm{~g}$

(tested up to $800 \mathrm{~g}$ ).

scale.

Temperature correction : from $-10^{\circ} \mathrm{C}$

to $+50^{\circ} \mathrm{C}$.

Storage temperature : from $-20^{\circ} \mathrm{C}$ to $+60^{\circ} \mathrm{C}$

- Operating Temperature : from $-10^{\circ} \mathrm{C}$

to $+50^{\circ} \mathrm{C}$ (under $+5^{\circ} \mathrm{C}$, add some

antifreeze (iquid).
- Stability after one year : $0,5 \%$ of full

Ces capteurs sont livrés etalonnés usine. L'étalon de pression utilisé $(0,025 \%$ de précision) est en confornité avec la norme Européenne en vigueur. These sensors are delivered calibrated in our facory thanks to a standard pressure device $(0,025 \%$ as accuracy) in accordance with international norms. 